\title{
Gendered Discontent: \\ Participation in the Feminist Movement in Ottawa
}

by

\author{
Polly Alexandra Leonard, B.A (Hons), BSW (Hons)
}

A thesis submitted to the Faculty of Graduate and Postdoctoral Affairs in partial fulfillment of the requirements for the degree of

Master of Social Work

School of Social Work

Carleton University

Ottawa, Ontario

(C) 2014

Polly Alexandra Leonard 


\begin{abstract}
This thesis explores the question of (cis)men participating in feminist movement in Ottawa, and the reactions from (cis)women. I spoke to eight people; three men, one genderqueer person, and four women, regarding their experiences of being identified as a feminist, as well as their perceptions of solidarity in the movement. The analysis of data drew upon feminist critical discourse analysis and poststructuralist theories. This analysis suggests marked gendered differences in emotional display, motivation and identity politics. Perceptions of space and safety differed amongst the participants depending on their gender and social identity. The research indicates three main themes: acknowledging women's limited authority, the necessity for alternative masculinities, and a reconceptualization of the term feminist to include an intersectional approach. These findings are not generalizable given the small sample size, but point to key questions for future research including race relations within the feminist movement, and social workers' affinity for feminism.
\end{abstract}




\section{Acknowledgements}

I would like to thank everyone who supported me through this often seemingly unending journey. I would not have been able to complete this thesis without the many people who supported me throughout my years in the Social Work Department at Carleton University. Thank you especially to Sarah Todd, who never stopped believing in me, and for Roy Hanes for cheering me on. I would also like to thank Karen Schwartz for allowing me to see research in large scale, and for our fun (and scholarly) travel to Corner Brook.

Growing up in a family where academia and social justice were seen as the obvious career path has indelibly left its mark. Thank you to my Mum for always being in my corner and letting me know that she believes I can do anything. Thanks for showing me that the data can speak for itself, but we must always be fighting for a just world. Thank you to my late Dad for suggesting I take a Women's Studies course over 12 years ago, and for telling us kids never to become social workers. Thank you also for teaching me about Marxism and instilling in me a revolutionary spirit. Thanks to my brother and his family for supporting me. I must of course thank my loving partner (who I believe is a feminist, really) for allowing me the support, nurturance and love I needed in order to finish. I would not have been able to work without a partner who made meals, cleaned the house and told me repeatedly how smart I was.

I would also like to send a big appreciation to all the womyn of the Sexual Assault Support Centre of Ottawa. Having the ability to learn from some of the strongest and most courageous, as well as loving womyn in Ottawa gave me the ability to write this thesis. Had I never joined such an amazing collective of womyn, I would not be where I am today. Thank you for truly teaching me what anti-oppression and anti-racism practice means. Thank you for being my feminist community.

Finally, I would like to thank the countless feminists who are risking their lives fighting worldwide to bring about essential radical transformative change. 


\section{Dedication}

For you, Dad... 


\section{Table of Contents}

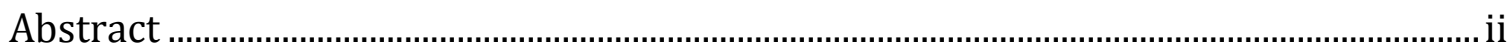

Acknowledgements...........................................................................................................ii

Dedication ..............................................................................................................................

List of Appendices .........................................................................................................vii

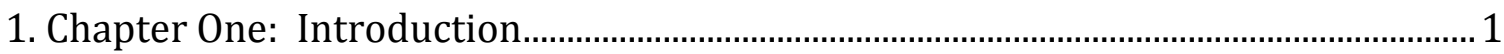

1.1 Research Question .......................................................................................................................

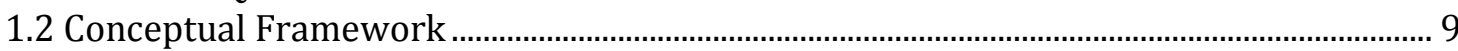

2. Chapter Two: Theoretical Perspective ……………………………………………….... 12

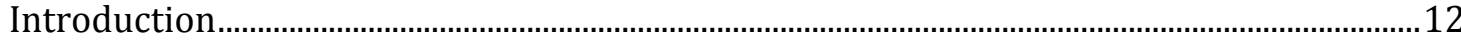

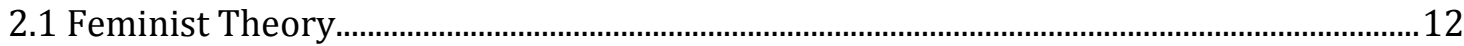

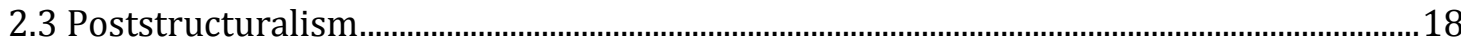

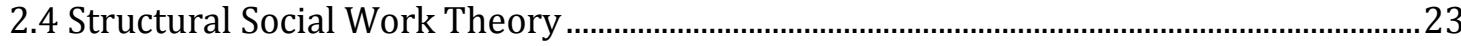

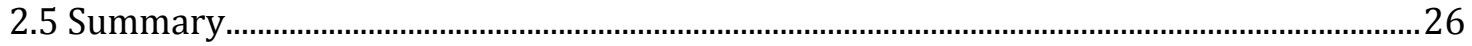

3. Chapter Three: Literature Review............................................................................ 28

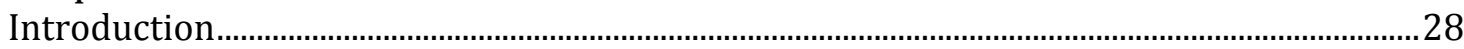

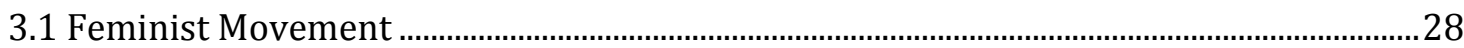

3.2 Masculinities and Feminisms ................................................................................................31

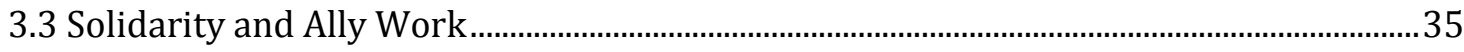

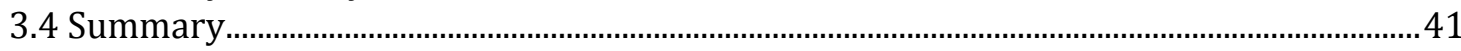

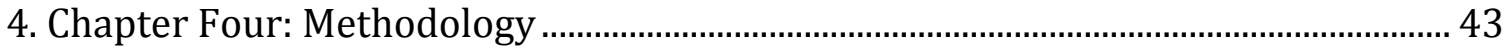

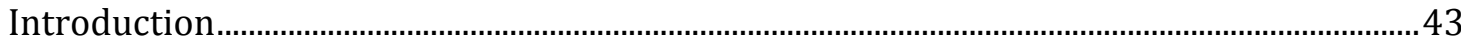

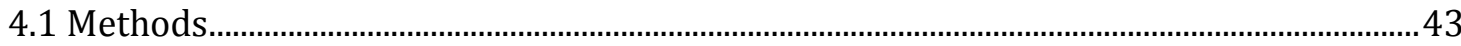

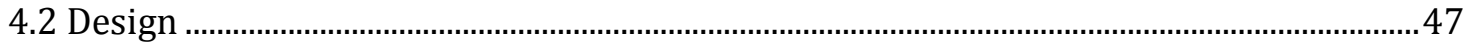

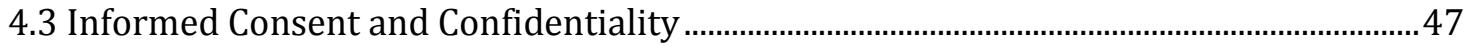

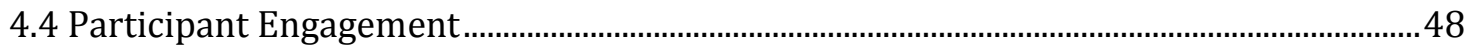

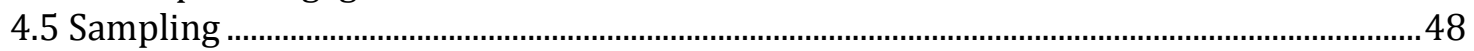

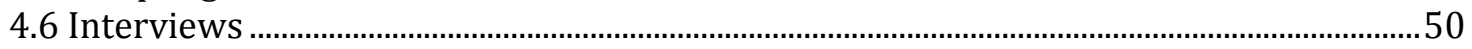

4.7 Transcription / Representation of Knowledge...................................................................52

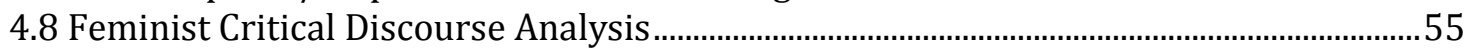

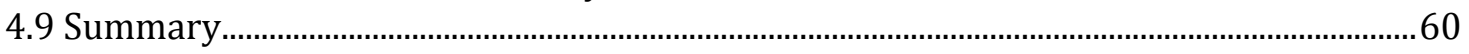

5. Chapter Five: Findings …………………………………………………………. 62

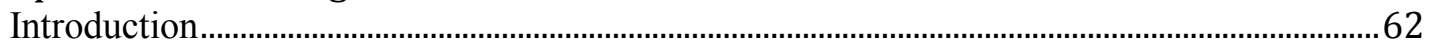

5.1 Section One: Social Movements and Emotions ……………………………………………...63

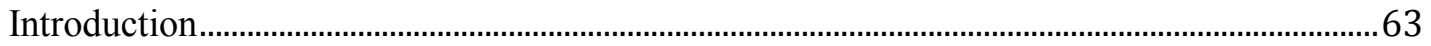

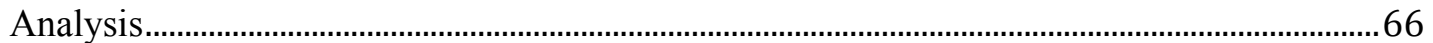

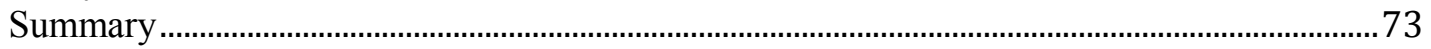

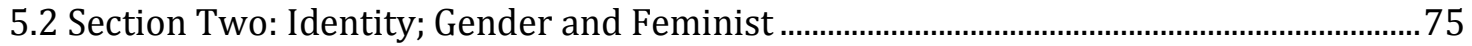

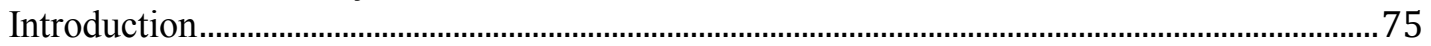

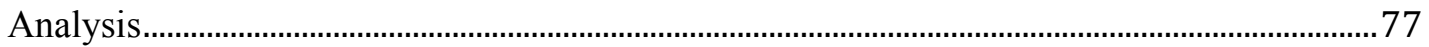

Summary …….................................................................................................................. 
5.3 Section Three: The Politics of Space and the Pathways of Feminist Identity

Development 105

Introduction. 106

Models of Feminist Identification. 108

Analysis

Summary

6. Chapter Six: Discussion and Conclusion ...........................................................................131

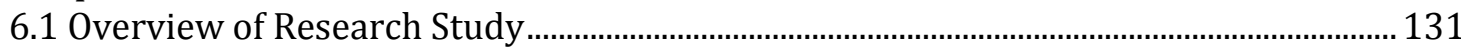

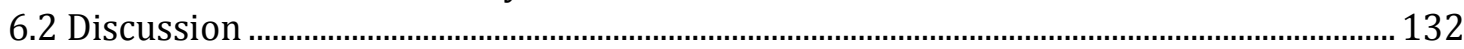

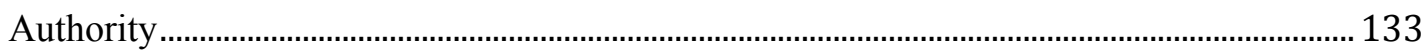

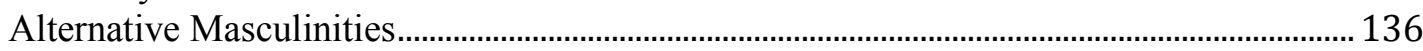

Reconceptualising the Term Feminist ......................................................................................... 138

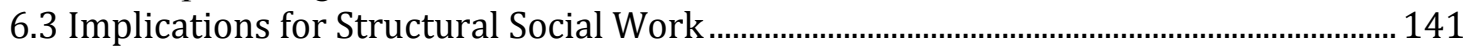

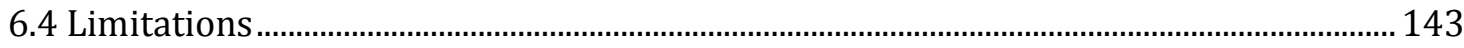

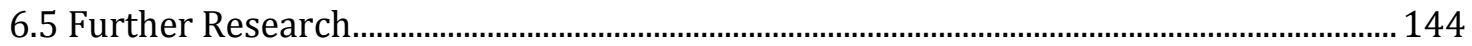

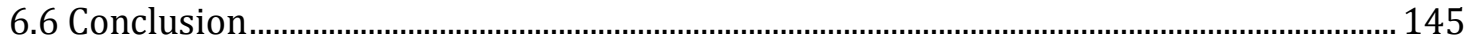

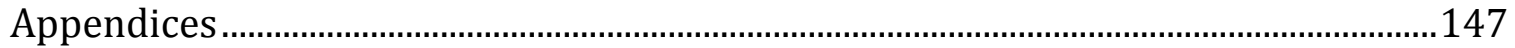

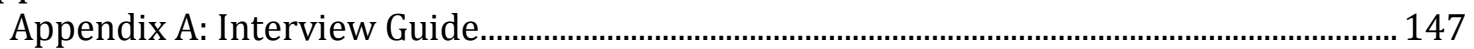

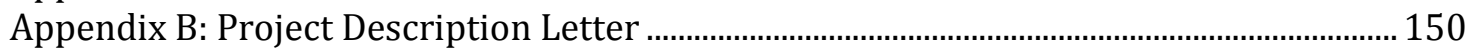

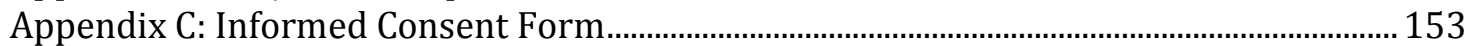

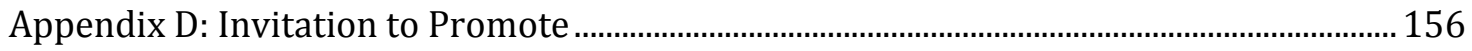

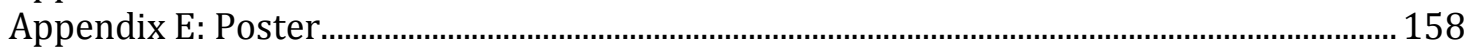

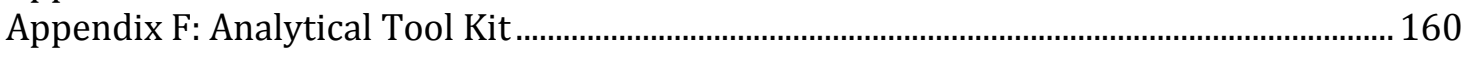

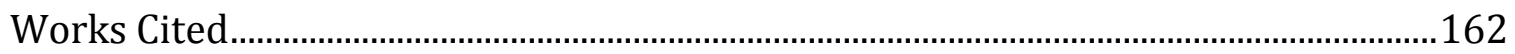




\section{List of Appendices}

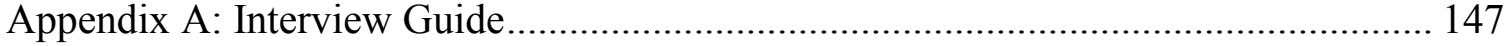

Appendix B: Project Description Letter ......................................................... 150

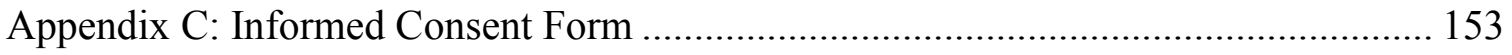

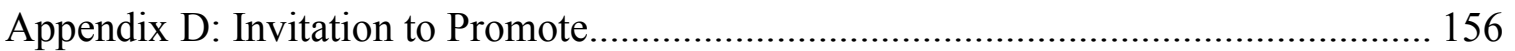

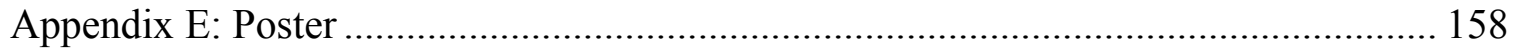

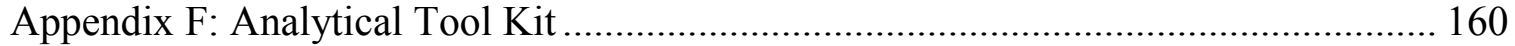




\section{Chapter One: Introduction}

Prediction:

Many men of conscience, if they notice they are doing nothing, will want to spend hours and hours struggling with the question of what is politically correct for them to do as men. As men: the two most paralyzing words in the vocabulary of the so-called man of conscience. He won't do anything until it is clear to him how it affects him and his brethren as men. He won't do anything unless it is clear to him in what sense he can do it with other men as men, unless their action particularly matters because they are doing it as men, unless the action makes them all feel much better about themselves as men.

As men. Words to live by. Words to do nothing by. (Stoltenberg, 1989, p. 182)

The above epigraph, from John Stoltenberg's radical feminist book, Refusing To

Be A Man, I argue connotes the experience of many men ${ }^{1}$ within the Ottawa feminist movement. Conversely, I believe that it reflects the ideas that women ${ }^{2}$ have about the

\footnotetext{
${ }^{1}$ In order to resist the oppositional gender binary and male supremacy, when I use the term men, I am actually referring to cisgender men to describe people who are not transgender (Tompkins, 2011). Cisgender is a term that was created in order to disrupt the gender hierarchy, normativity and heterogeneity of the categories 'man' and 'woman'. Therefore when I use the term men and women, I will be referring to their cisgenderedness. Pink Triangle Services Ottawa (PTS), a centre for the Queer community, defines cisgender as a "term used to describe people whose gender is not fluid; their gender identity and gender expression line up based on society's expectations that all aspects of gender should be congruent" (2012).
}

2 The spelling of womyn and wommon has a long history in radical feminist thought (Cameron, 1990). It is the intention of these feminists to use a spelling that does not render womyn as a derivative of the word "men." This is reclamation of a term that focuses on the oppositional binary of genders; womyn do not want to be defined against the male status quo. I have, after much debate, chosen not to use the alternate spelling of womyn. However, I would like to acknowledge it's political power. In order to properly explain, I borrow a passage from Debbie Alice $(1983,6)$ in A Feminist Dictionary

'Woman' is derived from the old English word 'wif,' and 'man.' 'Wif' meant woman, without any implications of a relationship to any man. The combined form of 'wifman,' from which comes 'woman,' explicitly connects an entity called 'woman' to 'man.' I deny the necessity and/or desirability of such a 
participation of men in the feminist movement. The purpose of my research was to uncover the tensions that exist in feminist movement in Ottawa. My aim was to understand the experiences of men and women in the feminist movement in Ottawa. Uncovering the lived realities of women in the movement, and how they view and work with the men in the movement is the main purpose. Themes of social movement participation, solidarity and motivation, identity creation, emotions, authority and masculinities will be explored.

The feminist movement has historically been plagued by critiques of its exclusivity and racism and, predominantly during the 1960's through to the 1980's; it's middle class whiteness (Collins, 2000; Smith, 2005; Enke, 2007). Women of colour and other marginalized women (such as women living with disabilities, lesbians and trans*3 folk) who felt underrepresented and misrepresented in the movement have fought back and have created their own spaces within the movement. It is my understanding (as a white woman) that the current feminist movement in Ottawa is striving to create an antiracist, anti-oppressive, decolonized movement, though there remains much work to be done to achieve this goal. The feminist movement has a long history of continuously reframing, reshaping and re-emerging with added diversity and complexities (Alcoff, 1988; Dietz, 2003).

connection, and use the spellings 'womon/wimmin' as one way of removing man and men from the picture (Kramarae \& Treichler, 1985, p.505).

${ }^{3}$ Pink Triangle Services Ottawa defines transgender as, A term used to describe a person whose gender identity and gender expression do not align based on society's expectations that that all aspects of gender should be congruent. A common term to express this concept is gender fluidity (2012).

The short hand trans* is used as an umbrealla term to describe anyone who does not ascribe to the gender binary. 
Underneath a presumably inclusive movement, there seems to exist among members some feelings of doubt about the "feminist man." It is this doubt that I explored through my research. Particularly I investigated how participants within the feminist movement in Ottawa frame their experience, with regards to the participation of men in feminist organizing, action or discussion. I am also invested in an anti-racist framework, and therefore examined how race is taken up in the narratives of the participants. Given the historical legacy of white women feminisms ${ }^{4}$, which made marginalized women largely invisible (Collins, 2000), the racial relations of the movement are important to examine. Discourses of gender (sustained through power and control) shape the feminist movements' participation of people who do not identify as women; these discourses will be uncovered and analysed through interview narratives.

\subsection{Research Question}

Throughout the past fifty years there have been numerous books and journal articles written about men and various feminist positions; including Men in Feminism (Jardine \& Smith, 1987), Dislocating Masculinities (Cornwall \& Lindisfarne, 1994) and Feminism and Masculinities (Murphy, 2004). However, there has not been a critical feminist discourse analysis exploring the views of women and men who are actively involved in feminist organizing or theorizing. This study aims to fill the gap by offering a qualitative investigation into how self-defined feminists within the Ottawa movement, frame their experiences through a gendered and intersectional lens. The participants are predominantly white (six), save for two women of colour. In addition to examining the

${ }^{4}$ I use the term feminisms as a way of distancing myself from ideological orthodoxy (Hudson, 1985). As well as to acknowledge the diversity of feminisms that exist in today's society (Lister, 2005). 
narratives of four women, I have also interviewed three men and one trans* person regarding their perceptions of their inclusion or exclusion within the Ottawa feminist movement. I allowed the participants to create their own personal definitions of feminisms, the 'feminist identity', as well as the work that feminists do. This permitted individual participants to generate their own discourses of feminisms.

The findings of this study raise the concern that the discourse of 'for women, by women,' a discourse which remains despite many feminist theorists' contrapuntal arguments of the intersectionalities of oppression and of a "matrix of domination" (Collins, 2000), provides a significant obstacle for men and other non-women identified folks to engage in feminisms.

My own lived experience is framing this research project; I have been involved in the violence against women movement in Ottawa for the better part of six years. Throughout my time within the movement, it has become clear that there is a divide among female members of the movement over the ability of men to "do feminism," be it engaging in discussions of reproductive health, organizing for the annual Take Back the Night event, or attending meetings with women's collectives, or inside women-only spaces. In my experience this divide is often silenced, due to fear of backlash and the necessity for support. In the following section I will outline some of the concerns that women have about the inclusion of men into feminist spaces, and I will then turn to my own bias with respect to the question of male inclusion.

In my experience, some feminist women view men in feminist spaces with suspicion: suggesting some men are using feminism(s) to gain status, or to promote their 
career. With the unending gender wage gap ${ }^{5}$, it is imperative that women gain power and control within their professional lives. The masculinization of 'public/out of the home' work and the perpetuation of patriarchal notions of the division of labour maintain the overrepresentation of men in high power and high salary employment positions. I believe that the fear that men will use their patriarchal power for employment opportunities within feminist organizations and government bodies is evidenced by the continuation of the "glass ceiling." Even within women's organizations the pillars of patriarchy, capitalism and colonialism still reign (Hepshiba, 2011; Combahee River Collective, 1978; DiQuinzio, 1993).

Another concern among activists that I have worked with is that the influx of men within the movement might take much needed funding away from women led organizations and advocacy campaigns. Violence against women affects millions of Canadians yearly (McInturff, 2013b; Johnson \& Dawson, 2011). The most recent Statistics Canada report from 2011 states that,

Family violence accounted for $26 \%$ of all police-reported violent crime in 2011 , a proportion similar to 2010. About half (49\%) of the nearly 95,000 victims of family violence were in a current or previous spousal relationship with the accused, including both common-law and legally married partnerships. ... As in previous years, the majority of victims of family violence were females. (Statistics Canada, 2013c)

Violence against women is also a very expensive form of violence and oppression. Recently researchers at the Canadian Centre for Policy Alternatives commented on how the 2013 federal budget was impacting the lives of Canadians, namely women, and the violence that is perpetrated against them,

\footnotetext{
${ }^{5}$ According to the Government of Ontario, and Statistics Canada the gender wage gap in Ontario is " $28 \%$ for full-time, full-year workers. This means that for every $\$ 1.00$ earned by a male worker, a female worker earns 72 cents." (The Government of Ontario, 2012)
} 
Violence against women in Canada costs our economy more than $\$ 7$ billion each year. Understanding what violence against women costs us can help us understand what we need to spend to put a stop to it. Not to mention how inadequate the current response is. ... Although the federal government has named violence against women as one of its priority areas, there is no coherent federal policy addressing violence against women at the moment. Federal spending on programs that address violence against women and girls is spread out across a number of departments and agencies and amounts to just over $\$ 56$ million in total. To address a problem that costs more than $\$ 10$ billion dollars a year and directly affects millions of Canadians. (McInturff, 2013a)

As evidenced by present cuts to funding in the public sector, the current government does not provide a large amount of support for the work that women in the feminist movement perform. In an ever-decreasing pool of funding, women are concerned that men who want to do anti-violence work will receive that funding, based largely on the fact that they are men. These men often receive high praise for their feminist actions, as it is seen as an anomaly and something outside the hegemonic box of masculinity (Murphy, 2013). Patriarchal relations sustain the attitude that men bring authority and legitimacy to concerns that when raised by women are often deemed unworthy of support. As Modleski (1991) states, "It remains for women to continue to claim the right to be taken seriously as authorities" (p. 74).

Another fear that I have heard stated is that men will act in patriarchal ways in their private lives, while espousing feminist ideals in public. In a section from Tania Modleski's controversially titled book Feminism Without Women, Culture and Criticism in a "Postfeminist" Age, she demonstrates how the famous 'personal is political' slogan of feminist movement has significant personal consequences as well as political importance,

In raising 'the personal' in public discussion, feminist action has in this way both questioned and began to challenge some of the most extreme manifestations of male power and has, therefore, great political significance. (1991, p. 33) 
One more potential worry is that the involvement of men in the feminist movement will take power away from marginalized women to define their own emancipation, be the authorities in their own lives and to be creators of valued knowledge (Modleski, 1991).

My own bias stems from the belief that feminist education and participation in feminist thought can have compelling personal as well as political consequences. Feminist thought should not be withheld from those who wish to study it; women should no longer be the 'gatekeepers' of feminist praxis. If feminists are going to effectively end violence against women, a starting point from the structural as well as ideological roots of patriarchy, which promotes power, privilege and oppression is necessary (Lundy, 2004). These roots can be seen everyday, as North American society is being called a "rape culture" 6 (Buchwald, Fletcher, \& Roth, 2005). A rape culture, along with hegemonic masculinity creates a societal culture that promotes violence against women as normative and views violence as a legitimate choice for conflict resolution. 2013 and 2014 have seen some of the highest rates of reported sexual assaults across North American campuses (Johnson, 2014; Rennie, 2014; Turcotte, 2013; Wakefield, 2014). With a whole men's hockey team being suspended over rape and sexual assault allegations here in Ottawa (Rennie, 2014), and the most recent statistics from 2012 reporting a record high number of assaults in American colleges,

\footnotetext{
${ }^{6} \mathrm{~A}$ complex [set] of beliefs that encourage male sexual aggression and supports violence against women [and girls], a society where violence is seen as sexy and sexuality as violent, and a continuum of threatened violence that ranges from sexual remarks to sexual touching to rape itself. A rape culture condones physical and emotional terrorism against women [and girls] and presents it as the norm. (Buchwald, Fletcher, and Roth 2005, XI in Fletcher, 2010).
} 
The 55 schools currently facing Title IX sexual assault investigations averaged 12 reported assaults in 2012. The ten schools with the highest number of reported assaults average 27.9 in 2012 . As the chart shows, the number of reported assaults is on the rise at many institutions. (Johnson, 2014)

These statistics implore me to believe that North American society is currently in a stage of 'rape culture.'

Many scholars and activists alike maintain that the majority population have been socialized with the dominant discourse of victim blaming ${ }^{7}$, which is evidenced by society's stronghold on ideas of female subordination and hegemonic masculinity (DeKeseredy \& Schwartz, 1998, Connell \& Messerschmidt, 2005, Stark \& Flitcraft, 1996). This concept is entrenched in both patriarchal and racist narratives that are found throughout Canadian society (Jiwani, 2006). The social construction of this 'rape culture' can be seen throughout media that promote the hypersexualization of children and women, supports the perpetrators of violence and blames the victims and a Canadian government which persistently and consistently fails to act with due diligence in regards to the over 600 missing and murdered Aboriginal women (Amnesty International, 2004).

It is my belief, that in order to change this narrative, people who do not identify as women must be engaged in feminist discourse and accepted into the feminist movement, what bell hooks calls, "the movement to end sexist oppression" (hooks, 1984). One cannot transform society with only a few people; in order to affect real social change people must join each other in solidarity (hooks, 2004). It helps little if women have their consciousness raised; yet men are continuing to perpetuate sexism and rape myths through their discourse and actions (DeKeseredy \& Schwartz, 1998). In order to

${ }^{7}$ For a closer examination of victim blaming in the media see Meyers, 1997; a newspaper article outlining the incident of a male police officer speaking to law students at the University of Ottawa, and urges women to not "dress like sluts," in order to reduce the number of sexual assaults and rape they experience. 
transform social life into a space where people are not oppressed because of their membership in a distinct group, unlearning hegemonic heteronormative patriarchal colonial narratives should be a top priority for everyone.

Simone DeBeauvoir stated, "One is not born a woman, but rather becomes, a woman" (1989, p. 267). Contemporary feminists, including myself, argue that this is true for feminist identity as well. One is not simply born a feminist, but one becomes feminist through a process of consciousness raising and unlearning dominant narratives (Schacht \& Ewing, 2004). It is for this reason that I have chosen to interview feminist women who ascribe to feminist values, and take part in feminist actions, and the men with whom they share the struggle.

\subsection{Conceptual Framework}

The emancipatory goals of structural social work and of feminisms parallel one another. Moreau \& Leonard (1989); Saulnier (2000); Hudson (1985); and Wood \& Tully (2006) have all claimed that social work, most notably structural social work and feminisms share a great deal in common. Both the structural approach to social work and feminist theory aim to deconstruct oppressive relations within society (Dominelli \& McLeod, 1989; Mullaly, 1993). Feminisms and structural social work understand societal and personal problems as overall individual manifestations of the larger structural society, a society that bell hooks refers to as; "White-supremacist-capitalist-patriarchy" (2004, p. 51). bell hooks' terminology exposes the power structures of domination and subordination within our current neo-liberal paradigm. Both approaches to social analysis provide an understanding of society that encourages and emphasizes individual level as well as societal transformation (Seymour, 2012; Lundy, 2004). Hick and Murray (2009) 
illuminate the commonalities between feminisms and structural social work by drawing on one of the most notable feminist sayings, made famous by radical feminist Carol Hanisch in 1969 'the personal is political' to state that,

In understanding that 'the personal is political,' structural social work emphasizes that social and political change begins within the social relations of people's everyday lives, such as in sexuality, family roles and the workplace. (2009, p. 89)

This core principle is embedded in feminist theory and practice as well as structural social work, and can be seen in many of the work and actions of the Ottawa feminist movement. Shifting violence against women from a private concern into a public struggle for bodily autonomy exemplifies the personal is political globally.

I argue that once feminisms are deconstructed, both feminist theory and structural social work use what structural social work theorists such as Robert Mullaly have described as a dialectic approach to practice. In the 1993 book, Structural Social Work: Ideology, Theory, and Practice, Mullaly explains the dialectic approach;

This tradition is actually two traditions - an idealist tradition that persuades individuals they can effect great changes through self-determination, and a structural determinist tradition that sees individuals as the victims of a deterministic social environment that cannot be changed. (1993, p. 143)

Mullaly describes the dual philosophies of feminist theory and structural social work, one is the emancipatory notion of change through individual empowerment and agency, and the other is the realization that individuals and populations are oppressed based on the hierarchical structures of society (1993). One cannot adhere to one principle, without awareness and reflection of the other.

In order to change people's patriarchal views about women, views that increase acceptance and prevalence of violence against women (Johnson \& Dawson, 2011; DeKeseredy \& Schwartz, 1998; Stark, 2007), everyone must unlearn patriarchal attitudes, 
and what better way than to engage in feminist thought or action? The question of how women and men experience the specific involvement of men in feminist movements and organizations is of fundamental importance to structural social work in which male social workers actively position by drawing upon and allying with feminisms.

Structural social work and feminist theory and action are compatible. Both fields of study and work share similar views on social action and social movement building, the pair are seen as imperative for transforming oppressive social relations (Mullaly, 1993; Dominelli \& McLeod, 1989). The authors Lundy (2004), Carniol (2005) and Mullaly (2002) all share similar sentiments in regards to social change and everyday activism, "The anti-oppressive perspective (AOP) encourages students to think of collective social change and individual advocacy as central to one's career as well as integrated into everyday life" (Baines, 2011, p. 79). Feminist theory and structural social work both operate within an anti-oppressive paradigm (Dominelli \& McLeod, 1989). 


\section{Chapter Two: Theoretical Perspective}

\section{Introduction}

My research aims to deconstruct the gendered narratives of social movement participation, and to enrich an examination of the structural approach to social work and social transformation. For my theoretical perspective, I based my research in feminist theory and poststructuralism, with particular attention to anti-racist feminists and feminist writers who attend to gender construction. In this section I will provide summaries of the fundamental tenets of each theory, and will discuss key components of structural social work theory.

\subsection{Feminist Theory}

As a consequence of the diversity of feminist thinkers; there is no one singular definition of feminism, no single framework or lens from which to critically analyse or organize resistance to social structures. For each feminist, it is up to themselves to cocreate their own approaches to feminist practice based on their own conglomeration of feminist theories. In 2003, Mary Dietz, in her article, Current Controversies in Feminist Thought, expressed this diversity,

Thus, what really exists under the standard rubric of feminist theory is a multifaceted, discursively contentious field of inquiry that does not promise to resolve itself into any programmatic consensus or converge onto any shared conceptual ground. (p. 400)

Several theorists have expressed not concern, but delight at the multitude of theories of which feminist thinkers create and elaborate from. Echoing Carol Aylward, in her "Canadian Critical Race Theory" text, there is no universal feminist theory, there are numerous. However, all "Mainstream feminist theories... have gender oppression at their 
core" (Aylward, 1999, p. 17). Gayle Rubin (2011) famously coined a "slogan" describing the oppression of women; “...in its endless variety and monotonous similarity, crossculturally and throughout history..." (p.35). Noting the difficulty of attempting to uncover a 'common oppression.' I will therefore, not attempt to provide a rigid definition of feminist theory I will however discuss some of the main tenets of feminist theories and a few key scholars whom I look toward for direction. The central principles include an analysis of the oppression of marginalized populations, namely women, a call to action to dismantle the oppressive structures of society, a mandate to question the social construction of gender and race, and an understanding of the lived realities of the intersectionalities of oppression.

Writing on poststructuralism and feminist theory, Chris Weedon (1987) explains,

Feminism is a politics. It is a politics directed at changing existing power relations between women and men in society. These power relations structure all areas of life, the family, education and welfare, the worlds of work and politics, culture and leisure. They determine who does what and for whom, what we are and what we might become. (p. 1)

Weedon points out the political drive that was the origins of feminist theory. Without strong emancipatory goals, and a will to transform the oppressive, patriarchal institutions that theory elucidates, feminist theory is ineffective (Dietz, 2003; Knowles, 2010). The term 'praxis' comes to mind here (Freire, 2010). In social work, researchers and practitioners continuously engage in praxis, which signifies the connection between theory and practice. Each must be informed by the other. Speaking of race theory, Caroline Knowles, states that one cannot explain a theory of race without providing a call to action to eliminate racism (2010). Without action, theory is useless. 
One of feminism's central tenets is the social construction of sex and gender, a rejection of biological determinism and therefore a refusal and resistance to the gendered (sexual) division of labour, the gender binary, expectations of femininity and masculinity, and a deconstruction of essentialism (Dietz, 2003; DiQuinzio, 1993; Rubin, 2011). The feminist theory that I adhere to, takes a "...social constructivist approach to gender formation" (DiQuinzio, 1993, p. 2), taking key ideas from Judith Butler (1990) and Gayle Rubin (2011). Gayle Rubin was among the first to conceptualize a sex/gender system in her 1975 structuralist anthropolitical account. She examined and named specific cultural and institutional structures that socialized biological males and females into a gendered hierarchy, where the females where dominated by the males (Dietz, 2003).

Marxist Feminists view the oppression of marginalized populations including women and people of colour as stemming from unequal divisions of labour (DiQuinzio, 1993). These divisions are created on the social construction of gender. Women and racialized populations are constructed as inferior and 'less than' those with hegemonic power (white men), which supports the normative and patriarchal gender role assignation, and therefore the gendered and racialized division of labour (Rubin, 2011; Wodak, 1997). When thinking of oppression, it is important to understand how the idea of 'othering' occurs, this is what makes the oppression of women, people of colour and other marginalized populations simply the status quo. Margaret Anderson, writing on Edward Said's Orientalism, provides a narrative of race theory, and the 'oppositional binary' that can be helpful to my view of feminist theory. She writes about how the dominant 'race' group identifies itself through "othering" the subordinate group (Andersen, 2010). The 
dominant group increases the feelings of belonging amongst its members by positioning itself in opposition to the "Other" (Andersen, 2010).

Along with the social constructivist theories of sex and gender, ideas of patriarchy are also socially constructed, perpetuated and maintained through the institutions, policies, religions and heteronormative, ethnocentric structures of society.

The term 'patriarchal' refers to power relations in which women's interests are subordinated to the interests of men. These power relations take many forms, from the sexual division of labour and the social organization of procreation to the internalized norms of femininity by which we live. (Weedon, 1987, p. 2)

Patriarchy purports that those who are biologically male are superior to those who are biologically female; this domination is embedded into our daily lives and our national and international policies (DiQuinzio, 1993). However, it is very important not to forget that there are other systems of oppression that also affect people's autonomy, mobility and daily life, in crucial and important ways.

Chandra Talpade Mohanty expresses her sentiments of white Western feminist thought, and the pitfalls of essentialism and single narratives in her ground breaking piece, Under Western Eyes,

It ought to be of some political significance at least that the term "colonization" has come to denote a variety of phenomena in recent feminist and left writings in general. From its analytic value as a category of exploitative economic exchange in both traditional and contemporary Marxism's (particularly contemporary theorists such as Baran, Amin and Gunder-Frank)' to its use by feminist women of color in the U.S. to describe the appropriation of their experiences and struggles by hegemonic white women's movements, colonization has been used to characterize everything from the most evident economic and political hierarchies to the production of a particular cultural discourse about what is called the "Third World."' (Mohanty, 2003, p. 333)

One cannot speak of difference, oppression, feminism and racialization without highlighting the work of Audre Lorde. In Audre Lorde's renowned speech, "The Master's 
Tools will Never Dismantle the Master's House," she states that the tools of the patriarchy, tools of oppression such as exclusion, segregation, alienation and colonization, cannot be used by feminist theorists or activists to create positive social change that will demolish structural patriarchy (2003). She articulates that feminists continue to reify the authority of patriarchy and colonialism when they follow and employ patriarchal notions; such as the abhorrence to difference, which maintains white male supremacy (Lorde, 2003). She describes how white feminist theory is plagued with racism and homophobia, maintained by an insistence on exclusion and separation, this is problematic and must be challenged, otherwise white feminists are simply perpetuating the exact unequal power relations and oppressions that they are hoping to challenge (Lorde, 2003).

Audre Lorde argues that instead of the essentialist notions within mainstream feminist theory, difference ought to be celebrated and enabled for creative unity (2003). Audre Lorde declares that rather than using the patriarchal tool of "divide and conquer" feminists should "define and empower" (2003, p.27). This, Audre Lorde states will increase the power of feminist discourse, as there is no power in reinforcing the essentialist 'single story' of women's oppression (2003). Without inclusion of difference there is no power to transform the patriarchy, as essentialist feminist theory is recreating and maintaining oppression and patriarchy through exclusion, tokenism and the maintenance of the status quo.

Such tokenism and exclusion from feminist theory reinforces stereotypical representations of racialized women defined through limited space and patriarchal roles. This white feminist theory that Audre Lorde is speaking on, is one that upholds the binary, the patriarchal model, of colonizer and colonized. Therefore, white feminist theory 
cannot be used as a strategy of resistance without the inclusion of multiple lived realities. Feminist theory will only be emancipatory and powerful, when it unites all women through differences. Audre Lorde therefore views difference as a source of power and unity (2003).

Turning now to an exploration of Patricia Hill Collins and black feminist thought. Collins does not want to adhere to the biological deterministic notion of black feminist thought, that would have only women of colour able to produce and theorize with this specific epistemology (2010). Collins claims to be in agreement with Beverly GuySheftall (1986) who says that both men and women can identify as black feminists (cited in Collins, 2010). Collins states that adhering to a strict guideline on who can identify as black feminists is problematic because this notion brings up traditional views of the 'naturalness' and 'biological' categorization of race (2010). This categorization also does not allow for identities to be fluid or have historical specificity. She argues that by having such rigid guidelines on who can be a black feminist essentializes gender and race, thus ignoring the social construction of both concepts (Collins, 2010).

Collins also contends with the idea that all women who are black are automatically placed into the category of being a black feminist (2010). This assumes that women by the sheer fact of being born women already hold some essential consciousness and awareness about gender and race (Collins, 2010). She clearly states, “...not all women are feminists" (Collins, 2010, p. 342). In her rejection of certain views about black feminist thought, Collins speaks of a specific standpoint (2010). This standpoint, Collins explains, are experiences that are felt and shared by African-American women, and thus provide insight into different social relations and practices, this standpoint is 
also cantered in Afrocentric thought (2010). There are five core themes of black feminist thought, they are; a legacy of struggle - against racism and sexism, understanding the interlocking nature of race, class and gender domination, changing negative and exploitative images of black women with images that have been defined by the black women community, leadership and black women's activism and the last theme is sexual politics (Collins, 2010).

Collins emphasizes that black feminist thought is rooted in and empowered through its relationship with the black women community (Collins, 2010). Without this, the theory would not have a materialist base, it would be far removed from a black women's standpoint. This relationship with the community is one of the main driving forces of the influence that black feminist thought has on the actual lived realities of women (Collins, 2010). This echoes what was already said about how theory without practice is useless; theory that is not rooted in the lived realities of who or what it is theorizing has no basis in reality. Without a material basis, theory cannot change anything. Collins argues, like Andersen (2010) and Knowles (2010) that theory must be used for and in conjunction with action to promote social change (2010).

Weaving feminist theories into one unifying framework is complicated, especially now when feminists aim to disrupt the category of "woman," and maintain that there are no essential truths, or universal notions of oppression or patriarchy. With this in mind, I turn to my second theoretical framework, poststructuralism.

\subsection{Poststructuralism}

Throughout my research I draw on feminist poststructuralist epistemologies. In the section that follows I outline the key concepts of poststructuralism, making the 
theoretical connections with feminist theory apparent. Poststructuralism derives some of its ideas from other frameworks such as; psychoanalysis, linguistics, postmodernism and political theory (Valverde, 1990). Much of traditional poststructuralist thought is based on Michel Foucault (1990), Jacques Derrida $(1973,1976)$ and Jacques Lacan (1977). Judith Butler (1990) is much relied upon for feminist poststructuralist analysis, and I draw much knowledge of this subject from the work of Chris Weedon (1987).

In her article, Poststructural Feminist Pedagogy in a Post-Katrina World, Gloria Pierce expertly sums up the origins of feminist poststructuralism;

Arising from a postmodern worldview, poststructural feminist discourse grew out of the postmodern agenda that seeks to deconstruct, debunk, and dismantle the positivist belief in scientific objectivity and the commonly accepted assumptions of a masculinist culture. (Pierce, 2010, p. 37)

The main tenets of poststructuralism are a destabilization of the subject, a rejection of essentialism, and a need for the deconstruction ${ }^{8}$ of hegemonic notions of identity, experience, language, discourse and power.

Feminist poststructuralist writers such as Chris Weedon argue that this shift in subjectivity from being natural and unchanging, leads to the possibility of transgression and change (1987). She provides a succinct definition of subjectivity as used in poststructuralism, “'Subjectivity' is used to refer to the consciousness and unconscious

\footnotetext{
${ }^{8}$ Linda Alcoff (1988) states that,
}

This term is principally associated with Derrida for whom it refers specifically to the process of unraveling metaphors in order to reveal their underlying logic, which usually consists of a simple binary opposition such as between man/woman, subject/object, culture/nature, etc. Derrida has demonstrated that within such oppositions one side is always superior to the other side, such that there is never any pure difference without domination. The term "deconstruction" has also come to mean more generally any exposure of a concept as ideological or culturally constructed rather than natural or a simple reflection of reality. (p.416) 
thoughts and emotions of the individual, her sense of herself and her ways of understanding her relation to the world" (Weedon, 1987, p. 32). Focusing on transgressing traditional notions of subjectivities, feminist poststructuralists, as well as many women of colour feminists, trouble the category "woman" (Alcoff, 1988; Pierce, 2010; Weedon, 1987). Judith Butler remarks on Denise Riley's (1988) book Am I That Name?

If one "is" a woman, that is surely not all one is; the term fails to be exhaustive, not because a pregendered "person" transcends the specific paraphernalia of its gender, but because gender is not always constituted coherently or consistently in different historical contexts, and because gender intersects with racial, class, ethnic, sexual, and regional modalities of discursively constituted identities. (1990, p. 3)

Making the observation that instead of people having a pre-assigned gender at birth, their gender is actually created and constructed based on the interactions and the structures in society. Thus recreating their subjectivity on a daily basis. Judith Butler and Denise Riley, among others state that there is no universal woman and no universal "...hegemonic structure of patriarchy or masculine domination" (Butler, 1990, p. 3). This disruption of the category woman is pervasive throughout modern feminist theories. Women of colour theorists, and postcolonial feminist thinkers similar to Chandra Mohanty, state that "the category woman" is a Western idealized concept which places the white woman in the centre, leaving marginalized women and other populations even further on the margins (Mohanty, 2003). It is not only the category woman that is troubled, but all categorical identities are deconstructed; and it is not the belief of poststructuralists that humans are not "...undetermined but, rather in the belief that we are overdetermined (i.e., constructed) by a social discourse and/or cultural practice" (Alcoff, 1988, p. 416). Gayle Rubin notes that; "It is impossible to think with any clarity about the politics of race or 
gender as long as these are thought of as biological entities rather than as social constructs" (2011, p. 147).

From the notion of multiple constructed subjectivities, a rejection of essentialism becomes apparent. Gayle Rubin states that essentialism has been deeply rooted in historical Western thought and mythology;

Sexual essentialism is embedded in the folk of wisdoms of Western societies, which consider sex to be eternally unchanging, asocial, and transhistorical. Dominated for over a century by medicine, psychiatry, and psychology, the academic study of sex has reproduced essentialism. (2011, p. 146)

It is this essentialism that postcolonial and poststructural feminist thinkers reject, stating that this notion of universal oppression, and universal categories fail to account for the significant cultural, historical and colonial contexts with which they take place (Butler, 1990; Mohanty, 2003). Judith Butler argues that this form of theorizing had much criticism,

For its efforts to colonize and appropriate non-Western cultures to support highly Western notions of oppression, but because they tend as well to construct a "Third World" or even an "Orient in which gender oppression is subtly explained as symptomatic of an essential, non-Western barbarism. (1990, p. 3)

Speaking on the formation of sexual difference and gender identity, Chris Weedon writes that the term 'patriarchal' relates to the structures of power inequality between men and women, and how men's interests are dominant (1987). She notes that these power imbalances are embedded in many relations, such as the sexual division of labour, reproduction, and normative constructs of femininity and masculinity. Chris Weedon states,

Patriarchal power rests on the social meanings given to biological sexual difference. In patriarchal discourse the nature and social role of women are defined in relation to a norm which is male (1987, p. 2). 
Thus, women are not seen as autonomous humans, but as a subordinate reference (a signification) to what they are not; men (Alcoff, 1988).

Language is also contested in poststructuralist feminist thinking, when discussing Jacques Lacan's influence on feminist postructuralism; Chris Weedon states that, "Language is a site for political struggle" (1987, p. 9). This is also connected to knowledge, knowledge production and legitimacy; worth noting that the central poststructuralists are male. It has been said that feminist poststructuralism based on Michel Foucault's theories of discourse and power make the political assumptions of language and meanings explicit (Weedon, 1987). Poststructuralism places meaning within language. Power and the ability to create knowledge have consequences for who possesses the skills to express themselves linguistically, who gains authority to use language, and who will be legitimized and heard when they use language. Language is constituted through discourses of power; many feminists attempt to disrupt this by analysing masculinist language, or by creating their own feminist language (Cameron, 1990). For example, American radical feminist Mary Daly,

Undertakes a radical deconstruction of patriarchal language and attempts to construct a new feminist discourse in which words acquire new meanings, which validate and celebrate a new, positive version of women and our oppression by and resistance to patriarchy. (cited in Weedon, 1987, p. 9)

Another key concept that poststructuralism troubles are that of experience, much of feminist theory was once based on the idea of a universal "Sisterhood" (Morgan, 1970), or the universal concept of women's oppression and male domination. However, poststructuralists, as was noted when speaking of essentialism and identity, view experience as socially constructed and without a universal "truth." All experience is constructed, rather than being solely based on knowledge, 
This involves understanding how particular social structures and processes create the conditions of existence, which are at one and the same time both material and discursive. (Weedon, 1987, p. 8)

Many feminist theorists are criticized for their reliance on experience alone as the basis for feminist theory. The disruption of the category woman, along with the repudiation of experience can be a problem for feminist thinkers, as much of feminist theory maintains "woman" as the primary feature. Linda Alcoff states this paradox,

But as a concept it is radically problematic precisely for feminists because it is crowded with the overdeterminations of male supremacy, invoking in every formulation the limit, contrasting Other, or mediated self-reflection of a culture built on the control of females. In attempting to speak for women, feminism often seems to presuppose that it knows what women truly are, but such an assumption is foolhardy given that every source of knowledge about women has been contaminated with misogyny and sexism. (1988, pp. 405-406)

As a consequence, Linda Alcoff argues that feminists must deconstruct and deessentialize the very subject of their theories (1988). Feminist poststructuralists must take up the notion of the power of difference (Lorde, 1984/2007), this, Linda Alcoff suggests will render gender no longer central to theories of social organization (1988). Instead, positionality (multiple subjectivities, multiple discourses, multiple differences, multiple realities) is the focus of poststructuralist feminism (Pierce, 2010).

\subsection{Structural Social Work Theory}

The structural approach to social work that was espoused during the mid seventies was a radical approach to social work that embraced conflict theory, Marxism and feminism (Moreau \& Leonard, 1989; Wood \& Tully, 2006; Lundy, 2004). Based on the literature, there are approximately seven key elements of the structural approach to social work. They are,

1.The defence of the client, 2. Collectivization or collective consciousness, 3 . Materialization, 4. Unmasking oppressive structures and critical consciousness 
raising, 5. Increasing the client's power in the worker-client relationship, 6. Empowerment through personal change, and 7. Social activism and political change. (Hick \& Murray, 2009, p. 93)

Structural social work's emphasis is on changing the structures of society to meet the needs of its people, as opposed to changing the individual in order to cope in an oppressive society (Hick \& Murray, 2009). This greatly contrasts with traditional social work's reliance on Freudian theory and the pathologising of individuals (Wood \& Tully, 2006; Moreau \& Leonard, 1989). At this time, Goldberg and Middleman were also pioneers of structural social work. They are quoted in Lundy (2004) stating that the goal of the structural social work approach is "...to improve the quality of the relationship between people and their social environment by changing social structures that limit human functioning and exacerbate human suffering" (p.57). Also noteworthy is the acknowledgment of the damage to personal lives that occurs as a result of the patriarchal, colonial and capitalist structures of society. Maurice Moreau, an influential structural social work theorist noted that,

Social problems are not caused by deficits in communication between individuals and systems as both ecology and systems theory posit. Differential access to power and conflict between systems are the problem and not a lack of mutual fit, reciprocity, interdependence and balance between individuals and systems. (1989, p. 23)

Moreau was also instrumental for including an intersectional approach to oppression and to the structures that create those oppressions within the structural social work approach. He maintained that the "primary structures' of oppression; “...patriarchy, racism, capitalism, heterosexism, ageism, and ableism" negatively impacted the "secondary structures' “...personality, family, community and bureaucracy (including those of the media, schools and government)" (Carniol, 1992, p. 5). Moreau contended that these 
'secondary structures' were often rife with conflict “...especially when individuals, families, and organizations struggled against the unjustifiable domination of exploitative relations" (Carniol, 1992, p. 5). A significant element of this theory is that oppressed people internalize their oppression, which causes self-hatred, guilt and the maintenance of subordinated position (Carniol, 1992). In order to combat this, structural social workers, according to Moreau should act accordingly,

Considerable attention must be given to helping the client confront and reclaim repressed, disowned feelings of fear, hurt, and anger in order that these feelings may be validated and connected to their true source, that is channelled outwardly instead of against oneself. (Moreau, 1990, p. 60)

The structural approach to social works' origins in conflict theory has a direct impact on how practitioners critically view the contradictions inherent within capitalism (Mullaly, 1993). This is exemplified in the weight that is placed on critical consciousness, collective action and a call for a radical restructuring of society (Lundy, 2004). Alongside the ideal of restructuring society through anti-oppressive actions, the structural approach is also deeply committed to personal change from an empowerment and dialectical approach (Wood \& Tully, 2006). The dialectical approach views, ““...individual agency” and social structures - related, co-existing constructs engaged in a mutually reinforcing relationship where one organizes and perpetuates the other" (Hick \& Murray, 2009, p. 89).

Practitioners of the structural approach do not blame their clients for the oppressions that they face, rather they empower the clients to "Name (rather than suppress) the more obvious oppressions affecting their living and working conditions," (Carniol, 1992, p.10). This approach relies heavily on Paulo Freire's theory of conscientization and education (Lundy, 2004). Through conscientization, the structural 
approach empowers people to join in their own emancipation process (Carniol, 1992; Lundy, 2004). The feminist influence on structural social work is exemplified through both approaches' application of consciousness raising and collectivizing what some view as individual pathology. In 1992, Carniol stated that,

Feminism has strengthened the backbone of social services and has had a constructive influence on social work education. Feminist counselling has provided a fresh way of helping women (p. 25).

A year later, in 1993 Mullaly goes even further and stated that,

Given its increasing importance as a major social work perspective, along with the predominance of women among users and providers of social work services, the feminist perspective is an epistemological imperative for structural social work (p. 148).

One key way that people can engage in their own emancipation is through joining social movements that work towards social justice goals. The active participation by their client in feminist movement is something that is often encouraged by feminist support workers and structural social workers alike. Linking client's personal oppressions to political movements empowers clients to become aware of the political implications of their personal lives.

\subsection{Summary}

Having noticed a growing tension within the Ottawa feminist movement regarding the inclusion or exclusion of men, I explored the narratives of eight selfdefined feminists. This research study seeks to uncover gendered narratives and feminist discourses that shape participation and experiences in the Ottawa feminist movement. My research is based in theories of feminisms and poststructuralism; as they are developed by Butler (1990), Carniol (1992), Collins (2000), Foucault (1990), hooks, (1984), Lorde (1984), Lundy, (2004), Weedon (1987). Structural social work and 
feminist action share similarities, focusing on the root causes of oppression and inequality, both envision and strive to create an emancipatory society. Structural social workers and feminist support workers practicing in the field of violence against women, often align their efforts with a feminist analysis of power and control. Concentrating on this topic of violence, the literature states that in order to end these atrocities, men must be included in the conversation (Flood, 2011; Kaufman, 1987). It is my hope that understanding the cynicism and apprehension of feminists to include men in the movement, will open up possibilities for future male inclusion. In the following sections I will provide a literature review of several fields of study; feminist movement, masculinities and feminism, and solidarity and ally work. I will then outline my methodological design and interview process, before moving into the analysis and discussions of my findings. 


\section{Chapter Three: Literature Review}

\section{Introduction}

A preliminary literature review was completed in order to gain a deeper understanding of the main themes informing this study of men and feminisms. These themes are feminist movements, masculinities and feminisms and theories of structural social work, solidarity and ally work. This preliminary review of the literature focused on defining key concepts within each theme, as well as discussing how feminisms construct gender discourse, along with theories of masculinity and men's ability to engage with feminisms. I then examined how the role of structural social work, solidarity and ally work can be effectively employed to further our comprehension of male feminists and their role within the feminist movement and as social justice advocates within social work.

\subsection{Feminist Movement}

Looking at Ann Cudd's 2006 work, Analyzing Oppression provides an effective starting point for an analysis of feminisms and men. In modern Western society, feminists have argued for decades that men are the oppressors of women. What makes the role of men within feminisms a contradiction is that the oppressors are attempting to resist their own active oppression of others. Ann Cudd historicizes oppression for us, noting that Mary Wollstonecraft in 1792 was among the first to use the word to "...refer to the denial of equal education and equal freedoms to women" $(2006$, p. 8$)$. The term oppression was subsequently used by John Stuart Mill, and then gained a wider analysis through Hegel and Marx's use of the term to describe oppression respectively "....as a 
failure to recognize the equal moral worth and dignity of another," and "... as causally based in the economic system" (Cudd, 2006, p. 8). For a greater understanding of feminist theory, we must understand resistance to oppression. One of the founding mothers of European feminism, Susan B. Anthony promotes resistance as going against the prevailing norms of society; she states,

Cautious, careful people always casting about to preserve their reputations or social standards never can bring about reform. Those who are really in earnest are willing to be anything or nothing in the world's estimation, and publicly and privately, in season and out, avow their sympathies with despised ideas and their advocates, and bear the consequences. (cited in Cudd, 2006, p. 187)

In order to understand the potential future of feminist movement, one must situate the history of feminist movement. In Becoming a Feminist: The Social Origins of 'First Wave' Feminism (1986) Olive Banks, provides the reader with an in depth study of individual feminists, women and men alike, during early nineteenth century England. Olive Banks examines the role of men within this 'first wave' of feminism, stating that during that time there was a great need for "a male spokesman to represent them in public" (p. 107). While at the same time arguing that one of the "...most striking thing(s) about feminism is the extent to which it has been a movement of women and not just for women" (Banks, 1986, p.106, emphasis in original). It is with these words that I ponder the question "what is a woman?" and I begin to wonder whether the feminist movement still requires men to be advocates for women in the public sphere? Capitalism and patriarchy have yet to be overthrown, therefore misogyny and discriminatory practices against women continue to be the norm in modern North American society. Until all marginalized populations have reached emancipation, there is much to be said about those in power advocating alongside those struggling with/or against oppression. 
American feminist bell hooks whom has received critical acclaim for her writings on race, class and gender, famously wrote a non-academic book entitled Feminism is for Everybody: Passionate Politics (2000). It is clear that she will have much insight into the politics of gender and inclusion in feminisms. Her work, Feminist Theory: From Margin to Centre (1984), differs greatly from 'first' and 'second wave' feminist theorists writings as bell hooks discusses the need for solidarity amongst women, however not based on a perceived "common oppression" but based on a new idea of 'Sisterhood' (p.44). She calls for women to "...bond on our political commitment to a feminist movement that aims to end sexist oppression" (hooks, 1984, p.45). bell hooks has also been a defender of the inclusion of male identified feminists, referring to them as "comrades in the struggle" (1984, p.67), and notes the solidarity between genders that was necessary and effective during the American Civil Rights movement (1984, p.69). bell hooks' feminism is not essentialist, and does not adhere to some radical feminists' notion that all men are oppressors of all women.

bell hooks demonstrates similar views on gender that were made famous by Judith Butler's influential book, Gender Trouble (1990). Judith Butler's pivotal theory on the separation of sex from gender enhances our analysis of men engaging in feminisms. If there is no recognized relation between sex and gender, no such thing as gender naturally, and all gender is actually performative; then there must be no reason why those who fall into the gender category man cannot partake in feminist movement (Butler, 1990). Judith Butler's criticism of major feminist thought is the essentialist creation of a "woman" category of subjectivity. She argues that there is no such category; it is impossible to separate gender from other “...discursively constituted identities" (Butler, 1990, p.3). By 
adhering to the masculine/feminine binary, Judith Butler argues that feminists and nonfeminists alike are continuously perpetuating male supremacy. Judith Butler states that the subsequent feminist theories should contest and challenge the categories of gender (1990). If there were no uncontested category "woman" then perhaps Judith Butler would say that there is a positive role for men to engage within the movement.

\subsection{Masculinities and Feminisms}

If we are to decipher the contradictions of male feminists engaging in social justice and the views that other feminists have of their role, it is necessary to discuss John Stoltenberg's classic radical feminist book, Refusing To Be a Man (1989). John Stoltenberg has written extensively on men and feminisms. John Stoltenberg does not adhere to the categorization of gender, and this is clear when he quotes famous radical feminist Andrea Dworkin (1974) on the subject of "man" and "woman,"

The discovery is, of course, that "man" and "woman" are fictitious, caricatures, cultural constructs. As models they are reductive, totalitarian, inappropriate to human becoming. As roles they are static, demeaning to the female, dead-ended for male and female both. (cited in 1989, p. 28)

His major theory rests on the premise that, “...male sexual identity is the conviction or belief, held by most people born with penises, that they are male and not female, that they belong to the male sex" (Stoltenberg, 1989, p. 31). This identity, Stoltenberg asserts, is what perpetuates the violence, domination and oppression of women by men (1989). Therefore, he urges men to refuse to engage in the system of privilege and power that creates their supremacy over women. He declares similarly to Judith Butler, that the binary category of gender creates opposition and oppression. He is a long time advocate of men engaging and participating in feminist movement, he labels these men as "men of 
conscience" (Stoltenberg, 1989 p.182), and he himself has been active in the American feminist movement for decades.

There have been many scholarly books written about men and feminist theory, see for example Digby, 1998; Hopkins, May, \& Strikwerda, 1996; Jardine \& Smith, 1987; Lemons, 2008; Schacht \& Ewing, 2004; Schacht, 1998; and Snodgrass, 1977. However something that is often left out is an analysis of the discourse of feminist thought that is contributing to the feelings, assumptions and concerns that women have with men joining the feminist movement. It is this area that I will be addressing in my research. However, before we can do this, we must review the relevant literature on men's role within feminisms. One such book that has contributions from significant feminists such as Sandra Bartkey and Sandra Harding is Men Doing Feminism edited by Tom Digby (1998). There are many important chapters in this book; I will however focus on one. In Chapter 9: Can Men be Subjects of Feminist Thought? (Digby, 1998), Sandra Harding asks the familiar question of the creation of the subjectivity of feminist thought. She notes that there is no argument about whether men have participated in the women's movement, but the question that has not been answered pertains to the creation of feminist epistemology. She states clearly, "To understand what is problematic about the concept of feminist men, we can uncover what is problematic about the concept of feminist women" (Digby, 1988, p. 174, emphasis in original). The theme of gender as a binary category that must be contested is significant when examining who can create and participate in feminist thought and movement. Sandra Harding concludes with an appeal for further discussion “...of the real concerns both women and many men have about co- 
optation, paternalism, appropriation, infiltration and the like that provoke such scepticism toward putative feminist men" (Digby, 1998, p. 192).

One of the most influential terms often used throughout many books, journal articles and cultural references is 'hegemonic masculinity.' In order to attain a more thorough interpretation of this term, we look now to the original creator of the term, and their updated impressions. In the article, "Hegemonic Masculinity: Rethinking the Concept" (Connell \& Messerschmidt, 2005), R.W. Connell a well known Australian trans woman, academic, professor and one of the founders of the current theories of masculinity, (Connell, 2010) and James Messerchmidt, revisit a much contested designation. The authors state that the term was created in the 1980s and was subsequently employed in many different feminist works, mainly to discuss men's role in transforming patriarchy (Connell \& Messerschmidt, 2005). The authors argue that the term has been used in ways that it was not deemed. The true meaning of hegemonic masculinity was based on the notion of multiple masculinities where most masculinities were subordinated to the hegemonic masculinity (Connell \& Messerschmidt, 2005). Connell and Messerchmidt (2005), explain:

Men who received the benefits of patriarchy without enacting a strong version of masculine dominance could be regarded as showing a complicit masculinity. It was in relation to this group, and to compliance among heterosexual women, that the concept of hegemony was most powerful. Hegemony did not mean violence, although it could be supported by force; it meant ascendancy achieved through culture, institutions, and persuasion (p. 832).

The term hegemonic masculinity had been and continues to be used, perhaps incorrectly, in current feminist thought and masculinity studies as a term describing the ideal masculine identity as dominant and oppressive, offering little room for variety (Connell \& Messerschmidt, 2005). The authors refuse the usage of this term to connote a 
"...fixed character type, or an assemblage of toxic traits" (p. 854). The authors conclude by stating that hegemony is something that is increasingly necessary to resist, and that new global realities are creating even more space for men to resist hegemonic masculinities together (Connell \& Messerschmidt, 2005).

The book Men and Feminism (2009) by Shira Tarrant, provides a brief however in depth historical analysis of the role of men and feminisms. She reiterates the same claim to a resistance to the essentialist notion of feminisms, which would therefore allow for the inclusion of men into the world of feminist thought and movement (Tarrant, 2009). She historicizes men's involvement with feminist thought and movement through descriptions of the abolitionist movement, the early civil rights actions and campaigns, the sexual revolution of the 1960's and 1970's, and current discussions of men's engagement to end violence against women. She concludes with a call to action for men and women alike to engage in feminist action, and in particular urges men to "...break out of the man box" (p. 82), a term made famous by American anti-violence educator and activist Jackson Katz (Tarrant, 2009).

Turning our attention now to a journal article written by Casey and Smith. ““'How Can I Not?" Men's Pathways to Involvement in Anti-Violence Against Women Work" (2010), is an analysis of a qualitative study, which examines, “...factors that precipitate men's engagement as anti-violence "allies"' (p. 953). A key piece of information that is made explicit in this study is the relationship between certain notions of masculinity and propensity or acceptance of violence. Also noted is the responsibility men have in ending violence against women,

Based in the reality that the majority of perpetrators of violence are male (Tjaden \& Thoennes, 1998), that risk for violence is connected to traditional notions of 
appropriate "masculinity,"' (Heise, 1998; Murnen, Wright, \& Kaluzny, 2002) and that men are more likely to be influenced by other men (Earle, 1996; Flood, 2005), there is increasingly widespread agreement that the project of ending domestic and sexual violence requires male participation (Flood, 2005;DeKeseredy, Schwartz, \& Alvi, 2000). (cited in Casey \& Smith, 2010, pp. 953-954)

This work is relevant to my thesis however what this study, like many others, fails

to answer is what are the perceptions that the women have of men's involvement with feminisms? Each study that I have come across analyses the steps taken to engage men with feminisms, the personal accounts of men's development as a feminist or as an antiviolence activist. However, I have not found a study that examines how the women within the movement feel about men's involvement or role within feminisms. There is often an unwritten sense that women in the movement are contemptuous or suspicious of men's involvement. I have not come across any concrete analysis of this.

\subsection{Solidarity and Ally Work}

The term solidarity is often used within activist circles that I have belonged to here in Ottawa; members of activist groups want to be in solidarity with each other across intersectionalities. However, this desire is seldom reflected in reality; there is a distinct often unmentioned separation along gender, race, class and ability lines. This is problematic. In order to analyse this problematic feature within feminist movement a review of relevant literature surrounding solidarity and ally work is necessary. My thoughts are that through solidarity and ally work, the beginnings of a delicate relationship between genders and across racial lines within feminist movement is possible.

Sara Ahmed, makes a strikingly important point in her 2004 book; The Cultural Politics of Emotion, when she examines the relation between feminisms, anger and "the politics of pain" (p. 172). Much of the early feminist consciousness-raising and feminist 
organizing stemmed from multiple women's lived experiences of pain and the anger that comes from discrimination, oppression and violence (Ahmed, 2004). It is worth noting that this reflects the ideas of solidarity that was first mentioned by the 'white bourgeoisie first wave European feminists' what they called 'a solidarity of oppression, a sisterhood of victimization' (Banks, 1986; hooks, 1984). Despite not wanting to adhere to a solidarity that comes from 'common feelings of oppression,' we must however reflect on these painful realities.

Sara Ahmed suggests, through examining Burstow's (1992) account of radical feminist therapy, that to rely on pain as a form of solidarity remains quite problematic.

So if pain is what compels feminism into being, then is this a sign of feminism's failure to 'move away' from the site of subordination, or more specifically, to resist transforming that subordination into an identity claim? ... This model is problematic because of its fetishism: the transformation od the wound into an identity cuts the wound off from the complex histories of 'being hurt' or injured, histories which cannot be gathered together under a singular concept such as patriarchy (Ahmed, 2004, p. 173).

She states clearly “...there are good reasons, then, to avoid assuming that women's pain provides the foundation for feminism"(Ahmed, 2004, p.173). From this view, we can see a distinct separation of feminisms being rooted in a common feeling of oppression felt by "all women." This opens up the inclusion, acceptance and willingness of engagement for men to join in the movement, and for women to view these men as allies in solidarity. Sara Ahmed refers us to Chandra Talpade Mohanty's (2003) term “transnational solidarity." Sara Ahmed explains her argument for solidarity amongst all people in order to affect real change, and maintain our feminist anti-essentializing notions of community,

Indeed, speaking for something, rather than someone, often involves living with the uncertainty of what is possible in the world that we inhabit. Solidarity does not assume that our struggles are the same struggles, or that our pain is the same pain, or that our hop is for the same future. Solidarity involves commitment, and 
work, as well as the recognition that even if we do not have the same feelings, or the same lives, or the same bodies, we do live on common ground. (2004, p. 189)

This provides understanding for solidarity across gender lines. Stating that even if the population is diverse, communities can struggle together. Ahmed (2004) affirms that although there is no 'common oppressions,' solidarity is possible. This provides great insight into understanding the involvement of men in feminist movement.

Moving away from a notion of solidarity as connection with others based on perceived shared experiences of oppression and pain, Margaret Price, offers an interesting investigation into activism, ability, feminisms and racism, in her 2011 essay; "Cripping Revolution: A Crazed Essay." She focuses on white activism, white alliance and the intersections of queerness and disability. Margaret Price speaks of the usefulness of having a checklist for ally work, in the social work field this is often referred to as a toolkit. She also warns readers and activists alike of the barriers to using checklists,

Checklists are important tools when talking about privilege and how to be an ally. They offer a starting place, a framework for further discussion. But they also contain an inherent risk: that the list will be seen as a list, rather than as a story. A recipe, not the dish made from it. (Price, 2011, p. 6)

Margaret Price problematizes the use of the word ally, "No one is an ally, any more than anyone is disabled" (2011, p.6 emphasis in original). This is interesting, as the word ally is used as an identity marker throughout activist organizations and within several of the relevant literature that I will review in the coming pages. She states that people instead of being allies, actually practice alliances (Price, 2011). Margaret Price also brings into the debate the notion of ableism within activist communities. It is often those who are able-bodied and present at the protests, at the marches for women's rights that are then labelled as the 'one's who are participating in the women's movement' 
(Price, 2011). This, for Margaret Price is problematic and oppressive towards people living with disabilities. Another aspect would be those who cannot offer their bodily presence to marches and protests because of other personal and or professional constraints that they might have, such as employment, childcare, or illness. This leads me back to notions of inclusion within feminisms, and the ability to name who is a feminist. It is problematic to state that in order to be a feminist you must have bodily presence within the feminist movement during protests and marches. Margaret Price's personal and theoretical analysis about being an activist, “...to realize that my struggles with showing up-for reasons ranging from brain fog to physical exhaustion to fear of crowds - were not simple failures marking me as a — bad activist" (2011, p. 11).

In order to situate our understanding of ally work and solidarity, I now turn to the writings of Vikki Reynolds. Her 2010 dissertation, Doing Justice as a Path to Sustainability in Community Work, presents insightful knowledge into the realms of social work in the community (read doing justice) and notions of solidarity between the workers and those whom they are working with.

Vikki Reynolds attempts to align community work with local activism, this I believe to be a strong proponent of the structural social work approach. Advocating on behalf of those whom you work with, as well as politicizing their individual experiences and fighting against oppression within a broader context of social justice and policy, are all key concepts of structural social work. Reynolds argues that community workers should share a sense of solidarity with each other,

In this difficult work we can be connected with each other across differences despite being on separate paths. We can go on somehow, fortified by knowing that others are moving in similar directions with shared hopes that we are 
"establishing connections just below the surface of every day life, eventually bursting forth in unpredictable ways." (2010, p. 3)

Vikki Reynolds offers a lot of important writing on the concept of ally work and supervision, I can garner from her insights that she believes that everyone must come together across intersections of identity and location. She believes that everyone is bound together by a shared resistance to oppression; a shared vision for social justice transformation; and a shared knowledge that everyone must act in order to achieve revolution (Reynolds, 2011). Vikki Reynolds states,

Solidarity speaks to the interconnections of our collective movements towards social justice, and in resisting oppression. This spirit of solidarity has been beautifully articulated by Lily Walker (no date), an Australian Aboriginal women's leader, speaking to non-Aboriginal activists at a land rights protest: "If you come here to help me, then you are wasting your time. But if you come here because your liberation is bound up in mine, then let us begin." (2011, p. 4, emphasis in original)

With a deeper understanding of the complexities of solidarity and ally work, I will now review two journal articles dealing with qualitative research of ally work, one within anti-racist activism, and the other working within the Lesbian, Gay, Bisexual, Transgender, Queer, Questioning (LGBTQ) community. Smith and Redington's article "Lessons From the Experiences of White Antiracist Activists" (2010), is based on lessons that can be learned from ally work and then incorporated into psychology practices, which is relevant when integrating these approaches with social work practice.

Their study is important as it outlines the significance of people with a multitude of intersectionalities, including privilege, engaging and role modelling from an anti-racist approach (Smith \& Redington, 2010). It would be problematic for me to suggest that oppression based on race is the same as oppression based on gender; therefore I cannot simply replace one for the other. However, I can incorporate the insights of white anti- 
racist ally work with models of ally work for women's rights. The authors propose a straightforward definition of the concept ally, incorporating views from several different authors,

O'Brien's explication dovetails with the concept of the social justice ally, a role which was described by Roades and Mio (2000) as having three primary elements: “(1) recognition of the oppression faced by groups other than one's own, (2) recognition of the privilege that comes with membership in a dominant group, and (3) active support of and effort to speak out for and stand up for others and work to change the status quo" (p. 65). Similarly, Kivel (2002) described an ally as a person who "takes an active but strategic role in confronting racism." (p. 115) (cited in Smith \& Redington, 2010, p. 541)

The authors conclude by suggesting that one of the "...concomitants of contemporary racism" (Smith \& Redington, 2010, p. 542), is the silencing of the work that white anti-racist allies engage in. Suggesting that other white anti-racist allies do not have role models from similar privileged locations to guide them in their work. Contemporary knowledge of men feminist leaders is slim. If social justice advocates are to promote the engagement of men within feminist movement then feminists must promote and allow men who practice feminism space to act, work and live.

Matthew Eichler's 2010 journal article, “Joining the Family: Experiences of Being and Becoming Ally Activists of LGBTQ People" examines the lived realities of three straight identified LGBTQ ally activists. He suggests there are two levels to becoming an ally activist: 1) become an ally, 2) be moved to action (Eichler, 2010). His study was influenced by his relationship with activism and with straight allies in particular,

These straight allies took upon activism, that is, activity designed to elicit a change in law or policy or other social structure. Their activism was powerful for me, because it seemed they had nothing to directly gain from their activism. (Eichler, 2010, p.91) 
Here Eichler touches on several key concepts of ally work and solidarity, ones that are relevant to my research on men within feminist movement. These concepts are, his definition of activism, that is working towards change, what Vikki Reynolds might term "doing justice" (2010), and the notion that straight allies have 'nothing to gain' from their work in gay rights activism (Eichler, 2010).

This second concept has been debated for decades, perhaps the summation of this, is what is echoed in the truths of theorists past, that if one person is oppressed, we are all oppressed. Matthew Eichler provides us with a study of straight ally activists who have developed their identity as allies, while freeing themselves of the constraints of hegemonic discourses of gender and sexuality. This will prove invaluable to my understanding of men engaging in feminist movement, while perhaps re-imagining discourses on feminisms and masculinities.

\subsection{Summary}

While Olive Banks (1986) situates male engagement with early 'first wave' feminist movement, by also noting that male participation seemed to taper off following the suffragist movement. bell hooks (1984) is a firm believer that Feminism is for Everybody (2000) and that feminists must recreate the concept of 'Sisterhood' and solidarity in order to overcome the past meanings that were tied up with racism and victimization. Judith Butler (1990) contests the categorizations of gender, and argues that it imposes an oppositional binary. Which calls into question the title of John Stoltenberg's book Refusal to be a Man (1989), if there are no fixed categories, perhaps everyone should refuse to be gendered? When R.W. Connell and James Messerschmidt rethink the concept of hegemonic masculinity, this opens up the debate for what Harding 
(1998) refers to when she uses the radical feminist language of, “..."a different kind of man," or perhaps even better, a human, a person, in a truly gender-neutral sense" (p. 182). It is clear that there are debates surrounding the category of 'woman' and 'man' as uncontested limited genders, and perhaps transcendence is possible. For without transcending the essentialist notions of what it is to be a 'man', or a 'woman', feminists will never be able to work in solidarity with each other. As Sara Ahmed (2004) argues, it is not a solidarity of pain, but a solidarity of visions for a social justice/feminist future. The literature on men's roles in feminisms is extensive, however the research is limiting when focus is solely on their development as allies, or the extent of their participation within the feminist movement, I have yet to read research that is based on how the women identified feminists feel about the inclusion of men in feminist movement. 


\section{Chapter Four: Methodology}

\section{Introduction}

In this section methodological design and interview process are discussed, as well as the rationale behind the selection of such methods. Ethical considerations are also explored. The methodology that guided this project are feminist critical discourse analysis. Qualitative methods of interviewing were employed to understand how participants experience men's involvement in the feminist movement and how they comprehend their own feminist identity. Ten participants were interviewed using a flexible interview guide (see appendix A), upon completion, reflection notes were written, and the interviews were transcribed verbatim, save for two audio files that were corrupted, and thus had to be removed from the study.

\subsection{Methods}

As my research question is rooted in understanding and challenging hidden notions of patriarchy, power and ideology within the feminist movement, I am employing feminist research methods. Feminist research methods were born out of a critique of the traditional research methodology that espoused objectivism and positivism to be the truest form of scientific inquiry (Ann Oakley (1981) as cited in Reinharz, 1992, p. 27; Kirsch, 1999, p. 3). Many authors have written about the patriarchal views and conduct that is perpetuated and maintained by traditional research methods (Kirsch, 1999, p. 1). Shulamit Reinharz asserts how imperative it is for feminist researchers to challenge patriarchal knowledge creation,

Patriarchal knowledge is based on the premise that the experience of only half the human population needs to be taken into account and the resulting version can be 
imposed on the other hand. This is why patriarchal knowledge and the methods of producing it are a fundamental part of women's oppression, and why patriarchal knowledge must be challenged - and overruled. (1992, p. 7)

Shulamit Reinharz states that women cannot be understood as in opposition to men (1992). In order for empowerment through consciousness raising and feminist knowledge to be created, one must look into the lived realities of women, as women. Adhering to feminist research methods allows me to subvert traditional research paradigms that tend to centre the masculine experience.

While 'second wave' feminism was gaining ground, feminists who studied methodology were concerned with acknowledging what Dorothy Smith (1990) called "alternative ways of knowing" (as cited in Hesse-Biber \& Leavy, 2007, p. 5), that did not enable or preserve the status quo. Traditional research methodology was based on the scientific method and the ideas from the Western male dominated Enlightenment. Western feminists reclaimed research; they did not want to reproduce the same harm that had already been done to marginalized populations by traditionalist researchers (Reinharz, 1992). Traditional research methodology upholds patriarchal notions of identity, representation and power (Hesse-Biber \& Leavy, 2007). It was and still is today important for feminist researchers to be able to use methods of collecting data that does not perpetuate the confining societal norms that women and other marginalized peoples are boxed into.

Stemming from my adherence to feminist research practices, I chose feminist critical discourse analysis as my methodology. One of the main themes of feminist critical discourse analysis that is stated throughout the literature is the focus on critiquing discourses that perpetuate and maintain the patriarchal order within society, namely 
analysing how unequal power relations systematically recreate male supremacy (Lazar, 2005). Furthermore, feminist critical discourse analysis' aims are not just in deconstructing the discourse of power, but in creating social change and practicing reflexivity, similar to a structural social work approach. Michelle Lazar, refers to "analytic activism," when she asserts that,

The intervention of a feminist critical discourse analysis in current practices of recuperative reflexivity is a form of analytical activism, which keeps going critical feminists' efforts at radical social change. (2007, p. 160)

Due to the explicit focus on power, gender inequities and hegemonic patriarchy, it is no wonder that this methodology of discourse analysis is politically charged. The aim for feminist critical discourse analysis is to reveal where the power rests and how those with power control those without. One cannot subvert power without understanding where it comes from, or who has control of it.

I chose to use qualitative feminist research methods, as this method most aligns itself with feminist theory. As noted in the Anselm Strauss and Juliet Corbin 1998 book, Basics of Qualitative Research: Techniques and Procedures for Developing Grounded Theory,

...qualitative methods can be used to obtain the intricate details about phenomena such as feelings, thought processes, and emotions that are difficult to extract or learn about through more conventional research methods. (p. 11)

This methodology will enable me to unearth participants' insights into their experiences in the feminist movement in Ottawa.

Sherry Gorelick reminds us that feminist research methodology is not simply about giving voice to women's oppression, but about challenging it (1991). Mary Fonow and Judith Cook have identified four elements that operate within feminist research. They 
are 1) engaging in reflexivity, 2) having an action orientation, which includes emancipatory goals, 3) paying attention to the affective components of the research, and 4) having the ability to "use the situation at hand" meaning paying attention to the daily lived experiences of those with whom you are doing research (Fonow \& Cook, 1991, p. 2). These four characteristics can be seen through my reflective analysis of the interviews, orientating my research to the goal of social justice through the creation of a larger (perhaps more cohesive, while maintaining difference) feminist movement in Ottawa. My analysis includes a section on the emotional affect of participating in social movement, as well as answering specific questions.

Natasha Mauthner and Andrea Doucet (2003) encourage researchers to practice reflexivity by recording their interpretations, and suggest "...that the validity of interpretations is dependent on being able to demonstrate how they were reached"... and to pay close attention to, "the importance of recognizing the social location of the researcher as well as the ways in which our emotional responses to respondents can shape our interpretations of their accounts" (p. 418). Throughout my interviewing process I have kept a notebook of my personal reflections upon completion of each interview. This has allowed me to 'tune-in' to my own assumptions and perceptions of the participants. I have also focused on my biases when analysing the data, and these prejudices will be explored more thoroughly in the findings and discussion sections. I hope this research will allow those active in the feminist movement to reflect upon discourses surrounding male participation in the movement. In addition, I hope it will add to the current dialogue around gender accountability within the movement and contribute voices to this conversation that are often overshadowed. 


\subsection{Design}

Through this process, I have aimed to uphold the feminist goal of ensuring that the lived realities of the participants are taken into account, as well as my own personal reflections. In order to reach this goal, I used several design elements to shape this research. I began by using a qualitative method, which consisted of performing face-toface interviews with the participants, at a neutral location of their choice. Acknowledging the power differentials between the participants and myself, I tried to give the participants ample space and time to reflect on the questions, and gave them all a few weeks to withdraw from the study or to provide feedback about their interview. None of the participants chose this option. I kept written notes of the interviews as well as audiorecordings; these notes allowed me space to reflect on my own positionality and biases. The interviews were then transcribed verbatim, in order to adequately reflect the participants' speech patterns and use of vocabulary. Upon completion of this thesis, all participants will receive either an electronic or paper copy of this thesis, as they indicated that they would appreciate this.

\subsection{Informed Consent and Confidentiality}

Ethics approval was obtained through the Carleton University Research Ethics Board. I provided all participants with a project description letter (see Appendix B), which described the research study and process, as well as a letter of informed consent (see Appendix C). The participants were given time and space to read the informed consent and project description, and then signed the consent form. All of the information that was gathered in the form of hand written notes and audio-recorded files were kept in 
a secure drawer that was locked. Once the information was transcribed I kept it on a password protected USB stick, in a locked drawer.

\subsection{Participant Engagement}

I used purposive sampling techniques, as I was able to choose specific participants based on the inclusion criteria (Palys, 2003). I made use of my own social networks as a resource and approached a few people whom I knew were active in the movement. I circulated a project description as well as posters and created an anonymous email account as a medium for contact between potential participants and myself. Limitations of this sampling procedure were that there was a lack of diversity amongst participants. I did attempt to diversify the sample by contacting agencies, organizations, social justice groups and university centres asking for permission to promote my research (see Appendix D). I also sent them a project description and posters (see Appendix E). Despite these efforts the sample ended up being predominantly white academic feminist community members who were under the age of 35 .

\subsection{Sampling}

Based on a review of the literature the majority of non-probabilistic sampling procedures in qualitative research are purposive, as this sample style is "...always criterion-based and purposeful — that is, participants are selected according to (1) specific criteria that correspond to the questions guiding the research, and (2) the potential for them to provide significant data" (Smith \& Redington, 2010, p. 542). This research used non-probabilistic sampling procedures in order to gather the richest data from key informants within the feminist movement in Ottawa. The inclusion criteria for this research study was broad and self-ascribed; participants where to be based in the 
Ottawa region, one had to self-identify as being a feminist, or as active in the Ottawa feminist movement, and identify anywhere on, or not on, the gender continuum. ${ }^{9}$

My aim for my sample was to include approximately five self-identified men and five self-identified women from various backgrounds and social locations. I was also eager to include participants who do not fit within the gender binary. The experience of trans* folks within the feminist community has the potential to provide insight into the power and oppressions that are maintained within the movement. This proved to be slightly more difficult than I thought, because the overwhelming number of respondents ended up being from academic settings. The first sample that I was able to interview consisted of ten participants, five who self identified as women, one who identified as gender-queer ${ }^{10}$ and trans*, and four who self identified as men. One participant identified himself as gay, and one identified as queer. Of the ten participants three were women of colour, and all were from an academic setting, with six being active in community

${ }^{9}$ During my participant engagement phase, I had the opportunity of meeting a person who is influential in feminist social work in Ottawa. I approached her and told her who I was and what my research was based on, she asked to be involved in the research. The Carleton University Research Ethics Board provided me with an amended ethical clearance in order to use her name, only with her strict consent. She provided me with consent to use her name. That person was Helen Levine. Helen Levine has been a social worker, professor and author for many decades. She introduced women's issues and feminist approaches into the syllabus at the Carleton University School of Social Work during the late 1960's. In 1989 she received the Governor General's Award in Commemoration of the Persons Case for advancing the equality of women in Canada (Status of Women Canada, 2008).

${ }^{10}$ Pink Triangle Services Ottawa defines gender-queer as, An umbrella term used to describe gender identities that do not fit the gender binary of man and woman. While gender-queer identities vary, the most commonly used are being both a man and a woman, being neither a man nor a woman, or as a gender outside man and woman (a third gender). The one commonality that unites all gender-queer people is their rejection of the notion that there are only two genders (2012). 
organizing and support work within the feminist movement, and one having retired from being active in the feminist community. Clearly, this is not representative of the feminist community in the Ottawa region, but it could speak to the overrepresentation of white academic feminists within feminist movement in Ottawa. The fact that I am a white academic feminist could have also played a role in who responded to the participant engagement information. It could also speak to a tradition of racist research projects, where those most marginalized are hesitant and sceptical of white feminist researchers (Agyeman, 2008; Kirsch, 1999; Mohanty, 2003; Smith, 2012; Brown \& Strega, 2005).

The academic background of the participants could be seen as both beneficial as well as a weakness in my sample. As most of the participants had studied feminist theory and gender studies previously, all were accustomed to the specialized language of feminist academia. Therefore, most of the participants seemed to have well rehearsed or at least well thought out answers, as well as answers that tried to maintain their outward persona as anti-oppressive. It would have been beneficial to have some participants who are not currently in academia. This would have proved useful for insight into the lived realities of women and men who do not have access to middle class institutions such as the university. It would have been valuable to my project to have interviews with those who perhaps have not had the ample education or time to think through the nuances of feminist theory as it pertains to the feminist movement and gender.

\subsection{Interviews}

I conducted 10 semi-structured, in depth interviews. Each interview took between 60 and 90 minutes. Unfortunately, during audio-recording and transcription process two of the audio-recorded files were corrupted, therefore my final sample consisted of eight 
participants; three who self identified with the pronoun he, four who self identified with the pronoun she, and one who self identified with the pronoun they. Of these eight participants, one identified as queer, two were women of colour, and all save one were currently working or studying in academia. Six were active in community organizing within the feminist movement, three were also feminist support workers, one was a social worker, and one was a retired feminist counsellor and activist.

An important aspect of creating a comfortable interview setting would be to follow guidelines from the book Qualitative Interviewing: The Art of Hearing Data (Rubin \& Rubin, 1995), which aims to turn interviews into 'guided conversations.' The authors state that first one should create natural involvement, by starting with informal chats that slowly points toward the topic at hand (Rubin \& Rubin, 1995). In this project the interview process began by meeting the individual participants at a public neutral location of their choosing, where we engaged in informal conversation about the weather, how our days where going and so forth. This provided me with a chance to build rapport and decrease nervousness on behalf of the participants and myself. Following this informal meeting, the interviews took place at either the offices of the participants, an office that I was using for the sole purpose of interviewing, one interview took place in a spare room at my house, and one interview took place at a participant's home. A second guideline from Rubin \& Rubin suggests that I “...encourage conversational competence” (1995, p. 130) and “...show understanding” (1995, p. 131). I did this by reassuring the participants that I valued their knowledge and was interested in what they had to say, while also being empathetic to their lived realities. I was then able to ask pertinent 
questions, as well as focus on sensitive topics as I had gained rapport with the participants.

I used a flexible interview guide, one that can be elaborated or changed to respond to the particular priorities of each participant. The interview content was framed in four categories; 1. Feminisms, 2. Personal Experiences, 3. Community Involvement, and 4. The Future. I used accessible language and terminology that reflected the participant's own use of language. I aimed to create an interview process that was intervieweeguided'; this means that I focused more on understanding the participant's perspective, as well as getting most of my questions answered (Reinharz, 1992). However, I am aware that this research study will be based on my interpretation of other people's experiences, and will not objectively reflect their perspectives.

\subsection{Transcription / Representation of Knowledge}

None of the participants contacted me with further information or insights upon completion of the interview, even though I expressed that they had this option. During the transcription process, personal identifiers such as agency names, university names, and participants' own names where omitted. Any personal information that the participant stated they wanted to be deleted from the transcript was removed, as well as any other identifying information.

My role as researcher is somewhere between insider and outsider. As I have been involved in feminist movement for the better part of six years, focusing in the violence against women community in Ottawa. I am also a member of several activist communities, which adds to my insider knowledge about the community I studied. This provided me with the opportunity to steer clear from traditional power imbalances and 
oppressive research methods when researching a community of which you are not a member. I attempted to decrease researcher bias while interviewing by asking clarifying questions of concepts that I was already aware of, but wanted to hear the participants' meanings of a concept, rather than my assumed meaning. The differences within feminist theory, as expressed by participants and myself, was further addressed by way of stating (in the introduction to the interview) that the interviews are about challenging perceptions, and that the participants should not withhold information for fear of judgment or going against what they believe to be my feminist views. However, this is a tension that is not easily resolved, as many participants might not want to speak out against normative feminist discourses of gender, or about some of the more controversial topics that I brought up; such as women-only space and trans inclusion.

Nancy Naples suggests that a feminist standpoint analysis problematizes the uncontested dichotomy of insider or outsider (2003). She suggests that people's roles within research are more fluid than a simple binary would suggest, and that these roles are ever changing throughout the research process (2003). My role as researcher was fluid, as I was known to most of the participants, therefore outed as a feminist and part of the community of practice that I was researching, however they were also outed as feminists. My power was recognized, as I was the one asking questions, taking notes and would be analysing their answers. Conversely, I was also an outsider and insider due to my heteronormative white academic cisgender woman identity, as some of my characteristics did and did not mirror those of the participants. For example I am not knowledgeable of what it means to grow up in Canada as a women of colour who arrived as a child from a country in the South, my white family immigrated to Canada from 
England. Another aspect that problematized my role as researcher was that I interviewed other members of my community, however I also come from an academic social work perspective. I could be identified as what Sara Evans describes as the "knowledgeable stranger" position that falls between Denise Segura's "interviewer as friend" and Mary Zimmerman's "interviewer as stranger" (as cited in Reinharz, 1992, p. 27). Fortunately, Denise Segura claims, “...the quality of the interview data and their reliability is enhanced when the researcher is knowledgeable and integrated into the community under study" (as cited in Reinharz, 1992, p. 26).

My positionality as "knowledgeable stranger" had a significant impact on the study. Participants seemed to feel comfortable sharing stories that were not always favourable towards the feminist community, as they saw me as an insider who was already mostly aware of the tensions and hidden struggles within the movement. However, it must be noted that the participants were also hesitant to express some of their sentiments regarding their experiences with other members of the feminist community. The use of feminist language and jargon exemplifies the participants' understanding of my feminist background and enhanced knowledge of the theories and debates within feminist action. Participants were also able to refer to events or situations without having to go into detail about what the specifics where, as we shared a common background knowledge of the feminist community in Ottawa. My identity provided me access to a greater depth of information and nuances surrounding the debates within feminist movement. 


\subsection{Feminist Critical Discourse Analysis}

I performed feminist critical discourse analysis as the methodological approach to this research. This has enabled me to deconstruct the participants' own creation of discourse within the feminist movement. It has also allowed me to examine the functions of power and control in dominant discourses of gender within the movement. Feminist critical discourse analysis focuses on "Hegemonic discourses [as] ideas and words propagated through institutions and processes that serve the interests of dominant groups" (White, 2009, p. 171).

Based on the interdisciplinary scope of the literature it is evident that critical discourse analysis has a wide range of influences and usage. When speaking of the benefits of discourse analysis for social work practitioners, Sue White suggests that, discourse analysis can be used "...to identify in this talk dominant and taken-for-granted ideas about particular phenomena, such as childhood, gender, race, the family or mental health, and how these reflect particular historical, political and/or moral positions" (2009, p. 162). Sue White continues, by offering an excellent description of discourse analysis when she claims that it is an analysis of, “...the reproduction of social and political domination through talk and text" (p. 162).

The effect of feminisms on the field of critical discourse analysis originated with feminist scholars in other fields challenging the supposed gender neutrality and objectivism of scholarly practices, and asserting a need for a "feminist" label to differentiate their approaches (Lazar, 2007). Michelle Lazar's 2007 journal article, "Feminist Critical Discourse Analysis: Articulating a Feminist Discourse Praxis" provides insight. She states that feminist critical discourse analysis works, “...with the 
aim of advancing rich and nuanced analyses of the complex workings of power and ideology in discourse in sustaining hierarchically gendered social orders" (Lazar, p. 141). Allowing for a deeper understanding of ideology and control has enabled me to dissect the relationships of women and men inside the feminist movement in Ottawa. Lazar also comments on the influence of other standpoints on the meaning of discourse, stating that, "Poststructuralist theorization offers a critically useful view of discourse as a site of struggle, where forces of social (re)production and contestation are played out" (2007, p. 144). Focusing on participants' use of language, tone and inflection will allow me to explore the social reproduction of feminist discourses as they pertain to principles such as gender identity and theory.

Feminist critical discourse analysis, as an explicit methodology of discourse analysis, is a relatively new field, with few books written on the subject. However, I was able to base much of my analysis on the 2005 book edited by Michelle M. Lazar, Feminist Critical Discourse Analysis, Gender, Power and Ideology in Discourse while including key concepts from James Paul Gee's 2011 book, How to do Discourse Analysis, A Toolkit. In order to fill in the gaps of knowledge about feminist critical discourse analysis, I also incorporated the ideas of critical discourse analysis from Norman Fairclough (2003) Teun A. Van Dijk (2001), as well as several journal articles from the areas of feminist methodology and linguistics.

Feminist critical discourse analysis can be broadly defined as part of an emancipatory critical social science, with political aims to disrupt the patriarchal status quo. Michelle M. Lazar explains it as such,

Feminist CDA as a political perspective on gender, concerned with demystifying the interrelationships of gender, power and ideology in discourse, is equally 
applicable to the study of texts as well as talk, which offers a corrective to approaches that primarily favour one linguistic mode over another. (2005, p. 5)

She explains the need for a deliberately feminist approach to critical discourse analysis, “...by which I mean the need to theorize and analyse the particularly insidious and oppressive nature of gender as an omni-relevant category in most social practices" (Lazar, 2005, p. 3). This focus on gender as discourse creating and as continuously present within personal narratives reflects my own research question of understanding how participants of diverse gender backgrounds participate within the feminist movement. As gender constructs power within institutions and discourse, it necessarily constructs and propels power and control inequities within feminist movement in Ottawa.

One of the founding theorists of critical discourse analysis is Teun Van Dijk, he provides an excellent summary of the key elements of critical discourse analysis;

Critical discourse analysis (CDA) is a type of discourse analytical research that primarily studies the way social power abuse, dominance, and inequality are enacted, reproduced, and resisted by text and talk in the social and political context. With such dissident research, critical discourse analysts take explicit position, and thus want to understand, expose, and ultimately resist social inequality. (2001, p. 352)

He and other dominant figures in linguistics and critical discourse analysis, assert that power, hegemony and ideology are key components for deconstruction and analysis by critical discourse researchers, (Van Dijk, 2001; Wodak \& Meyer, 2009; Fairclough, 1995). Researchers look for discursive and linguistic ways of controlling text and discursive interactions, Van Dijk maintains that, "If controlling discourse is a first major form of power, controlling people's minds is the other fundamental way to reproduce dominance and hegemony" (2001, p. 357). Throughout my analysis, I will be searching for participants' creation of power, through discourse and maintenance of ideology. 
Critical discourse analysts believe that ideology is created through discourse and language, but it is also created through structural and personal interactions. Norman Fairclough, another principle CDA theorist stated;

Ideology is located, then, both in structures which constitute the outcome of past events and the conditions for current events, and in events themselves as they reproduce and transform their conditioning structures. $(1995$, p. 72$)$

These theories about discourse, ideology and power connect significantly with feminist theory and post structuralism. Feminist theory is focused on analysing the relations of power through structures and ideologies; discourse is created and accessed based on power. The interviews were all co-constructed through power and ideology, different discourses took precedence over others, and participants used power in divergent and convergent manners.

Feminist critical discourse analysis relies heavily on the Gramscian (1971) term "Hegemony" which is used to describe the power that, “...the dominant group exercises throughout society" as well as the "...direct domination" or command exercised through the State and "juridical government" (Gramsci, p. 12). Susan Speer (2001) points out that hegemony is unlike ideology, as hegemony cites domination through consent, and not coercion. She states, "The ruling classes, for example, maintain their domination by defining and legitimating a certain definition of the situation, framing the way events are understood and morality is defined" (Speer, 2001, p. 108). Understanding how hegemony maintains and perpetuates patriarchy within society and within social discourse will allow me to critically analyse the participants' responses.

The interviews were read several times so that I could become familiar with the data. In order to practice feminist critical discourse analysis, I analysed the interview data 
by deconstructing the participants' use of language specifically how they (through the use of their own words) create their own gender discourse. I have based much of my analysis on interpreting the participants' interviews through a feminist lens, while using the guidelines set out by James Paul Gee (2011). These guidelines include a set of 27 tools to direct critical discourse analysis. These tools are framed into themes 1. Language and Context, 2. Saying, Doing, and Designing, 3. Building Things in The World, and 4. Theoretical Tools (Gee, 2011).

For the purposes of my analysis, I focused on nine out of an average of 20-25 questions in the interview guide. The questions that I included in my analysis were: 1) Can you tell me a story about what it means to be a feminist? 2) Do you consider yourself to be a feminist? 3) Do you think anybody can be a feminist? 4) Can you tell me a story about how your peers/friends view your feminist stance? 5) Can you tell me a little bit about women-only spaces? 6) Would you like to talk a bit about your experiences with Take Back the Night? 7) What do you think of men engaging in feminist practice? 8) What do you think of men joining marches? and 9) What do you think about transmen and transwomen being part of feminist movement? These questions were specifically chosen because of the depth of information they provided. I asked many questions that I subsequently realized where not focused on the inclusion of men in feminist movement, many of the questions provided a detailed description into the lives of the participants and their own feminist epistemology. However, including questions pertaining to their family, friends and colleagues perceptions of their feminist identity, and their hopes and fears for the future of feminist movement do not provide more depth to my specific subject matter. This data is important, and could be used for further research. 
Pairing down the number of questions to analyse enabled me to do in-depth feminist critical discourse analysis for each of the participants' answers to these nine questions. Using James Paul Gee's (2011) 27 tools for critical discourse analysis, I concentrated on six key analytic tools (see Appendix F). I focused on six tools, as the size of my study is large enough to caution against the amount of time it would have taken to use all 27. However, I still wanted to cover each of the themes that Gee presents in his toolkit, therefore I chose the most relevant tools for my analysis, ensuring there was one from each theme. Beginning with the first tool, I critically analysed each response for each participant. I then categorized my discoveries into themes, which I will present later on in my findings and discussion section. This process provided me with a wealth of information, pertaining to the use of language, discourse and power creation and insight into the representations of the lived realities of the participants.

\subsection{Summary}

In response to traditional scientific research methodology, feminist research methods were created (Kirsch, 1999). These research methods differ from traditional methods in that they subvert the status quo, by allowing space and voice to often silenced populations (Hesse-Biber \& Leavy, 2007). In order to align with my theoretical framework, feminist qualitative research methods were employed. Focusing on reflexivity, affect and emancipatory goals my methodology mirrors my research study's aim.

I received ethics approval from the Carleton University Research Ethics Board. Purposive sampling techniques were used, however the final sample does lack a degree of diversity. I unsuccessfully attempted to mitigate this by promoting the research through 
various avenues and means. I conducted ten semi-structured in depth face-to-face interviews that were audio-recorded and transcribed verbatim. Participants were made aware of the limits to confidentiality and were given time to understand their informed consent document.

Feminist critical discourse analysis provided the foundation for my analysis. Relying heavily on the writings of Norman Fairclough (1995), Paul James Gee (2011), Michelle M. Lazar (2005) and Teun Van Dijk (2001) I outlined the steps taken during my examination of the interviews. In the following sections I will illuminate my findings and discussion of the narratives created in the interview process. 


\section{Chapter Five: Findings}

\section{Introduction}

In the following sections, I will present my analysis of the narratives created by the participants and then present some ideas and themes for discussion. This analysis was guided by feminist theory, post structuralism and feminist critical discourse analysis. Due to the long interview time and the detailed answers, I will not be discussing all of the data. Throughout my feminist critical discourse analysis, three themes emerged; they are Social Movements and Emotions, Identity; Gender and Feminist, and The Politics of Space and the Pathways to Feminist Identification.

Below I have provided some information for each of the participants, including their gender identity (as was discerned by asking what pronoun they use), racialized identity (based on how they present) and approximate number of years formally involved in the feminist movement (defined by each participant). Instead of simply numbering the participants, I believe that providing a pseudonym is preferable for creating a more personalized understanding of the data. The participants were not allowed to choose their own, for fear of lack of anonymity. The final participant is Helen Levine, who gave me informed consent to use her name.

1. Alice: preferred pronoun she, white cis-women, 10 (or 26) years.

2. Brandy: preferred pronoun she, cis-women of colour, 14 years.

3. Celeste: preferred pronoun she, cis-women of colour, around 26 years.

4. Derrick: preferred pronoun he, white cis-man, 20 years.

5. Eadlyn: preferred pronoun they, white trans*/genderqueer person, 6-10 years.

6. Finn: preferred pronoun he, white cis-man, 6 years. 
7. Gavin: preferred pronoun he, white cis-man, 5.5 years.

8. Helen Levine: preferred pronoun she, white cis-women, around 50 years.

\subsection{Section One: Social Movements and Emotions}

\section{Introduction}

As Theodore Kemper noted, "Social movements are awash in emotions" (2001, p. 58). Members of social movements participate in organizing and performing actions for a variety of reasons; these reasons often have emotional affects attached to them. My interviews with a small group of men, women and transpersons involved in feminist activism pointed to key questions. I explored the emotions of participants in movements and reflected on their gendered nature. The emotional charge that some of my interview questions provoked suggest that, in my study the women and trans* folk expressed anger, and the need for survival when discussing their participation in feminist movement. By contrast, participants who self-identify as men expressed a very different emotional response to the interview questions. There was significantly less anger and the majority of emotional affect behind their participation in feminist movement suggested that altruism, empathy and feelings of obligation where what drove these participants. In the following section I will explore questions about how emotions play a significant role in participation in social movements. Exploring concepts of self-identity, identity politics and collective identity; I will reveal how power and oppression shaped by gender impact people's participation in social movements. While the pattern of discussion in my sample suggests that gender is in play in the emotional experience of feminist activism, the 
sample size of eight participants (three men, four women and one transperson), means that this analysis raises questions for future research.

Social theorists have been researching social movements for decades, and this field of study has seen great changes in understanding motivations behind joining social movements. Beginning with revolutionaries such as Marx, Lenin and Trotsky, theorists viewed participants in social movements (agents of social change), “...as rationally pursuing their material interests" (Goodwin, Jasper, \& Polletta, 2001, p. 3). Thus these theorists focused solely on the material gain of joining a movement. The radical community organizer Saul Alinsky, “...portrayed his members as both rational and emotional; emotions were a useful strategic factor" (cited in Goodwin, et al., 2001, p. 3). He was aware of the emotional impact that the lack of material resources and solid employment had on his followers, he was able to use these emotions to increase participation and enthusiasm for change (Alinsky, 1971). Early academics, fuelled by Freudian psychotherapy believed that social movement participation was powered by craze inducing crowds, or “...oedipal concepts for protesting students" (Goodwin, et al., 2001, p. 4).

The significant increase in social activism during the 1960's was due to a greater number of marginalized groups “...pushing for equitable redistribution of power and access" (Henderson \& Jeydel, 2007, p. 43). As social movements gained greater societal legitimacy throughout the 1970 's, more academics were sympathetic to the movements they were examining. Theorists began acknowledging that the participants in social movements were acting upon their feelings of oppression, lack of power and control (Goodwin, et al., 2001). These members were seen as pursuing political interests that 
were characterized by structural positions, such as class, gender and race (Goodwin, et al., 2001). Due to marginalized populations lack of access and power to formal political avenues such as voting and running for leadership roles; oppressed populations turn to "noninstitutional politics" (Henderson \& Jeydel, 2007, p. 43). Henderson and Jeydel state that this form of “...informal politics, encompasses any political activity that does not take place directly within formal political institutions" (2007, p. 43).

Much of the literature on social movements speak to the difficulty of settling on one definition for all social movements, this task becomes increasingly difficult when attempting to define the feminist movement. Here is one definition of social movement; proposed by McBride and Mazur (2008); Meyer, et al., (2005) and Tarrow (1998), “...a social movement is a form of political organization in which membership and action is based on a shared sense of purpose and/or identity, aimed at changing social practices or prevailing power relations" (cited in Weldon, 2011, p. 11). Similarly to the difficulty of defining social movements, Henderson and Jeydel state that there is no singular universal 'women's movement,' and that to try to define one would be detrimental to the mobilization of a diversity of women with a diversity of goals (2007).

Over the past three decades, there have been considerable contributions and evolutions in the study of social movements (Goodwin, et al., 2001). A key concept is that of group solidarity, “....and loyalty to a collective identity” (Goodwin, et al., 2001, p. 5). This concept is all used to actively engage potential members and to retain existing members. Social networks and the power of peer pressure are also used to attract potential members, relying on collective ties and the creation of social bonds (Goodwin, et al., 2001). Collective identity based on ascribed traits, such as gender, class, race and 
ability, “...is also used to describe a sense of solidarity among members of a social movement itself, suggesting bonds of trust, loyalty, and affection" (Goodwin, et al., 2001, p. 8). Powerful emotions about group identity contribute to social movements and actions being enjoyable and satisfying. Social movement participation can have individual affects, particularly as one becomes politicized through membership and action.

\section{Analysis}

In my research, I have found an often-clear demarcation of expressing emotions between the participants who identify as women and those who identify as men. Clearly these are not generalizable but this demarcation opens up questions. Those who are in the subordinate group tend to be motivated by anger, pain and indignation. These emotions are clearly expressed during the interviews. What I have found suggests the gendered practices of expressing emotions, as the men had fewer outbursts of rage or pain. The social construction of affect and feelings, one that is based on gender roles and expectations, suggest that men remain silent and stoic, and women are reactive and 'overly emotional' (Ahmed, 2004; Moffatt, 2012; hooks, 2004). This construction of gender performativity is limiting to all genders; women are rarely seen as rational, and men are discouraged from expressing sorrow or crying. My study suggests that perhaps the differences of emotions as expressed by my participants, are due to investments in feminist movement and social location.

During the Black Nationalist movement in the 1960's, the participants performed and made use of a "politics of rage" (Goodwin, et al., 2001, p. 22), this tactic was then picked up by gay rights and feminist movement (Goodwin, et al., 2001). As such, anger has been a driving force to much social movement participation. As those who are 
members of the most oppressed populations, hooks (1984) asserts, gain the most insight into oppression, it is no wonder that the most marginalized are the angriest (Bunch, 1987).

Charlotte Bunch states,

On the other hand, oppression brings out the strengths necessary to survive as oppressed peoples; endurance and ability to cope with changing and difficult situations, less obsession with individual ego, and more focus on group survival. $(1987$, p. 85)

Anger and pain mixed with the desire for survival was evidenced throughout the interviews. This suggests a number of participants experienced the threat and dominance that marginalized groups experience on a daily basis.

Examining the interviews with women and trans* participants, I will showcase a few examples of situations where anger, pain and the desire for survival were the strongest. In response to the question, "Tell me a story about what it means to be a feminist," Alice says:

I think being a feminist means you have to be prepared to not be liked and to have a difficult time navigating through space. I didn't identify as a feminist in high school, I think I honestly didn't even really know the term in any way shape or form but I definitely was a feminist who was seen as a bit of a killjoy and kind of being that person that would kind of kibosh the fun times.

Here, Alice is clearly expressing her reality of having people not like her, of having people who have pre-judged her personality based on her identity as a feminist.

In speaking on her experiences taking up space in the public sphere, Alice talks about the social construction of constrictive gender roles relating to how women and men engage in conversation differently.

But there's a lot of tone policing around... Right? Like if you weren't so angry people would listen to you right? Which I think is like, which is mansplaining 101 right? Which is like I'm just trying to have a rational conversation, and you are just being extremely emotional. I think my personality inherently challenges a few people, so one I think there is a certain level of sort of internalized patriarchy, 
internalized misogyny, internalized sexism where women who are loud...and... aggressive... are threatening, domineering and... bad for the movement.

Here she speaks of what Ken Moffatt refers to as the dichotomous relationship "instrumental/emotional" between the rational man and the emotional woman (2012).

In the following two excerpts from Celeste's interview, her anger and a strong desire to survive in a world that has been built against her is clear. She holds firm to her convictions, and state that her anger and pain will not go silenced.

$\mathrm{C}$ : I think what it means to be a feminist, in my experience is to... Consistently see your life as a battlefield, or a battleground, where you are constantly challenging, negotiating, various spaces. As an academic feminist it's been mainly about trying to survive.

P: Can you tell me a story about how your feminist stance is viewed by your friends?

C: Aggressive. (laughs) Aggressive. Aggressive. (Laughing) ah yeah. I think sometimes I get told that I'm too critical, of everything. I'm like HOW CAN YOU NOT BE?

Celeste's experience of struggle is more pronounced. Her use of militarized language to describe her experiences as a woman of colour feminist exemplifies her struggles. However this discourse, usually associated with the military reproduces a discourse of patriarchal power. Linguist Crawford (1995) notes that a gendered analysis of language is complex,

Conceptualizing language as dynamic and fluctuating in response to speakers' goals and intentions in particular social circumstances makes counting sex differences more complicated and suggests the use of interpretative research strategies such as ethnomethodology. (cited in Stokoe, 1998, p.218)

Perhaps Celeste's use of masculine language was used to evoke a feeling of dominance and power, alternatively of subordination and powerlessness in the face of the "battlefield" of racist patriarchy. 
Her narrative speaks to another strongly felt tension in activist movements; participants have such resolute convictions that are often not widely shared with people outside the movement. Continuous explanations of reasons to take social action within feminist movement can become tiring and wear on participants' determination. It is for this reason that solidarity within the movement is paramount.

Helen's interview exemplified the concept of anger versus reason when speaking about gendered relations. Here, when speaking of her colleague's views of her feminist ideologies, she juxtaposes it with their feelings about her husband. A man with similar ideologies, and a similar social justice viewpoint.

I was the angry one, and I was the one who was sort of fighting for my place in the sun. And I was seen as the difficult one, and he was seen as the pretty great guy.

Helen's experience of how her colleagues held different feelings about herself and her husband exemplifies again the social and cultural expectations of women. Patriarchal restraints on women, perpetuate the idea that women are not to take up a lot of space in the public sphere, nor should they speak out against their oppression. Meanwhile, her husband, also a social justice advocate was held in high esteem. In the field of linguistics, there lies, "An extremely pervasive and enduring dichotomy in the literature - that women's talk is considered to be cooperative whereas men are typically thought to interact in a competitive way" (Stokoe, 1998, p. 219). This could be viewed as women's discourse of passivity and a male discourse of authority. Men's access to power and privilege enables men to gain dominance in social interactions. The term "conferred dominance"(2006, p.23), comes to mind here, author Allan Johnson defines this as one group having power over another. He continues to state that, "The common pattern of 
men controlling conversations with women, for example, is grounded in a cultural assumption that men are supposed to dominate women" (Johnson, 2006, p. 23). Based on Allan Johnson's research and anecdotal evidence, he states that,

Men are more likely than women are to control conversations and be allowed to get away with it and to have their ideas and contributions taken seriously, even those that were suggested previously by a woman and dismissed or ignored. (2006, p. 28)

From my own experiences as a feminist participating in the Ottawa feminist movement, my male partner (whom others describe as feminist) experiences different reactions from our peer group and the wider public. I am often seen as "too radical," and "always having to make a statement," whereas he is viewed with awe and admiration at the thought of a man speaking out against male violence against women. Even though we are both touting the same political ideas, his are seen with greater legitimacy and 'rationality.' This is due to living in constant patriarchal social relations; gendered discourse is still mired by the prevalent myth of the "rational man" and the "emotional woman." Examining these interactions through a feminist critical discourse lens, allows me to expose the discourse of power at work. As Johnson explains,

In a patriarchy... power is culturally gendered in that it is associated primarily with men. To the people living in such a society, power looks "natural" on a man but unusual and even problematic on a woman, marking her as an exception that calls for special scrutiny and some kind of explanation. (2006, p. 91)

These excerpts speak to the social construction of gender roles and emotions, placing women as the weak emotional passive figure against the men who are supposedly viewed as the rational, intellectual beings. However, through my interviews a strong voice that is motivated by anger, pain and a will to survive is a common factor uniting the 
women in my study. Thus, showing a subversive performance of femininity, one that is powerful with unwavering convictions.

The social construction of masculinity hinders men's ability to non-violently express their feelings (Moffatt, 2012). The men in my study were not participating in feminist movement because of feelings of being oppressed, anger against the patriarchy or because they wanted to survive in a patriarchal society. The men in this study appeared to act out of feelings of guilt, and obligation to "do the right thing." This could also be constructed as wanting to be altruistic. Altruism, in humans; as has been discussed in much social movement literature (Goodwin, et al., 2001; Jeffries, Johnston, Nichols, Oliner, Tiryakian, \& Weinstein, 2006; Kemper, 2001), is never solely for the benefit of the other. There are many critiques that suggest that altruism is distinctly tied to feelings of superiority and ego,

Auguste Comte is credited with coining the concept of altruism, and introduced the paired concept "egoism-altruism" in his Positive Philosophy to indicate a fundamental principle, one on which he believed all social relations are based. Durkheim had much to say about altruism: its role in the dialectic of social integration/disintegration, most famously_ but hardly exclusively — as a factor in certain types of suicide, and implicitly as an element of his concept of morality. (Jeffries, et al., 2006, p. 68)

However, many theories of altruism maintain that it is for the benefit of another (Jeffries, et al., 2006). Solidarity is a concept that can also be tied to altruism; "The concept of solidarity is used to refer to the positive ways of relating to others included in the concept of altruism as they are expressed in a form of interaction" (Sorokin, 1947: 93-144; 1954a: 13, cited in Jeffries, et al., 2006, p. 68).

It is important to reflect on the availability of discourses for men participating in feminist movement. Do the men have any other choices of discourses when discussing 
their feelings about feminist movement? If they were to enact a discourse of selfishness about why they participate and what positive feelings they acquire from their participation, they might be met with resistance. Men when discussing their emotions, have only a few options to choose. Perhaps speaking from feelings of obligation, guilt and altruism is more straightforward and receives less negative feedback than speaking from a discourse of selfish motivation to participate (Anderson, 2009).

Speaking directly to this notion of gaining status through performing a feminist identity, Derrick is quick to note that for him, this is not the case.

But as a guy I think you're always... I didn't agree to do this [interview] because I wanted to defend my role and... and gain points or anything like that, but you do feel I think sometimes, that you are having to... justify or legitimize what you do.

Here Derrick also speaks to the notion of continuously being challenged on his feminist identity. There seems to be little pain or anger motivating his feminist identity.

In the next excerpt, Finn speaks about how he does not want to be on the side of the oppressor anymore.

Absolutely, I mean you kind of go through the history. I mean this can be connected to you know an anti-colonialist stance, an anti-racist stance. It's looking at you know, who's ruled the world throughout history? It's been men. And especially you know we learn about the age of enlightenment and modernity. And how you know rational thought was always spoken of, men have sort of let [the oppression of women continue?] and I don't want to be a part of that [male dominance] in my life. Anymore. And I have been a part of that.

When speaking about his experiences engaging in feminist action, Finn remembers a time when he felt excluded based on his gender. He remembers this as a very negative experience, one that he seems to not have healed from.

Ok so a really good example is the Take Back the Night walk here in Ottawa, there was a couple of years ago here where the women's centre decided that men are not allowed to be a part of that that walk. And I took exception to that, ok like I understand that it should be, it should be an empowering thing right? So that 
women who experience that oppression, the voice should not be coming from males. And I totally agree with that. Where I took [exception] was the fact that, that I should be not included in that. And so I, you know, I took exception to that.

Since men have experienced unrestrained access to most public spaces, it is difficult for them to be excluded (Penelope, 1990). Finn's anger at being excluded could suggest a discourse of hegemonic masculinity and male power to be anywhere and have access to all spaces, (Penelope, 1990). For centuries men have experienced uncontrolled access to all public and private spheres, men dominated all institutions, political campaigns and educational systems. Currently, there are spaces in the public sphere that women occupy, this occupation of the public sphere should not be seen as a radical act. However, women in the public sphere remain a threat to hegemonic masculinity and patriarchal structures of society. Perhaps it is this threat that concerns Finn. As Johnson notes, this fear is widespread, "When women gather together, even just for lunch, men may suspect them of "being up to something" - planning some subversive use of power that needs to be monitored and contained," (2006, p. 92). Another reading of this excerpt speaks to Finn's longing for belonging. Finn is trying to gain a sense of belonging in the feminist movement, and these moments accentuate his non-belonging or a belonging only at someone else's pleasure.

\section{Summary}

Acting out of obligation or guilt can be seen as a valid reason, much like anger and injustice, to participate in feminist movement. Critics may say that a peripheral understanding of oppression leads to a misunderstanding of the goals of the movement (Digby, 1998). However, altruism remains a strong motivator, and can be a strong predictor of action (Kemper, 2001). Theodore Kemper, in his discussion on the structural 
approach to social movement emotions, explores reasons why people who are not from the marginalized group might participate in social movements (2001). In the following passage he examines ideas of moral outrage or 'noblesse oblige' and guilt.

The motive may be moral outrage or noblesse oblige... These are guilt and/or shame phenomena. ... To fail to act in their [(the "other")] behalf is to court feelings of having wronged them or having failed to act in a worthy, statusdeserving manner with respect to them. (Kemper, 2001, p. 68)

What is evidenced by the findings from my research is that members of social movements are not universal; there is no universal activist or feminist. The women discussed how their anger fuelled their need for participation; whereas the men seemed to feel the need to legitimize their participation. The social construction of gendered behaviour influences the capacities to which genders are allowed to behave. The idea that women who are passionate and expressive about their ideologies and their indignation; are people who should not to be trusted, respected or taken seriously, enables the subordination and continuous dominance of women (Ahmed, 2004). This has a great affect on how the women in my research experience their daily lives in the public and private sphere as a feminist. The men in the study have a lot more power when it comes to navigating the public sphere; therefore they express a lot less anger when discussing their feminist identity. Through these interviews, it can be shown that members of different genders, based on their experiences of power and oppression have very different feelings and express different emotions when discussing feminist ideology. It is important to understand that there is a multitude of experiences within the Ottawa feminist movement; with this knowledge, progress and growth is possible. In the following section, I will be examining how the participants navigate their gender identity with their feminist identity. 


\subsection{Section Two: Identity; Gender and Feminist}

\section{Introduction}

In this section I will explore how the participants gave meaning to their identity as feminists, as well as to their gender. The relationship between gender identity and feminist identity, for some is simple. It would be easy to assume that all feminists must be women, or that all women must be feminists. However, history and current social situations prove this to not be the case. There is an often-uneasy relationship between one's gender identity and feminist leanings. In doing critical feminist discourse analysis, there were a variety of social scripts; and a range of discourses evident in the interviews that highlight how the participants navigate their lives. These discourses reveal how each participant viewed their identity, based on their perception of inclusion or exclusion in the feminist movement, and their analysis of feminist theory. What follows is an interesting example of how a group of people who identify as feminists, have divergent definitions of that identity. Although the sample size is relatively small, and no conclusions or generalizations can be made, this research acts as a stepping-stone to further exploration into the relationship between involvement in social movements and identity formation. My research raises multiple questions about feminist movement participation. Must a feminist identity be tied to one's gender identity, to one's experience of living in the woman category? It also asks what happens when those who experience male privilege ally with those seeking to challenge male privilege. Important to note here that power and privilege are fluid concepts that all people have in varying degrees, binaries such as oppressor and oppressed only reinforce unequal social relations.

Scholars of social movement theory have focused on the idea of collective identity; where a group creates or is created by a shared focus, meaning or aim (Polletta 
\& Jasper, 2001). The definition of collective identity that grounds my research is, “...a perception of a shared status or relation, which may be imagined rather than experienced directly, and it is distinct from personal identities, although it may form part of a personal identity" (Polletta \& Jasper, 2001, p. 285). Throughout my research it is clear that the research participants who are members of feminist movement in Ottawa share a collective identity, most of them do not act alone, and participate either passively or actively with other members of the movement. The idea of solidarity with others, and the need for a collective strength is evidenced in these two excerpts from Helen. When discussing her comfort level with self-identifying as a feminist, she had previously stated that as a young adult she became a Marxist Feminist. Helen states, "I am enormously grateful to the women's movement," she continues by saying that she would not be where she is today if it were not for the consciousness raising groups and the friends that she made in the women's movement. She then states, "Well I don't think you can be an individual feminist," further emphasizing the necessity of collectivity and solidarity amongst other like-minded individuals.

Social movement participation is, as much about group dynamics as it is about political will to action. The group dynamics within feminist movement has a particular tension based on experiences of oppression and gender identity (Moraga \& Anzaldua, 1983). This research provides an example of the gendered nature of social movement participation. Social movement theorists note that,

It is argued that gender exerts pervasive influence on every aspect of social movement activities. The patterns of mobilization, political and cultural opportunities, framing process and intra-movement dynamics are all gendered. It is argued that although ample evidence demonstrates that protest is gendered, we do not yet know whether there is any general pattern of influence of gender on 
social movements, a pattern that enables a systematic explanation of the effects of gender on social movement dynamics. (Yulia, 2010, p. 628)

Collective identity theory can shine light on some of the questions around feminist identity and gender identity. Several social movement theorists have written about collective identity theory, including Francesca Polletta (2001), James Jasper (2001), and Zemlinkaya Yulia (2010). The core components of collective identity theory as espoused by numerous social movement theorists, include,

... imagined as well as concrete communities, involves an act of perception and construction as well as the discovery of preexisting bonds, interests, and boundaries. It is fluid and relational, emerging out of interactions with a number of different audiences (bystanders, allies, opponents, news media, state authorities), rather than fixed. It channels words and actions, enabling some claims and deeds but delegitimating others. It provides categories by which individuals divide up and make sense of the social world. (Polletta \& Jasper, 2001, p. 298)

This theory can be used in my study as a way of examining the motivations and behaviours of social movement participants. Acknowledging that individuals can have fluid identities, and that those identities can be constructed personally and as a result of the communities or protests that people participate in, can enhance my understanding of feminist movement participants. Most specifically the question, "Is the identity a group projects publicly the same one that its members experience?" (Polletta \& Jasper, 2001, p. 285), can have an impact on my analysis.

\section{Analysis}

The ways that the participants' identities converge and diverge is fascinating. At one end, they all understand themselves to be feminists, however some, notably the two women of colour and the genderqueer participant articulate a feminist identity that is constitutive of a plethora of defining characteristics. Brandy articulates being more than 
feminist. Her identity is not additive, but rather she pronounces her identity as encompassing many aspects of her lived experience, she does not wish to be defined by a single existence.

I think of myself as being a feminist in PRACTICE, I don't think of myself as necessarily having to define myself as a feminist for any particular reason. I don't mind if people see me as one, I don't' mind calling myself one, but I feel like even within itself it is a restrictive thing. Cause even feminism doesn't include everything that I believe in, and doesn't go far enough to include everything and you know? For example, like a humanist would believe, so I feel like I am a feminist first but most likely like a combination of things at the same time. I rather, I don't like labels even in general, so I'd rather I don't get labelled.

Following her previous statement, Brandy continues her discourse on labelling herself a feminist.

Because to me, feminism is a way of being rather than just a label. Because there's a lot of people who call themselves feminists do very un-feminist things. (laughs) Cause [the way] I see it, feminism is a frame of mind. And a, you know some, a way of THINKING, so you don't really need to have a label for something like that. But you know if someone was to ask me, I wouldn't mind but, generally I just don't like labels. Yeah, well within this framework, because I feel like a lot of this framework that feminism gets trapped in. Is like first, second, third, wave you know? Like why is that?

It is possible that these restrictions Brandy speaks of are due to the rigidity of being labelled a singular identity, when she believes that everyone embodies multiple identities. She speaks to a desire for a multifaceted subjectivity to demonstrate that feminism is more than an identity, but also a worldview, a framework, a paradigm that one lives their life through and with. Brandy articulates the restrictive feeling of feminism; she speaks to a hope of an expanding discourse of feminisms. She notes her frustration with working within a framework of feminism that is continuously defined by rigid structures (first, second and third waves). Perhaps what she is seeking is an 
intersectional feminism. Speaking of a feminist intersectional approach and a rejection of the deconstruction of categories, authors Lutz, Vivar, and Supik state,

Intersectionality not only challenges us to integrate marginalized perspectives but also demonstrates the necessity of understanding relations of rule and power differentials as co-constituted and co-constitutive. This is the aspect to which black feminists have drawn our attention by arguing against an exclusively deconstructive way of dealing with categories, i.e. what McCall calls an anticategorical approach (see hooks 1992, Mohanty 2003). (2011, p. 8)

As is evidenced by many of the participants, there is a theme of intersectionality that weaves its way through each transcript. Similarly, Celeste, while she was firm in her feminist identity, wanted to add descriptors to this label, acknowledging that there are more structures than just patriarchy that are affecting her and other's safety, quality and mobility of life. This can also be linked to critiques of Western feminist theory, where the category of woman is always perceived as white, able-bodied and English speaking (Hepshiba, 2011). As can be seen in the next excerpt from Celeste, a feminist identity is not something that can be navigated easily.

(Inhale)... Lord have mercy... Yes. Based on my definition of feminism, ... I mean there's multiple definitions. It changes on a day-to-day basis, it's not static, and I think that's the beauty of it. But I do consider myself to be a feminist now, but, I'm going through the process, I'll be honest, I'm going through the process right now, really questioning. What feminism means to me so far as my, if we were to give a definition of myself. I would consider myself to be a critical, antiracist, de-colonial feminist (Inhale) and I add feminism because of that gendered perspective... but there's a lot of pain and hurt in being a feminist... not necessarily the like, "Oh my god you're a bra burning chick," but the pain and hurt that you feel from your own community, and those who you felt were feminists...

Sara Ahmed suggests that being engaged in the dismantling of oppressive structures, which inadvertently requires one to understand individual and societal oppression, causes pain (2004). She claims, "I want to suggest here, cautiously, and tentatively, that an ethics of responding to pain involves being open to being affected by that which one 
cannot know or feel" (Ahmed, 2004). Although analysing the participants' responses is an act of 'trying to know,' it is paramount to remember that I cannot understand how the participants feel, think or act outside of the specific transcripts from these interviews. Celeste's statement raises questions about how people's investments in feminism are often textured and nuanced, questioning how to create visible space for this nuance in political struggle. In particular it can be heard as one of many calls for a feminism based on intersectionality.

As is noted in many of the writings on feminist intersectionality, the term was first introduced into the public sphere by Kimberle Crenshaw (1989),

When she discussed issues of black women's employment in the US. She was eventually invited to introduce the notion of intersectionality before a special session on the subject in Geneva during the preparatory session to the World Conference Against Racism (WCAR) in September 2001 in Durban, South Africa. (Yuval-Davis, 2006, p. 193)

Floya Anthias and Nira Yuval-Davis wrote an article arguing against the view at the time, in the 1980's, of what was called "triple oppression" (Anthias \& Yuval-Davis, 1992). This was an attempt to analyse the lived experiences of black British women, from a viewpoint that these women are suffering multiple oppressions (1992). However, the earlier versions differentiated the oppressions as separate and unique to each other. "They suffer oppression as: Blacks, women and members of the working class" (Yuval-Davis, 2006, p. 195). The authors argued, “...there is no such thing as suffering from oppression 'as Black', 'as a woman', 'as a working-class person"” (Yuval-Davis, 2006, p. 195). The authors maintained that systems of oppression are based on interlocking (intersecting) oppressions, rather than additive, distinct experiences, Yuval-Davis notes,

For example, as 'a Black person' is always constructed and intermeshed in other social divisions (for example, gender, social class, disability status, sexuality, age, 
nationality, immigration status, geography, etc.). Any attempt to essentialize 'Blackness' or 'womanhood' or 'working classness' as specific forms of concrete oppression in additive ways inevitably conflates narratives of identity politics with descriptions of positionality as well as constructing identities within the terms of specific political projects. (2006, p. 195)

The discourses that are created in my research call for an expansion of the rigidity of traditional feminisms, they call for an expansion of feminist theory; an intersectional feminist theory.

Eadlyn also uses the label of feminist for self-description, however has had and continues to feel excluded from certain feminist spaces, which constrains solidarity. Eadlyn answers the question of whether they are a feminist with clarity as well as vagueness; "Yeah, I mean, I'm definitely, like, a feminist in my, like, you know, like, as part of my identity and a part of the work that I do, like, I feel.” Eadlyn echoes Brandy and Celeste by stating the necessity of acknowledging the multiplicity of feminisms.

And it's just also acknowledging that there's all, there's multiple types of feminisms too, and I think we get stuck on like, you know, this is the best way or this is the only way... and I think that's really... I don't know, it takes the nuance and the complexity and the richness out of it. How different structures of oppression effect different identities in different ways, and how there's kind of like a commonality in that... and we can like move beyond that kind of identity based politics.

In the book based on interviews and research with transgender people, TransForming Gender, Transgender Practices of Identity, Intimacy and Care, Sally Hines (2007) notes that, "Transgender raises questions about the formation of identity, and the extent to which we can shape and reshape individual and collective identities," (p. 3). This is important as I move forward with analyses of Eadlyn's narrative, as complex ideas emerge about the distinction between sex and gender and the ability to name oneself a feminist without identifying as a woman. Given Eadlyn's self identified gender 
identity, they have experienced isolation and exclusion based on perceived gender nonconformativity from many different groups within the feminist community. They attribute this exclusion to be based in a narrow understanding of feminist politics.

Because I think feminism became kind of stuck in that both like very invested in feminist approaches and practices... but I also feel kinda like ...like someone who identifies as genderqueer and trans and more on the masculine spectrum, I've also felt a lot of tension in feminist spaces too and a lot of kind of isolation.

The gendering of space, the policing of genders and the category of woman are major themes in feminist discourse surrounding the feminist movement and community in Ottawa.

Eadlyn also reveals the pain they experience from being excluded, something that the male identified participant's express as well, but there is a difference here. Eadlyn has a unique understanding of feminist spaces. Eadlyn used to frequent the women-only feminist spaces with ease until beginning to transition to a non-binary gender. Again, Sally Hines (2007) notes that there has always been a tension between transgender identities and feminism, however it is also interesting to note that in her research the majority of transmen stated that they were once heavily involved in the feminist movement. Focusing on the tension between feminist spaces and trans* folks, Sally Hines suggests that, "Transgender women have been seen to reinforce a stereotypical model of uber femininity, while transgender men have been located as renegades seeking to acquire male power and privilege" (2007, p. 18 emphasis in original). This idea that transmen have access to male privilege echoes with my research findings.

When discussing the idea of including trans* folk in a violence against women collective, Alice acknowledges the difficulties of trans* identities and the apparent ability 
to gain male privilege through transitioning from female to male. Here Alice is restating a prior conversation she had with another individual,

"You know how do you feel about what we're saying? You know, about only women should be answering the phone?" And they said, "You know I agree ... I am gaining from male privilege now and so I need to understand that although I might identify with someone because I myself have been sexually assaulted I now need to respect the fact that they don't view me as an equal anymore, because I am read as a man and so for me to say, "No no no I hear you, I understand." They could be, "No you don't, and in fact you telling me that is triggering and upsetting."

Exclusion from feminist spaces is nothing new for large populations of people. This brings to mind the 1995 Nixon v. Vancouver Rape Relief Society case. "In 1995 Kimberly Nixon a post-operative transsexual woman who had experience and training in counselling victims of male violence, sought to volunteer as peer counselor at the centre" (Scott-Dixon, 2006, p. 139). Kimberly was turned away from the centre; she was informed that she did not, "...share "life experience" of being female that, for political purposes, was required of those who conducted peer counselling experiences" (ScottDixon, 2006, p. 139). She filed a human rights complaint on the basis of sex discrimination, and the British Columbia Human Rights Tribunal awarded her \$7,500 in damages (Scott-Dixon, 2006). However, Vancouver Rape Relief appealed the decision to the BC Supreme Court, and "...the court overturned the tribunal's ruling and affirmed Rape Relief's claim that its restrictive policy was a bona fide occupational requirement for peer-counsellor volunteers. This ruling was subsequently upheld by the BC Court of Appeal" (Scott-Dixon, 2006, p. 140). Until unity based on common goals instead of common identities, feminist movement in the West will remain tension filled.

When thinking about the inclusion of non-binary gender conforming people into the feminist movement, I cannot help but think of the historical mistakes and significant 
oppressions that have been enacted in the name of feminism (Lorde, 1984/2007; hooks, 1984; Moraga \& Anzaldua, 1983). Our current climate, including my research, could indicate that the feminist movement might be on the cusp of a new direction; with more feminists opening up to the idea of men's roles within the movement, the next logical discourse is around trans inclusion (Feinberg, 1996; Hines, 2007; Scott-Dixon, 2006).

Lorde discusses how it is not our differences that divide us, but our differences, which provide the movement with so much strength and resiliency (Lorde, 1984/2007). It is important to acknowledge the many trans* feminist writers who have been bridging the gap between lived experience and trans* feminist theories. Trans* activist, writer, theorist, Leslie Feinberg (1996) remarks on their identities and oppressions,

I feel the combined weight of women's and trans oppression in my own life. I am forced to battle both, simultaneously. As a result, I personally experience the relationship between women's and trans liberation, because these demands overlap in my own life. (p. 109)

Trans* realities propel feminist movement into new spheres; it forces essentialist feminists to rethink women's oppression (Feinberg, 1996). For decades the feminist movement has been able to turn away from trans inclusion questions, however I believe that the movement can no longer reject the realities of trans* oppression. As Leslie Feinberg states,

We need to expand the dialogue, because women don't just need to understand the links between what they and trans people suffer in society, they need to realize that the women's and trans liberation movements need each other. (1996, p. 109)

They continue by stating that the policing of women's only spaces have always been fraught with difficulties and uncertainties,

And there are many people, like myself, who were born female but get hassled for not being woman enough. We've been accused of excluding "male energy." Now that's a frighteningly subjective border to patrol. Do all women - or should all 
women - have to share the same "energy"? (Feinberg, 1996, p. 109 emphasis in original)

Leslie concludes their section on solidarity within the movement, by calling for greater understanding and inclusion across difference. They state that solidarity and social action based on identity, aesthetics and fashion, creates discrimination and exclusion, however unification based on struggling against the structural relations of society that oppresses everyone will provide better results (Feinberg, 1996). Feinberg urges for solidarity across movements,

The modern trans liberation movement is redrawing the boundaries to show the depth and breadth of sex and gender oppression in this society. It is this common enemy that makes the women's and trans communities sister movements for social justice. (1996, p. 118)

Instead of feminist movement, Leslie Fienberg continues to stress the need for solidarity across gender differences; by stating that what is needed is the "Sex and Gender Liberation Movement!" (1996, p. 119).

Continuing with this idea of the necessity for difference within a movement, Sally Hines, states that there is a clear similarity between apparent separate movements, "Feminism and lesbian, gay and bisexual movements are significant here as social movements that challenge the meanings of gender," (2007, p. 85). This can definitely be seen in the discourse that Eadlyn presents, as they are heavily involved in the feminist movement, claim the feminist identity as well as challenge the gender binary. Eadlyn touches on a dominant tenet of feminist theorizing; questioning the positionality of women's oppression, is it the universal "woman" category? Or do race, class, culture, ability, language, and other intersecting identities differentiate it? This speaks to the essentialist versus difference theories within feminist identity politics (DiQuinzio, 1993). 
Eadlyn reiterates what other participants have said about the diversity of feminisms, and the concern for others' perception of your identity. In this quote, Eadlyn describes their personal feminism,

...the way that feminism [omit] is seen ... as a like women-based. A lot of people are cautious with feminism because people feel like ... it's like stereotypes of feminists are like you know like man hating or their lesbians, all those kinds of like interesting ways... or like we are in a post-feminist world or like all that stuff. But if you look at like the issues and like who's centred at those issues it's definitely like you know women make seventy cents to the dollar, or like the incidences of sexual violence are really like male ... violence against women is very like the statistics are really high, or like shaming and like slut shaming and all that kind of stuff and rape culture.

The perception that feminist theory has nothing to do with the intersectionalities of identities and oppressions can also be seen when Derrick states one of his criticisms of feminism is the lack of attention paid to class. This is a clear critique of feminist theory, however I would argue that it is in fact a critique of white Western feminist theory. Women of colour theorists such as Sara Ahmed (2004), Patricia Hill Collins (2000), The Combahee River Collective (1978), bell hooks (1984, 2000), Audre Lorde (1984, 2003, 2007), Andrea Smith (2005) and Nira Yuval-Davis (2006), have for decades provided feminist theories that include racialized experiences of women, theories that do not centralize gender, but focus on the intersecting identities of oppression, including class.

Eadlyn continues by expressing their frustration with what Nigerian novelist, Chimamanda Ngozi Adichie, refers to as "The single story" (2009). Eadlyn describes something that is pervasive throughout the feminist community and it's relationship with mainstream discourse. It is the fear of being negatively or narrowly perceived by the public. One of the reasons why people shy away from the label feminist is due to a fear of being improperly labelled a negative stereotype; this speaks to the need for a feminist 
identity that embraces intersectionality. In July 2009 Chimamanda Ngozi Adichie, spoke at a TEDGlobal event, her speech, "The Danger of the Single Story," asserts that "The single story creates stereotypes, and the problem with stereotypes is not that they are untrue, but that they are incomplete. They make one story become the only story" (2009). Here Chimamanda Ngozi Adichie, is calling for an intersectional understanding of identities. Interestingly, intersectionality theories have had a long history, however popular culture would have you believe otherwise (Tyler, 2005). Canadian feminist Angela Miles (1996), terms feminist intersectionality as "integrative" feminisms. She states that,

Integrative feminisms in North America (like those elsewhere) have a long and creditable history of struggle. Much current academic and political debate, unfortunately, colludes in the denial of this history and its potential. (1996, p. x)

Angela Miles notes the troubled histories of white Western feminism, and provides her analysis as a way of building solidarity across boundaries.

My emphasis on the promise of integrative feminisms is not intended to downplay the racism, homophobia, class prejudice, and other weaknesses that mar our movement. I hope to show how essential and how difficult it is to build politics that acknowledge and attack these divisions of power. (Miles, 1996, p. xi)

Angela Miles follows in the footsteps of many feminist writers that have been previously discussed in this research, women such as the members of The Combahee River Collective (1978), Patricia Hill Collins (2000) and Lutz, Vivar, \& Supik (2011).

There is a marked anxiety about being labelled feminist, or at least being labelled a feminist that inadvertently connotes 'white Western second wave feminism' (Aronson, 2003). Hence, why the participants are quick to add critical descriptors to their identities. Negative stereotypes of feminists have been plaguing our cultural consciousness for decades (Tyler, 2005). Many writers have provided the example of Time magazine's 
seemingly repetitive cover stories about the 'death of feminism' (Aronson, 2003; Tyler, 2005), as an example of our cultural depictions of feminism and feminists. As cited in Tyler (2005, p.26),

Negative depictions of feminism are not new to Time; in a response to Bellafante's article Erica Jong notes 'there have been no less than 119 articles in the magazine sticking pins in feminism during the last 25 years.' (Jong, 1998: 19)

Tyler continues by stating that this negative depiction of feminism and those who identify as feminists have severe effects on our culture's acceptance of feminism (Tyler, 2005). She references Susan Faludi (1992, p.104) in a quote explaining the power of popular journalism, "Trend journalism attains authority not through actual reporting but the power of repetition" (cited in Tyler, 2005, p. 206). This perpetual attack on feminism increases the likelihood that women will not identify as feminists for fear of stigma and discrimination. Interestingly, researchers have noted that many women currently do believe in the tenets of feminism; however do not label themselves as such (Aronson, 2003; Ramsey, et al., 2007).

A recent study (Bashir, Lockwood, Chasteen, Nadolny, \& Noyes, 2013) was conducted in conjunction with the University of Toronto and the University of Waterloo, where researchers set out to examine the negative impacts of stereotypes on the effectiveness of social change. The researchers, Nadia Y. Bashir, Penelope Lockwood, Alison L. Chasteen, Daniel Nadolyn and Indra Noyes, conducted several studies to look at the impacts of stereotypes of activists on their ability to create social change. One of the studies focused on feminists and environmentalists, the results from the surveys concluded that, "Specifically, feminists were described in terms of militant/aggressive traits, such as 'man hating' and 'forceful', and with eccentric/unconventional traits, such 
as 'behaves like a man' and 'unhygienic" (Bashir, et al., 2013, p. 3). The researchers continued to state that,

Overall, however, the traits provided were overwhelmingly negative, with only a handful of more positive traits (e.g. 'caring' and 'educated') appearing on either list. Thus, it appears that individuals have negative perceptions of both feminists and environmentalists, viewing them primarily as aggressive militants and unconventional eccentrics rather than as pleasant and personable individuals. (Bashir, et al., 2013, p. 3)

With negative stereotypes of feminists in social movements, possible links could be made to the hesitation of some of the participants, namely women and trans*folk, which found the label restrictive. It is important to note that the participants in my study who were men did not exhibit hesitation in labelling themselves feminist. Questions arise of privilege and social stigma around social action and identification. The men in my study, belonging to privileged groups in society, have greater power to control people's perceptions of them. However, the marginalized groups who are already being discriminated against do not hold the same amount of power to control people's perceptions.

By laying claim to the label feminist, people are inadvertently subjecting themselves to a life of negotiating spaces and having convictions scrutinized and often criticized. This can be seen in the following excerpts from participants in my research study. Here Alice articulates the backlash that she receives, interestingly most often from people within feminist movement in Ottawa.

So, yeah I think the most flack I get is from people within the movement, who think that I'm not legit enough. Either because of, I don't know my stance on this, or my stance on that, or my lack of stance on this. I don't know but as a feminist I definitely feel safe in all spaces, except for seemingly really far left feminist spaces, which is [difficult] 
She continues later on during the interview to return to her feelings of pain and hurt from within feminist movement.

So yeah, and so that's why I think, I know, that that's the most damaging, the most hurtful and the most just in terms of quantity (laughs) of backlash that I've gotten. Is always from self-identified feminists. Whether from academia, whether from the sort of grassroots whatever. I mean the fact that I've gotten more backlash from self-identified feminists than I have from internet trolls is pretty telling (laughs) because I live a public life as a feminist.

In this next excerpt Brandy reveals how her close friends and family members

perceive her feminist identity.

So there was a time when I would get into debates with my friends, that was like "That place you work, you need to not work there anymore" (laughs) because they don't see it as my own personal belief. Right? So the fact that I work for a feminist organization somehow means that, I only adopt this opinion because I work here. So there's that one-way that I'm perceived and then there's like my family and people who've known me, and know absolutely my feminist values, and always bring it back to you know "You are just too feminist!" So I'm seen as like you are too much, or you are not really, this is just because of this... So it's either my extreme identity, or just my pseudo identity that I've just assumed.

Celeste, in the following excerpt, expresses her experiences of pain resulting from being involved in feminist movement.

For me [my feminist identification] has also just in terms of this narrative, has also been a very painful journey, something in which that I do not disclose or talk about, because of positionality because of always being hyper aware, aware of what you say and do, and how that can reflect negatively on feminism.

In this excerpt, Celeste articulates how her feminist identity encourages her to engage in challenging others, and how complicated that can become.

Feminism has also been an exclusionary process for me, strictly speaking academically, more so than on the grassroots level. So if you were to paint a picture, of what feminism has looked like on that level, in terms of the dichotomy between academic and personal, or grassroots sorry. As an activist I have found that my feminist story has been one of reclaiming spaces, negotiating spaces, you know? Talking, trying to change the minds of people. As an academic feminist it's been mainly about trying to survive. 
All the participants in this study struggled with the public perceptions of the meaning of a feminist identity. They continually have to confront and challenge their family, and peers, and have to perpetually dismantle a very negative and impactful stereotype of what being a feminist actually means. I recall when Alice said that her friends immediately thought that she would be the "killjoy, that would kibosh their fun," dealing with the public's misinterpretation and dominant negative discourse of a feminist identity is something that all the participants must navigate and reconcile.

While experiencing struggles in public and personal life due to feminist identification has been evidenced in the women and trans*folk participants in my study, men's public and personal feminist identification persona holds divergent and convergent complications. By focusing on the interviews from the male participants, my research findings suggest that a male gender identity can be included in a feminist identity. In this group of eight participants in the feminist movement in Ottawa, those participants who are members of the most marginalized groups in society were the ones who's feminist identity were described as products of/or resulting from experiences of oppression from an early age. These participants expressed a feeling of being born into the struggle of feminism.

The identification with feminism came at a very early age, Celeste expresses this beautifully, when asked how long she had been involved in feminist movement, and her answer is to critically rethink my question.

At what point did the women's movement start? And at what point do you enter into it? And at what point are you innately born into it and don't have a choice right? And a choice in the sense that, because of the axes of oppression or privilege that you have, you are already ingrained into it... WHEN was I inducted into the women's movement? I'd probably say my first year of university, but honestly I would say at birth. 
Celeste's experience is in direct contrast with those participants who were able to occupy more privileged subject creations, and who embraced feminism through academia. This in contrast is, I believe, in part responsible for some of the tension, along gender lines, that is felt within feminist movement. The idea that for some a feminist identity is innate, and to others it is something that has to be learned. Zemlinkskaya Yulia (2010) poses this question to readers, "If the intersection between identity categories influences social actors' life experiences, it must also influence their political experiences" (p. 636). This is evidenced in the participants' interviews, as their ability to identify as a feminist often correlated with a position in society; those who are more marginalized, tended to claim the feminist identity as aligned with their subjectivity. In this section I have explored the ways in which participants situated with greater privilege made a conscious decision to participate in the movement. My research suggests that members of privileged groups might not have to think about their identities, or oppression, and therefore they can choose to never opt-in to a feminist identity. Whereas women with multiple intersecting identities are forced to see the oppression that is perpetrated against them, bell hooks refers to this in her book Feminist Theory: From Margin to Centre, when she speaks of the oppressed group having a deeper awareness of the dominant group, and an even greater comprehension of oppression and discrimination in society (1984). This is not to shame or discriminate against many populations who are not moved to action, suffering does not equal a motivation to social action. However, it is possible that those who are oppressed have a greater stake in social movement participation.

Charlotte Bunch, also speaks to the greater awareness of self and others when experiencing oppression, "Our attitudes and actions toward the givens of our lives are the 
primary means we have of starting to gain control over our own selves and destinies" she continues by stating that, "We can use our privileges to change society or to maintain it" (1987, p. 82). This speaks directly to the idea of the dominant group using their privilege to actively promote change, be them white women or men, everyone who embodies some type of privilege can effectively use that leverage to raise awareness of oppressions in society.

All three of the men in my research study were quick to positively affirm that they are feminists. The participants in my research study, who identify as men, do not express the same hesitation as the participants who identify as women and transpersons. This is an intriguing difference of personal attitudes towards feminist identification based on gender identity. Beginning with Derrick I will focus on key concepts about gender identity and feminist identity from each of the male participants.

In this excerpt, Derrick responds to my question, of whether he considers himself to be a feminist.

Absolutely. Yeah. I've been, I've been thinking about that because I don't know if I have a ... a good you know... nugget of a response but I think... in terms of my own, what I do as an academic, versus what I sort of do [personally] (omit) and my you know ... I think the two are bleeding into one another.

Another interesting experience for Derrick occurred when his employment status was publicly posted. It is important for confidentiality that I do not reveal many specifics, simply knowing that his job presumes a feminist identity.

And I have a colleague in this [place] (exhales) who's a bit of a ... little quirky shall we say and he saw the announcement, they posted the announcement or something on the (omitted) website, and he saw me and he said, "Yeah, I saw the announcement... your still a guy right?" Like he's, I was just like, "Yeah ... Uhh," 
Here Derrick speaks of the struggle with another feminist stereotype - that being a feminist is incompatible with being a man - or at least a "real" man. The fact that his colleague assumed that Derrick must have changed his gender identity from a man to a woman in order to accept his new job title speaks volumes to people's perception of masculinities and femininities. Eric Anderson (2009) has formulated a new theory of masculinity; which he calls 'inclusive masculinity.' This new construction of masculinity is based on Anderson's hypothesis of the existence of what he calls "homohysteria" (2009). I can analyse the interaction between Derrick and his colleague through Anderson's theory, his theory purports that current Western culture, in Anglo-American societies has gone through several stages of masculinity discourse, culminating in the creation of 'inclusive masculinity' (Anderson, 2009). Anderson's theory,

Conceptualizes what happens concerning masculinities in the cultural zeitgeists of three periods within Anglo-American societies: Moments of elevated cultural homohysteria, diminishing cultural homohysteria, and diminished homohysteria. $(2009$, p. 7$)$

His new term; homohysteria, is used,

To describe the fear of being homosexualized, as it incorporates three variables: 1) mass awareness that homosexuality exists as a static sexual orientation; 2 ) a cultural zeitgeist of disapproval of homosexuality, and the femininity that is associated with it; and 3) the need for men to publicly align their social identities with heterosexuality (compulsory heterosexuality) in order to avoid homosexual suspicion. (Anderson, 2009, pp. 7-8)

Perhaps what Derrick's colleague is aiming to do in this situation is to question Derrick's gender, while simultaneously questioning his sexuality, and legitimacy as a masculine identified person. Living in a climate of homohysteria urges Derrick's colleague to question his masculinity based on the perception of a feminized professional role. What can also be analysed in this interaction is that the current environment could also be in 
what Anderson (2009) refers to as "diminished homohysteria," noting that Derrick is actively working against the hegemonic masculinity that his colleague is trying to put forth. Referring to Anderson's "inclusive masculinity theory" provides the ability to analyse Derrick's behaviour as creating new discourses of masculinity. Anderson suggests that,

Inclusive masculinity theory argues that as cultural homohysteria significantly declines, a hegemonic form of conservative masculinity will lose its dominance, and softer masculinities will exist without the use of social stigma to police them. Thus, two dominant (but not necessarily dominating) forms of masculinity will co-exist, one orthodox and one inclusive. (2009, p. 96)

Anderson claims that with inclusive masculinity,

...previously stigmatized terrains and behaviours become available to heterosexuals without the need for one to defend their heterosexuality, it opens up yet further social and emotional spaces for heterosexual men to occupy without threat to their publicly perceived heterosexual identities. $(2009$, p. 96)

Through this lens, Derrick's actions as holding a 'feminized' professional role, laying claim to the feminist identity, and working with feminist theories, provides evidence for Anderson's theory of inclusive masculinity.

Derrick ends this section of the interview by remarking on something that Finn and Gavin both explicitly assert, the importance of role models who encourage and value men's role in feminism. The importance of male role models as feminists, allowed all three men to feel comfortable in their feminist identity. Speaking of learning about feminist theory in graduate school Derrick says,

And also I think, I remember taking some really good feminist theory courses in graduate school some of them taught by guys... oddly enough... and that too I think, it was important probably for me, to say, "Hey you know other guys are kind of taking this stuff seriously and maybe that's ok." 
In this excerpt, Derrick also reiterates the notion that feminist theory is perpetuated through the academic industrial context, which all participants assert as an obstacle to the accessibility and success of the feminist movement. As I will show in the next section, many of the participants had experiences on both sides of the 'academic wall,' thus enhancing and diversifying their understandings of feminist theory and praxis.

Finn remarks on his journey to feminist identification, "I grew up with no idea what feminism really was." He goes on to explain that not only was feminism absent but he was socialized into a misogynistic and patriarchal culture,

Those dominating ideas, subordination of women I kind of internalized that growing up. You know? The pornographication of our culture, you know, and sort of, like, dominating women again in that context.

Focusing on the masculinities theorist Ken Moffatt will enable me to analyse Finn's experiences growing up the dominant gender in a patriarchal society. Ken Moffatt (2012) asserts that,

In spite of the notion that multiple masculinities are not only possible but perhaps even preferable, one troubling legacy of masculinity is its tendency to be socially constructed as a singular, irrefutable, and unchangeable entity... Certain forms of masculinity are always more valued than others...The political purpose of expressing masculinity as if it were a singular entity is to create a dichotomous relationship to the feminine, which in turn maintains gender dominance. (p. 7)

Based on Moffatt's understanding, one could analyse Finn's behaviour as having been socialized into a false ideal of hegemonic masculinity that structured his behaviour of domination in relation to women. Moffatt continues to state that,

Men are defined as much by who they are not as who they are; the male identity is defined by the domination of women and of men who are marginalized according to race, sexuality, ethnicity, age, and able-bodiedness. (2012, p. 7) 
Finn's ability to reflect on his past behaviour as male dominance that was internalized exemplifies his understanding of power and privilege. This could also indicate a willingness on his part to accept new masculinities, not predicated upon violence.

Finn, like Derrick, exclaims "Absolutely," when asked whether he identifies as a feminist. In this excerpt, Finn speaks about his initial queries about his possible feminist identity,

And I remember, I was having a discussion about feminist thought in social work and I remember saying, "Well how can I be a feminist?" And it was funny because I remember having three or four of my male cohorts, sort of say, "Well I'm a feminist. I self identify." And I was like, "Oh wow! Well why can't I identify myself as a feminist?" And it sort of occurred to me at that moment, you know I sort of accept many of the ideas of feminism and I practice it in my own life. And you know yeah I am a feminist.

Researchers, Shaune Wiley, Ruhi Srinivasan, Elizabeth Finke, Joseph Firnhaber and Alyssa Shilinksky (2012), concluded that positive portrayals of feminist men increases male engagement and solidarity with feminism. Based on their sample of mostly white men, within the ages of 18 to 63 , their study was consistent with previous studies based on women, that "feeling connected to feminists is an important antecedent to men's collective action in support of women" (Wiley, et al., 2012, p. 61). Positive portrayals of feminists of all genders are important to increasing feminist self-identification, and solidarity within and without the movement.

This excerpt is similar to the one that Gavin provides in his first answer, where a professor asks students to raise their hands in accordance to their belief with feminist ideals. Gavin, like Finn, gains confidence in knowing that others are feminist, and that it can be seen as a positive identity. 
Another important point that Finn brings up in the interview is that sometimes one must be cautious about disclosing their feminist identity. He speaks of this again later on in the interview, when he discusses challenging his male friends on their patriarchal language and notions of women. Claiming that he does not outright say he is a feminist, as his friends hold preconceived misconceptions about what that means, but he states that he can challenge his male friends without using the word feminist.

Here, Finn is referring to his male privilege. He understands that a feminist identity is often one that is held by women alone, and he does not want to exploit his power by claiming someone else's identity.

I think that you have to be careful in some situations. So for example by me supporting feminist thinkers who disagree with the pro-life rally that happens in Ottawa every year, so, in that situation I tend to refer to myself as a supporter of feminists and for women's rights.

Finn understands his male privilege and makes this explicit. Perhaps he is also hesitant to voice his identity amongst this group, as he knows some women might disagree. He could also be recognizing the power that labelling yourself a feminist can have, and wants to take a step back from that, as being a white male he already holds much power. Finn continues his thought, "Because, I think that, you know, very easily my male privilege can end up sort of speaking for that movement; for women." Here he distinctly owns his male privilege and works against it by situating himself on the margins of the movement, so as to create space for women to speak.

This situation can be read in multiple ways. Dominant discourse of 'pro-choice' feminism states that personal autonomy should override governmental or medical institutions (hooks, 1994). Maintaining that women should have complete control over their reproductive health, can have unintended negative implications as well. As Jamie 
Landau noted in his study, upholding the linkage of women to reproduction, negatively reinforces the sexual division of labour and a view that women are simply vessels for procreation (Landau, 2012). Landau (2012) references feminist researcher Rickie Solinger (2005), on the idea of focusing on women's perceptions of trans men's ability to become pregnant,

This focus can reinforce the old tendency to construct fertility and reproductive politics as a "woman's issue." This focus can simply efface the male role in pregnancies and parenthood. It can also suggest that women are essentially reproducers and that biological reproduction is the special domain of women. A related problem could be reinforcing the idea that reproduction and motherhood are necessary conditions of motherhood. (Solinger p. 24, as cited in Landau p. 181)

Noting that reproductive health is not solely an issue for women is something that the feminist community has been slow to recognize (Carmen, 2014). Given that gender diversity opens up reproductive possibilities, this also requires health and medical fields to embrace gender non-conformity, as well as the predominantly female-identified "prochoice" movement. Finn believes that he should not speak "for" women regarding their right to access abortions. Finn demonstrates here an attempt to use his power for the positive, in support of women's reproductive rights. However, he is missing a trans* political statement here about access to reproductive rights services for trans* folk. Including trans* rights into feminist movement has increasingly become less deviant (Feinberg, 1996), especially as many members of feminist movement do not, or did not identify as cis-women. The opening up of sections within feminist movement that require addressing, such as the reproductive rights movement, provides evidence of a blurring of boundaries and an increasing in solidarity across difference. 
Gavin's immediate answer to the question of whether he identifies as a feminist, is to acknowledge the curious nature of such a question. He then questions whether his professional life and his involvement in feminist activism allow him to, or presupposes his identification as a feminist. "There's a lot of debate within feminist discourse about whether or not men should or shouldn't self-identify as feminists."

Gavin continues by stating his male privilege, and that in his mind, he does not have the power to self-identify as a feminist. "Umm, if it were solely up to me, and I recognize that it is not." Gavin understands that his identity is socially constructed, and that it is what others perceive him as, not how he himself identifies. He is also perhaps hesitant because he knows there is on-going debate surrounding men and feminism. "I would self-identify as being feminist. I choose not to do so publicly, umm, in recognizing my privilege." Clearly, there are two possible readings of such a statement. At one level it appears, like Finn, as an owning of privilege and an attempt to decentre it. At the same time, it opens up questions of how to balance de-centring with taking action for change.

Gavin is however, stepping aside so that women can lead their own movement, by taking direction on how to identify from women feminists, he is unpacking some of his male power. This can be seen in the following excerpt:

So, that if feminists choose to define me as pro-feminist, I'm alright with that, if they choose to define me as a feminist ally, I'm alright with that also.

By taking his lead from women, Gavin is actually practicing feminism, which is something that many feminists in the community (including Alice, Brandy, Celeste, Eadlyn, Finn and Helen) propose men should be doing if they want to be included in the movement. Gavin continues by talking about women's hesitation with men's participation in feminist politics. He suggests that perhaps women are apprehensive about 
including men because of fears that the men will appropriate and control the movement if they are included. Some of the participants touch on the "Men's Rights Movement," as evidence for women's concern, as well as providing ground for legitimate fear of male infiltration. There is a sense in these interviews that "some" men would be welcomed into the feminist movement, but others would not, and it is that distinction that is too difficult to make that therefore excludes all men. This idea that "a few good men" would be allowed in the movement, is something that Derrick also touched on. Derrick and I joked at the idea that some men would be able to attend the Take Back The Night marches, as long as they were wearing stickers that identified them as having been legitimated by women as 'non-harmful' men.

Gavin ends this section of the interview by putting forth the gender diversity discourse, and how non-binary genders disrupt this idea of exclusion or inclusion of men. He brings up the excellent point that this debate does not include a deconstruction of gender and gender diversity.

Umm, but I think it's impractical, in recognition of the diversity of gender, so where would for example genderqueer folks sit? Transmen, transwomen?

Gavin questions the practicality of excluding people from the feminist movement based on gender identity. The theme of gender policing comes up again through this discourse of inclusion and exclusion into feminist spaces. Feinberg states the complexities of the category 'woman,' and the reasons it is necessary while remaining controversial,

The question can't be considered without understanding that women face such constant dangers and harassment, day-in and day-out, that the attempt to define woman is generated by the need for safe space and clear-cut allies. That's a completely valid need. But how can we create safe space for women? I think that if we define "woman" as a fixed entity, we will draw borders that would need to be policed. No matter what definition is used, many women who should be inside will be excluded. (Feinberg, 1996, p. 109) 
By not wanting men involved in the movement, what implications does that have for people who do not adhere to the gender binary? Women-only spaces supposedly provide safe space for women, however this has been debunked by many feminists, most notably women of colour such as the many women who contributed to the influential book, This Bridge Called My Back, Writings by Radical Women of Color (1981) edited by Moraga \& Anzaldua. Focusing on the intersections of race, class and gender, Leslie Feinberg continues their analysis of male exclusion from feminist spaces by providing a look at the consequences of exclusionary practices,

Of course, as a result of the oppression women face growing up in such a violently anti-woman environment, some women draw a line between women as allies and men as enemies. While it's understandable that an individual might do so out of fear, this approach fails as theory. It lumps John Brown and John D. Rockefeller together as enemies and Sojourner Truth and Margaret Thatcher together as allies. This view of who to trust and who to dread will not keep women safe or keep the movement on course. (1996, p. 110)

Personal ideologies aside, this presents a compelling argument for the negative effects of gender exclusion. Leslie Feinberg asserts that a key component for understanding the necessity for trans inclusion, and it's difference from male inclusion, is that, "Trans people of all sexes and genders are not oppressors; they like women, rank among the oppressed" (1996, p.110). While this may be the case, acknowledging that intersections of both privilege and oppression exist in all of us, problematizes this notion. Sexist, racist, classist and ableist structures of society have constructed all of our social relations to be based on unequal access to power and privilege, regardless of gender identity.

\section{Summary}

Stemming from the transcripts of eight participants in the feminist movement in Ottawa, gender identity and feminist identity are convoluted aspects created by 
oppression and patriarchy. There are no conclusions to be drawn here, no decisive answer as to whether men should participate fully in feminist movement, or whether the idea of being a feminist must in some way be based on intimate experiences of gendered oppression.

Social movement participants can create an identity for themselves based on the collective identity theory (Polletta \& Jasper, 2001). Therefore, allowing space and possibilities for people with diverse backgrounds and gender expressions to form their own identities based on the communities they inhabit, and their personal relations to themselves and those communities. What was made clear in this analysis of the excerpts from my research is that there is no universal feminist theory. The 'traditional' feminist identity is seen as something that is rigid, restrictive and can create oppressive and exclusionary practices. The participants of my research are urging theorists and activists to adopt an expansion of what the term feminist means. The concept of intersectional approaches to feminist theory and identity are seen as paramount to the creation of an inclusive, anti-oppressive movement. Without embracing an intersectional approach, feminist theories will continue to exclude and marginalize certain voices, namely trans* and racialized voices (Yuval-Davis, 2006). With this broadening and releasing of barriers around feminist identity, trans* and male feminist realities can be created and accepted.

Given the decades of negative stereotypes faced by women and specifically feminists, it is no wonder why many people do not wish to self-identify as feminists (Aronson, 2003; Bashir, et al., 2013; Ramsey, et al., 2007; Tyler, 2005). However, it is encouraging to note that many women in North America currently support feminist ideals (Wiley, et al., 2012). If feminism is to remain at the forefront of the fight against sexist 
oppression, it needs to be reinvigorated and reinvented. I believe that intersectional feminism can provide a new image, thus with the expansion of feminist discourse, lies a chance to undo negative stereotypes of feminism. There is a chance here to 're-brand' feminism, as one that is truly focused on those who are the most marginalized and oppressed by "White-supremacist-capitalist-patriarchy” (hooks, 2004, p. 51).

Creating new possibilities for masculinities, such as Anderson's (2009) ‘inclusive masculinity,' could aid in the deconstruction and destruction of hegemonic masculinities. Accepting alternate forms of masculinity into our cultural and social relations, could allow for opportunities of male inclusion in feminist movement, as an inclusive masculinity is one that is not based on the subordination of women, and is therefore more amenable to feminist identification (Anderson, 2009).

Given the changes that can be seen in traditional discourses of masculinities, femininities and trans* identities, a feminist movement that does not work towards antioppressive, inclusive frameworks, is one that is destined for failure. This concept can be seen in the transcripts from my participants, they all want to live and work in a feminist movement that recognizes their diversity and complexities. 


\title{
5.3 Section Three: The Politics of Space and the Pathways of Feminist Identity Development
}

\author{
women's clinic \\ full \\ of women waiting \\ and one \\ old man \\ must be noticed. \\ he takes up \\ so much room: arms \\ flung over seats on either side \\ (mate, can't you see \\ the room is crowded, why \\ do you need three seats) \\ he takes up \\ so much room: legs \\ spread wide \\ talking, talking loudly \\ across the room to a woman. \\ when the doctor calls her \\ the old man hums loudly, sighs \\ reaches over his unneeded \\ stolen seat and \\ brushes my arm \\ looks my way \\ sees my book chapter: \\ ENDING FEMALE SEXUAL OPPRESSION \\ big and bold on the page \\ looks away, doesn't \\ speak to me \\ hums louder and louder \\ sings instead. \\ the old man takes up so much room \\ like so many men in the world \\ demands attention \\ demands notice \\ demands watching out of the corner of my eye \\ because he might do anything at all. \\ $i$ and bell hooks fold up in our chair \\ (arms tucked in, legs together)
}


pretend we have not noticed him at all.

he takes up so much room.

(Jetsilver, 2009)

\section{Introduction}

This poem speaks to some of the experiences and emotions that women express when men are included in women-only spaces. There are many complexities inherent in the theories of gender and space, gender segregation and fear. A number of these will be taken up in my analysis of the responses from the participants, which will draw on the theorization of fear, restrictions of mobility and the policing of space. These theories are based on writers such as, Petra Doan (2010), Hille Koskela (1999), Rachel Pain (1991) and Gill Valentine (1992).

Women-only space and gatherings have historically been at the core of feminist organizing (Blair, 2009; Bordt, 1997; Martin, 1990). They are an integral aspect of the feminist movement. As Carole Leathwood (2004) notes, the idea of "political separatism" is not only enacted in feminist movement,

Political separatism has a long history, not only within the women's movement but also in the civil rights campaigns in the United States, among working-class groups fighting for rights to education or decent working conditions, within the gay and lesbian communities, among groups campaigning for the rights of people with disabilities and so on. (p.449)

Many groups have utilized spaces of exclusion to increase their consciousness-raising abilities, without the burden of performative allegiances to those who maintain power and control in society (Leathwood, 2004). Jane Thompson (1997) argues in her work on sexsegregation and education, that,

The most effective way in which any group, conscious of its oppression and concerned to change the relationships of oppression, can organize, is without the 
participation of the oppressors in the process of resistance. (p.81-82, as cited in Leathwood, 2004, p. 449)

If the feminist movement had not created spaces for women to feel comfortable to speak about their abusive relationships, their unsatisfactory marriages, or what Betty Friedan called, "The problem that has no name" (1963), women might not have been able to raise their consciousness during the 1960's and 1970's. Without these “safer" spaces, in which marginalized voices were privileged rather than silenced, free from male domination and the male gaze, the current feminist movement perhaps would not have been actualized.

Since the beginning of consciousness-raising groups, where men have been excluded there has been backlash (Leathwood, 2004; Morris, 2005; Ruby, 2003; Siebritz, 2008). In fact, for decades of feminist movement organizing there has been a theoretical and practical divide among those who believe in integrationist and those who believe in separatist elements (Leathwood, 2004). My research asserts that this debate continues. With some participants believing in the absolute necessity of women-only spaces, and others contesting those spaces, or noting how they are excluded from such spaces.

From my analysis of the participants' transcripts the personal development of feminist identity and the different pathways to this identity reveal themselves when discussing the inclusion of men in feminist circles and women-only spaces. Participants whose main focus is violence against women tended to have a more circumspect view of men who want entry into these spaces. Participants whose pathway to feminist identification has been structured mainly through academia tend to be slightly less suspicious of and more open to, male participation. In the following section I will be examining distinct pathways to feminist identification and how these specificities play out in exclusion or inclusion of men in feminist spaces. 


\section{Models of Feminist Identification}

In 1985, Nancy Downing and Kristin Roush's article, “From Passive Acceptance to Active Commitment: A Model of Feminist Identity Development for Women," was the first attempt at creating a model of feminist identification for women. This model was based on the author's clinical practice, personal experience, the literature in the field and Cross' (1971) theory of development of positive Black identification (Downing \& Roush, 1985). The use of Cross' 'positive Black identity model' is based in the reality that women's lives are founded on experiences of prejudice and discrimination, Downing and Roush believe that women share similar "developmental experiences of a minority population" (1985, p. 696). This model of feminist identity development was

...based on the premise that women who live in contemporary society must first acknowledge, then struggle with, and repeatedly work through their feelings about the prejudice and discrimination they experience as women in order to achieve authentic and positive feminist identity. (Downing \& Roush, 1985, p. 695)

According to Downing and Roush, there are five stages of development in the model: "passive acceptance, revelation, embeddedness-emanation, synthesis, and active commitment" (1985, p. 696).

Here is a short description of each of the five stages of development:

Passive Acceptance: "describes the woman who is either unaware of or denies the individual, institutional and cultural prejudice and discrimination against her... toward the end there is a readiness - receptivity or openness to change or risk," (Downing \& Roush, 1985, p. 698).

Revelation: "one or a series of crises or contradictions that the woman can no longer ignore or deny," these crises can vary widely from, "consciousness-raising groups, realization of discrimination against female children, ending a relationship, divorce or denial of credit or job application, or involvement in the women's movement" (Downing \& Roush, 1985, p. 699).

Embeddedness - emanation: "Most women are so integrally involved in the dominant culture through marriage, work, and children that it is difficult for them 
to withdraw and to find and embed themselves in a "female is beautiful" subculture" (Downing \& Roush, 1985, p. 701). This stage involves increasing one's access to and involvement with other women who think similarly, places such as women's centres, women's studies classes and support groups are examples of places where women can experience embeddedness. This embeddedness reduces the "dissonance between one's newly emerging identity and the repeated experience of being treated as subordinate," (Downing \& Roush, 1985 , p. 701). Women in this phase "typically interact cautiously with men" (Downing \& Roush, 1985, p. 701).

Synthesis: women in this phase "increasingly value the positive aspects of being female and are able to integrate these qualities with their unique personal attributes into a positive and realistic self-concept" (Downing \& Roush, 1985, p. 702). Women in this developmental stage, tend to "transcend traditional sex roles, make choices for themselves based on well-defined personal values, and evaluate men on an individual, rather than stereotypic, basis" (Downing \& Roush, 1985, p. 702).

Active Commitment: "the translation of the newly developed consolidated identity into meaningful and effective action... Women in this stage select issues carefully based on their unique talents and the possibility of both personal gratification and effecting societal change" (Downing \& Roush, 1985, p. 702).

Since 1985 there have been many reviews and recommendations based on this model. Various re-incarnations include Rickard's 1989 Feminist Identity Scale and Bargad and Hyde's 1991 Feminist Identity Development Scale (FIDS) (Erchull, et al., p. 832). An article written in 2009 by Mindy J. Erchull \& Miriam Liss \& Katherine A. Wilson \& Lindsey Bateman \& Ashleigh Peterson \& Clare E. Sanchez, questions the model's applicability to young women today. Given that these models were created during the height of the 'second wave' of feminism, it is important to note that "young women today" believe that there are more opportunities open to them than were open to women in previous generations (Erchull, et al., 2009, p. 834). The authors' analysis of the Downing and Roush model supports its use for feminist identity development. However, there remain reservations, as research has found (Erchull, et al., 2009), that in current North American societies most women support the measures from the synthesis stage. 
Seemingly skipping the first two stages, creating a difficulty for researchers to adequately identify feminist personal identification. Consequently Erchull et al., believe that women today (not to generalize, as these studies are predominantly based on white Western university educated women (Enns \& Fischer, 2012)) begin in the synthesis stage of the model (Erchull, et al., 2009). Therefore, the older model of feminist identification (1985), which had synthesis and action as the end stage, will need to be reviewed. Synthesis is no longer an ending point, but a starting point (Erchull, et al., 2009). Researchers have stated that higher scores in the later stages, currently does not equate with feminist selfidentification (Erchull, et al., 2009). Otherwise, there would be a much larger population of women calling themselves feminists. Recognizing that there is a disconnect between women receiving high scores on the feminist identification model, while simultaneously rejecting the label feminist, a deeper understanding of why people do not want to label themselves feminist is needed (Erchull, et al., 2009). As has been noted, there are several reasons ranging from stigma to stereotype as to why people reject the label feminist.

It is worth noting that these models of feminist identification development do not account for race, class, age or any other intersecting identity that could influence one's political consciousness. Enns and Fischer's 2012 article, “On the Complexity of Multiple Feminist Identities," makes it clear that the research on the models of feminist identification tend to be confined to white university women. Here is an excerpt from that article explaining in further detail the pervasiveness of this restrictive methodology.

We are particularly mindful that respondents in this study were predominantly White women, and this aspect is consistent with many previous studies of feminist orientation (e.g., Liss, Crawford, \& Popp, 2004; Liss, O'Connor, Morosky, \& Crawford, 2001; Nelson et al., 2008; Stake, 2007; Yoder, Perry, \& Saal, 2007; Yoder, Tobias, \& Snell, 2011; Zucker, 2004). Although previous reviewers have identified the limited diversity of research samples as a concern 
(e.g., Moradi et al., 2002; Vandiver, 2002), many studies still rely heavily on White college female samples. (Enns \& Fischer, 2012, p. 1150)

Therefore, I must acknowledge the limitations of all models of feminist identity development before applying them to the participants in my research. The eight participants for my study are not homogenous on all identities, however they are all university educated; which will have an impact on their pathways to developing a feminist identity.

\section{Analysis}

There are different paths that people take to develop their feminist identity; these different paths can lead to tensions within a movement. One's personal journey to feminism often shapes one's feminist priorities. There is no single feminist issue; there is no ideal feminist type, only multiple complex identities with differing goals and priorities (Enns \& Fischer, 2012). It is this difference that creates such a dynamic, passionate and ever-struggling movement. Feminist identifications that are rooted in a violence against women framework will diverge from feminist identifications that are based in labour politics, or a humanist background, or an academic theory background. People's pathways to feminist identification along with their intersecting identities of race, class, gender and age are all contributing factors to a multivariate feminist movement. It is these differences within the movement that allow for tensions in the Ottawa movement regarding space and the inclusion or exclusion of men and trans*folk. While focusing solely on tensions here, it is important to note that this diversity also contributes depth and richness to the movement. If feminists are to work together to end sexist oppression, some feminists claim that working collectively in coalitions of distinct groups would be beneficial (Bunch, 1987; Combahee River Collective, 1978; Lorde, 1984/2007). Thereby 
acknowledging the unique experiences of women of colour, trans* folk and men, while recognizing that everyone has a role to play in ending violence against women. Charlotte Bunch states,

Diversity among feminists today can be a resource for gaining a broader understanding of the world. We see more clearly and our ability to create effective strategies is enhanced if we move beyond the boundaries of our assigned patriarchal slots. (1987, p. 150)

If feminists are to create lasting social change in the name of feminism, the identity must be one that is celebrated and inclusionary. Out of the four women participants, all of them spoke of the need for women-only spaces in a male dominated world. Two of the participants noted that due to the pervasiveness of male perpetrated violence against women, these spaces necessarily must exclude men. As the United Nations stated twentyone years ago in 1993, "Violence against women has been recognized, at both the national and international levels, as a serious and on-going impediment to gender equality and women's human rights and fundamental freedoms" (cited in Statistics Canada, 2013a). Current trends in violence against women maintain that women in 2011, were eleven "...times more likely than men to be a victim of sexual offences, and 3 times more likely to be the victim of criminal harassment" (Statistics Canada, 2013a). Given the low rates of reporting amongst women who are survivors of male violence (Johnson \& Dawson, 2011), the statistics on Canadian police reported incidents are much lower than the reality for women. However, the most current statistics are of police reported incidents of violence,

In 2011, police reported about 78,000 incidents of violence against women by current or previous intimate partners, including those by spouses (common-law and legally married partners) and dating partners. The overall rate of intimate partner violence against women was 542 per 100,000 women, almost four times higher than the rate for men. (Statistics Canada, 2013b) 
Alice states that since she came formally to feminist movement through the violence against women field, she can understand the argument for reasons for womenonly spaces.

We cannot CONTROL what triggers people, but we know that if a BIG trigger for the vast majority of survivors is the need to be in a space where they are not SEEING men or hearing men ... tell them what to do, or supporting them, or whatever the case may be. Then I think that needs to be respected.

This position of creating women-only spaces so as to recognize and honour the needs of survivors of violence is echoed throughout feminist literature (Morris, 2005; Ruby, 2003; Siebritz, 2008). These concerns of the impact male involvement may have on survivors hold even more weight when one considers the statistical evidence that the majority of perpetrators of violence against women are men (Pain, 1991; Statistics Canada, 2013c; Valentine, 1992; Johnson \& Dawson, 2011) and the high rates of abuse of women in heterosexual relationships,

As in previous years, the majority of victims of family violence were females. They represented $80 \%$ of spousal victims, $63 \%$ of parents victimized, $58 \%$ of extended family members victimized, $57 \%$ of child victims and $57 \%$ of sibling victims.[...] Overall, men were responsible for $83 \%$ of police-reported violence committed against women. Most commonly, the accused was the woman's intimate partner (includes both spousal and dating) (45\%), followed by acquaintances or friends $(27 \%)$, strangers $(16 \%)$ and non-spousal family members $(12 \%)$. This contrasts violent crimes against men, where intimate partners were among the least common perpetrators (12\%). (Statistics Canada, 2013a)

Alice acknowledges that exclusion from such spaces might not be "that fair to men." However, she repudiates the question of fairness, when she answers her own question of whether she believes that this is fair to all men; "Not really, but don't take it up with me, take it up with the men who are raping people." Her goal here is to place accountability and responsibility for the need for women-only spaces firmly on the unfair terrain of the men who perpetrate violence against women and the systems that sustain 
those practices. Alice is basing her understanding of women-only spaces directly on her involvement in the community and knowledge of violence against women. Women's fear of certain spaces and how that fear controls their agency, mobility and ability to live in the public sphere has been well documented, (Koskela, 1999; Pain, 1991; Valentine, 1992). According to Statistics Canada (2013a), "Women generally have higher levels of fear of crime compared to men. According to victimization data, this fear was heightened when women had been the victim of non-spousal violence" (p.9). Speaking of the situation in Sweden, Hille Koskela asserts that women's fear is equated with mobility restrictions and threat of violence. She suggests, “...spatial constraints are intertwined with gendered power relations" (Koskela, 1999, p. 111). Other researchers agree with her; "Female victimization is of special interest since gender is one of the most crucial factors affecting fear of violence and geographical mobility in urban areas (e.g. Warr, 1985; Smith, 1987; Pain, 1991)" (Koskela, 1999, p. 111). These researchers assert that fear restricts women's access to public space and activity (Koskela, 1999). Researcher, Rachel Pain suggests that women's fear is different from that of men's, in the intensity and the consequence it has on the lives of women (Pain, 1991). Koskela urges that, "It is not an inborn quality of women to be fearful" (1999, p.112), many theorists believe that it is in fact a form of social control (Koskela, 1999; Pain, 1991; Valentine, 1992).

As Rachel Pain (1991) has noted, women who experience violence and fear of the threat of violence can be drawn to activism. Many women and people of marginalized genders live under the threat of male violence, this can propel people to wish to separate from patriarchal relations (Leathwood, 2004). Women-only spaces provide a chance for women who are experiencing violence in the private sphere, to share their stories, have 
their voices heard and be in relative safety in the public sphere (Pain, 1991). The participants of my research, most notably Alice, Brandy and Helen remark on the feelings of empowerment and solidarity with others when they are in women-only spaces. In this excerpt, Alice speaks of how she feels at annual Take Back The Night marches,

I can't describe [the feeling] about bringing someone to their first Take Back The Night, I mean my own first Take Back The Night where you are downtown, in sort of the seedier parts of town where you usually with a group of friends STILL don't feel safe. With hundreds of other women ... chanting, "This is my space, these are my streets, and they belong to me!"

Writing about her experiences of women-only spaces, activist and writer Jennie Ruby (2003), expresses her positive reasons for the necessity of such spaces,

To me, creating and experiencing women-only spaces and feminist spaces is essential to bringing about social change to combat the male-centred and maledominant Western culture so much of the world struggles with. Within these spaces we can feel what freedom from oppression would feel like. (p.14)

Jennie Ruby also provides an important point for this research, the fact that men would benefit from male-only consciousness raising (2003). This concept might ease tensions within the movement. If some people agree that men should be engaged in feminist theory and practice, and that their engagement could support advocacy efforts against violence against women, then perhaps men should have a chance to raise their consciousness, in similar ways that historically women have had.

Analyses of men's experiences under patriarchy are crucial to the work of creating a better, nonpatriarchal world. I imagine that men must benefit from discussing these things in men-only spaces at times. As a woman, I certainly feel I understand a lot about men and would have a lot of good feminist advice for men who were exploring alternatives to patriarchy but that does not mean I think I should intrude on a men's feminist retreat ... I believe that women, and also men, need to explore alternatives in separate environments. (Ruby, 2003, p. 15)

Brandy bases her response to the question of women-only space in discourses of power and control. Her framework for involvement in feminist movement is based on her 
intersecting beliefs; during the beginning of the interview she states that feminism does not encapsulate all the causes or theories that she believes in. "For example, like a humanist would believe, so I feel like, I am a feminist first, but most likely, like a combination of things at the same time." Unlike the approach that Alice took, Brandy does not ground her response solely in the threat of male violence; she speaks about how privileged men take up space and silence women. "So... my opinion.... Is that womenonly space is EXTREMELY important." Brandy views these spaces as significant to women empowerment and solidarity with each other. She juxtaposes the experiences of mixed gender spaces, with those of women-only in this next excerpt.

Cause what tends to happen is, when you are working in an environment where there is NO women-only space, what you tend to see is women not being able to speak up, you tend to see more women go unnoticed, you tend to see women feel a lot more insecurity, there's a lot more sexual harassment, a lot more just general overall anxiety associated with not having safe space. Whereas in contrast if you offer safe space for women, they tend to be able to take on leadership roles, they tend to be able to feel more confidence, they tend to try to break through some of the cycles, just work dynamics that break through, the same thing for events [creating women-only events also provides space for women's empowerment].

Here, Brandy speaks from her experience in social justice organizing and working in support services for youth. The research is clear, women tend to be silenced and have a more passive role in discourse creation and participation, in mixed gender spaces (DelphJaniurek, 2000). This can have impacts on women's ability to heal, feel confident in leadership skills and have a sense of agency. The position that women in this research are taking is, in part, about trying to foster a sense of solidarity amongst women. The participants' feel that women-only spaces allow for a place where alternatives to patriarchal processes are accepted, a place where in their own experiences they can have 
their voices heard. For these participants, it is important to have a place that is not maledominated, as many women struggle with male violence and domination in their lives Speaking of women-only spaces in Namibia, Elzita Siebritz states the benefits of these spaces,

It's a place of empowerment, encouragement, energy, emancipation, and any other word that echoes our independence, beauty and strength. A women-only space is not simply a room filled with women; it's an ideological and political space, where patriarchy in all its oppressive manifestations is challenged. This space is used to educate women and to channel our energies. (2008)

Elzita Siebritz continues to state the necessity of women-only spaces for the creation of a more egalitarian world,

Feminism has thrived in the women's movements and the academies in the North because feminists in those countries have been able to acquire the necessary spaces and resources. Feminists in Africa therefore need this space where we can mobilise our limited resources in order to build a firm feminist foundation in our countries. It is in our women-only spaces where we can empower and train women as leaders as well as provide the necessary tools needed for emerging leaders. (2008)

Likewise, Brandy believes that men should not be allowed at women-only political marches. Take Back the Night marches are international events that have been held annually all over the world since the seventies (Take Back the Night Foundation, 2013). Women join in solidarity and walk throughout their cities in the streets, at night-time; reclaiming the "safety" of the streets for women. There is a debate within the Ottawa feminist movement about the inclusion of men in these marches. In this excerpt Brandy speaks of the pressure to include men in women-only spaces.

Well to me, that [reflects] an underlying [social] problem to say "well men really want to be there, so make space for them." Well it's not about them being there.

When speaking of the inclusion of men in the marches she asserts that; 
It doesn't matter if $95 \%$ of the women there are comfortable with having men allies, if only $5 \%$ couldn't come, or felt uncomfortable, or felt excluded, or whatever because there would be men there, those $5 \%$ really should make the majority.

Here, Brandy wants to ground the policies and organizational structures in the lived experiences of the women who face violence against them. Brandy argues that feelings of solidarity and empowerment are very important to the development of a strong feminist movement and personal ties amongst women should be fostered. Brandy believes that allowing men to be included would put other women at risk, and she thinks that this is unacceptable. Her position has been argued by others writing about the feminist movement (Leathwood, 2004; Morris, 2005; Penelope, 1990; Ruby, 2003; Siebritz, 2008), but is not a unanimous position (Freedman, 2012; hooks, 1984). Others argue that by excluding men it creates an environment of gender policing and boundary making (Doan, 2010). This also excludes the lived realities of violence within the queer community, and transwomen and men who have been involved in feminist movement for decades (Feinberg, 1996). Focusing solely on a gendered analysis for the creation of "safer" space also completely negates the intersections of race, class and ability to people's experiences of oppression (Leathwood, 2004). However, feminists like Brandy who highlight the ubiquitous nature of male dominated spaces in our society challenge such positions.

Men can have their own spaces, and men tend to have a lot of their own spaces. Lots of sports clubs are geared towards men, lots of social clubs are geared towards men, someone can argue that Cabinet and our Parliament system is geared towards men.

Brandy concludes her response by comparing the differences between predominantly men-only spaces and women-only spaces.

THEY have space, they demand space, no one questions their space. And if there space is ever questioned, it never gets adapted to include others, it's more like, 
"You gonna come in? You gonna come in on our rules and adapt to us." It's not, it's never the other way around.

Brandy is clearly expressing her anger and frustration at the challenges and contestation that occurs when women attempt to carve out specific places and spaces for them. Especially, when men have been able to create predominantly male only spaces, and have only recently been forced to include women into their spaces. Upon entry into these spaces, women are often met with hostility and devaluation ( $\mathrm{Ng}$, Staton, \& Scane, 1995). The glass ceiling, with obstacles such as lack of access to childcare in the workplace, and discrimination against pregnant or soon to be pregnant women, they create significant barriers to gender inclusivity and gender equity. There is research to support the notion that dominant discourses of work do not support the inclusion of women, or allow for alternative forms of masculinity (Ragins \& Winkel, 2011; Sirianni \& Negrey, 2000). Allan Johnson notes that,

Men are more likely to be given early opportunities to show what they can do at work, to be identified as potential candidates for promotion, to be mentored, to be given a second chance when they fail, and to be allowed to treat failure as a learning experience rather than as an indication of who they are and the shortcomings of their gender. (2006, p. 28)

In her narrative Celeste refers to the feminist poststructuralist argument of troubling the "category woman" (Butler, 2010; Riley, 1988). Celeste believes that women-only spaces are necessary, however she believes that, "They need to be more inclusive OF different categories OF women." She states that discourses on femininity and identity along with dominant notions of women-only spaces tend to privilege certain kinds of women; white, able-bodied, heterosexual. Celeste, herself has felt excluded from these supposedly "safer" spaces, where women are allegedly free from the structural forces of patriarchy, colonialism and capitalism. However, it is important to note; and 
Celeste mentions this in her interview, that subordination of women of colour, and gender essentialism along with patriarchal behaviours and actions still occur in women-only spaces. Other feminist theorists would agree (Hepshiba, 2011; Lorde, 1984/2007; Moraga \& Anzaldua, 1981; Ostrander, 1999; Scott, 1998) and suggest that white women take time to understand their white privilege and racial attitudes towards women of colour. Some organizations work hard to support anti-oppressive, anti-racist frameworks and often engage with anti-racist feminists to restructure the organizations (Hepshiba, 2011). Other times, the use of caucuses and separate coalitions within the same organization work best (Bunch, 1987). A lot of work needs to be done in order for white feminists to acknowledge, and work to diminish, the racism inherent in feminist movement.

Celeste does note that there are very few women-only spaces in Ottawa, however she states that they can definitely be places of exclusion. She mentions the disappearance and exclusion of transmen from women-only spaces as a serious problem. Noting that gender variant people are often the most marginalized and at a greater risk of violence ${ }^{11}$ than cisgender people, she challenges the benefits of "traditional" women-only spaces.

Helen's knowledge base of feminism is rooted in feminist counselling practices, therefore her discussion of women-only spaces includes a reflection on how conversation styles are gendered and how men tend to dominate. Researchers in this area agree and have found empirical evidence suggesting that patriarchal discourses are used to silence "women in the public domain" (Cameron, 1990, p. 70). They have also noted that traditionally, men have more competitive speech forms, and women adopt a more cooperative speech style (Cameron, 1990), thus enabling men to dominate conversations

${ }^{11}$ For detailed auto ethnography of the tyranny of gender see Doan (2010). 
and gain more power in each interaction. Researchers in linguistics have determined that, "Patriarchal inequality is produced and reproduced in every interaction (Wetschanow, 1995, 15, Harres, 1996, 18ff, West and Zimmermann, 1991, cited in Wodak, 1997, p. 12). As someone familiar with this literature, Helen believes that women-only spaces are still necessary,

Because I think women are silenced and we silence ourselves, so I think owning public space be it air time, or the streets or the nights, or whatever else is crucial...I think we are not safe in those forums... And I cringe at public occasions where there's a speaker or a panel or something like that, and then they ask for questions and the men line up, few women line up.

Her concluding remark is a helpful summation of the reasons in favour of women-only spaces,

What I was saying is that the world is designed for men by and large, where men are comfortable and where men feel in control.

Eadlyn's response is interesting, in that they have travelled through women-only spaces and events, been invited to speak for/on behalf of women, and have also been excluded and uninvited from speaking. Their analysis of feminist identification along with exclusion of feminist spaces provides insight into the challenges of how to disrupt gender binaries within a movement that is situated in gender analysis and experience. Society's reliance on the dichotomous gender binary has resulted in many obstacles for Eadlyn.

Eadlyn argues that much of the oppression that is felt by marginalized populations originate from similar, connected structures of power and control within our society. The structures of oppression in a society create the situations necessary for the domination and oppression of certain groups of people (such as the working class, people of colour, women and trans* folks) (Lundy, 2004). In the following excerpt Eadlyn states, 
Cause ... even ... if you look up the issues such as feminist spaces, women-only spaces... if you look at that it's ... you know what is that based in? Queer people experience misogyny; trans people experience misogyny ... racial [racialized people experience violence] you know what I mean? There's all these structures that affect us and impact us in different ways but for similar reasons, or like grounded and rooted in similar ways.

Here Eadlyn, presents a critique of a feminist politic solely grounded in a gender analysis. Similar to Lister (2005) and Riley (1998), Eadlyn is advocating for organizing and advocacy around the structures of oppression that affect multiple people in multiple ways, rather than by organizing around specific gendered identities.

Speaking candidly about their experiences throughout their gender transition, Eadlyn expresses that they have had "interesting kind of thoughts" around navigating through gendered spaces. Specifically, Eadlyn recalls a significant event that occurred that exemplifies some of the controversies around gender exclusivity.

For example there's a vigil that happens every year and I was asked to emcee it, which is fine and dandy until my name went out to the organizing committee... It was interesting to me...because in the past I had a more feminine name... or whatever it was fine and then... and nothing really changed, like my voice or ... there's not ... a whole lot of physical signifiers that would be different...its just that my identity was that, ... I started identifying in a different way and I changed my name to be more gender neutral or whatever so... There was a lot of like... kind of suspicion and I was dis-invited...

Here is an example of gender policing, and transphobia and essentialism that flow through some traditional feminist theory. This excerpt shows how powerful representations of gender can be, and how rigid people's views are about appropriate feminine and masculine names.

Eadlyn echoes the poststructuralist deconstruction of gender and the category woman, similarly to Celeste, when they say: 
I don't know, I find women-only spaces really hard, and also it's based on the fact that, if you are a women-only space but you don't allow transwomen, basically what you are saying is that transwomen aren't real women right?

Here Eadlyn mentions the erasure of the trans* body, much like when Petra Doan, writes about their very public transitioning period, and the prejudice and discrimination that accompanied people's perceptions of gender diversity (2010). Due to Eadlyn's political consciousness, which for them has been born out of their personal experiences, their responses have been created through an intersectional lens. Feminist writers, namely black feminists and poststructuralists, argue that one's political position must not always relate to one's identity (Butler, 1990), and therefore one does not need to be trans* to believe in the deconstruction of gender.

Throughout my analysis, I am becoming increasingly aware of the tensions when the feminist movement focuses on single goals. Due to people's unique personal histories and identities, trying to follow a singular pathway to feminist movement is incongruent with many people's realities. As another example, I will now focus on the three male participants and how their pathways to feminist identification have consequences on how they view women-only spaces.

Like all the other participants in this project, the male participants had commonalities and differences between each other. Derrick and Finn both bring up the role that other feminist identified men played in their own feminist identification. It has been noted in the literature "positive portrayals of feminist men increases male engagement and solidarity with feminism," (Wiley, et al., 2012, p. 61). This can have a significant impact on practices and policies on how to further engage men in feminist thought and ending violence against women. It is important then to note that perhaps this 
idea could have an impact on feminists criticizing the men who engage in feminist work. If a goal for feminist movement is to engage more greatly with men, then perhaps tensions arise when feminists feel they should not criticize the men who are already in the movement.

Derrick, Gavin and Finn all have fond memories of university. They all remark on times when they felt supported to learn about feminist thought, and all spoke of positive male role models who self identified as feminists, as was examined in the previous section. Most of the participants in this study suggested that education and the opportunity to read feminist books have supported them in their journey to identify as a feminist. Derrick refers to bell hooks, and Judith Butler, as key influencers in raising his consciousness about gendered oppression and the social construction of sex and gender. It is important to note that bell hooks is a predominant feminist thinker and author, and she not only supports but urges men to take up feminist thought, to engage in feminist practice and to be "comrades in struggle" (hooks, 1984). Judith Butler, as has already been examined is a dominant proponent of the deconstruction of the binary of gender (1990).

In this excerpt Gavin speaks about his feminist awakening during university,

Of course with this public understanding of feminism as a dirty word kind of, so I think that was the first time where I got a new understanding of what it meant to be feminist.

Here Gavin touches on many aspects of why people do not want to identify as feminists. Looking back on the research of the evaluation of feminists; Wiley, et al., (2012), noted that,

College students evaluate feminists less positively than women in general; they also perceive them as more masculine and less likely to be heterosexual 
(Anderson, 2009; Twenge \& Zucker, 1999)... Even undergraduate women who identify themselves as feminists think that the "typical" feminist has political views that are more radical than their own (Liss, Hoffner, \& Crawford, 2000). Conversely, feminist women are also seen as more competent, intelligent, and confident than women in general (Anderson, 2009; Berryman-Fink \& Verderber, 1985; Fiske et al., 2002; Twenge \& Zucker, 1999). Thus, feminists fit the profile of an envied group (Fiske et al., 2002): deserving of grudging respect, but also distrusted and disliked. (p. 61)

Therefore, there is a lot at stake when declaring a feminist identification, perhaps especially when you are male.

Each of the three male participants has a different understanding of their feminist identification, however they have similarly received education and role models that have supported their feminist views. With these differing pathways to feminist identification come different priorities for the feminist movement. In the section to follow I will examine the three participant's views on women-only spaces.

When asked about his thoughts on women-only spaces, Derrick spoke about a writing retreat that was divided by gender. He says that the reason for the division, as told to him by one of the women participants was out of fear of sexual tension. The coordinator of the event told him that; "it was that women requested it, that it was free of men, because it, because there are.... Pressures around relationships." Analyzing the use of the words "pressures around relationships" conjures up discourses of violence. My analysis of this request for a woman-only space at a writing retreat is that this appeal came because the women were worried about sexual assault; feeling "pressured" sounds like non-consensual sexual activity. This is my personal analysis, not an inference that Derrick shares. He believes that the women wanted to be alone because there would be consensual sexual tensions and flirtations. 
Like that the person told us that the women requested it because they were really concerned that being around other men would somehow poison the well, sort of give people. And the message was, was that it was all sexual. There would be too much sexual tension

Interesting here, how he uses the word "poison the well," as this is reminiscent to the benefits for women of women-only space. The difference between the analyses that I created based on what the coordinator told Derrick, and the analysis that he made himself, provides evidence for a gendered analysis of this situation. Perhaps, as a result of Derrick's power in social relations, he does not feel the need to separate from others who might "poison his well."

At one point Derrick acknowledge the benefits of women-only space, and refers to the feminist consciousness-raising groups that were purposively women-only. However, he also mentions problematic environments for women-only spaces, he refers to this as "snippy."

The woman only space that's snippy... is not really doing much [in the way of raising consciousness] or [it] is working against the goal [solidarity] of pulling together the women-only space right?

I cannot analyse his understanding of the women-only space as 'snippy,' is this something he has experienced, or is this due to negative social construction of womenonly and feminist spaces? Without more information, I cannot draw any conclusions. However, it does remind me of something that Allan Johnson stated in his book, Privilege, Power and Difference (2006), "When women gather together, even just for lunch, men may suspect them of "being up to something" - planning some subversive use of power that needs to be monitored and contained" (p. 92).

Finn's responses to women-only space and events echo Derrick's, his political views allow him to question the exclusion of men from certain events. As was previously 
mentioned, many researchers, women and trans*people have also questioned the exclusion of men (Anderson, 2009; Doan, 2010; Feinberg, 1996; Flood, 2011; ScottDixon, 2006; hooks, 1984). In an excerpt previously examined, Finn expresses anger at being excluded from a Take Back The Night walk in Ottawa. Finn's frustration at being excluded, as was analysed earlier, can have multiple meanings. What is important to focus on is that he is not the only one excluded from such events. Oftentimes, as was seen in Eadlyn's narrative, people who do not conform to the gender binary are also excluded. These spaces have also been criticized as only providing relative 'safety' for a specific type of woman. As can be seen in this next excerpt from Celeste, feminist movement has been known to create barriers to participation, by policing spaces of supposed safety. Here Celeste questions whether members of the movement should have power over who can and who cannot attend certain events.

P: What do you think of men joining feminist marches and protests?

C: (EXHALES)... If men want to show solidarity... I think that's great... I think for me...having men present ... is not necessarily a bad thing so long as they know, that they are there to be in solidarity for... So whether it's helping set up, clean up, whether it's standing at the back of the march. I think. Yeah that's ok. They can definitely engage, because... They need to right? And I recognize that women want their own space, but... I think in reality we can never tell a woman, you know, if her partner who is male and is one of her main supports and she wants him there at the Take Back The Night walking in the back, you know who are we to say, "No he's a man, and he represents this." When he could represent something completely different for her. Right? and I don't think we as feminists should have the right to take that away from women. But I do think that men have an innate role in terms of again, I'm talking about it in the context of cisgender men. I do want to make that very clear. That yeah they can walk in the back. Or help with the event, help with the nitty gritty, don't talk to the media, don't take you know the focus away from the women that are there. 
Celeste reiterates that it is paramount for men to engage in feminism, as it is a necessity for change, but mentions, similarly to the other participants, that they should behave in a way that maintains focus on the women.

Gavin's response to this question highlights an interesting progression of his views about women-only spaces, perhaps sustained by being embedded in feminist movement through Women's Studies classes and feminist action. He speaks of a time when he first began developing his politically feminist views, and how he did not understand the necessity for these gender specific spaces. However, Gavin has since become cognizant of the requirement for women-only spaces.

And my first reaction of someone who was not really engaged [in feminist movement] was, "Oh this is stupid, and I'm trying to help and they don't want me to." Right?... but after becoming engaged and learning a little bit more about masculinity and male privilege and the experiences that people have with male violence, I learnt very quickly that those spaces were critical to organizing ... Because you can't do your best work in organizing if you are not comfortable and safe.

Gavin demonstrates his frustration and hurt at being excluded from women-only organizing. His identity was sustained through people's gratitude and appreciation of his helping hand. In the literature this is referred to as noblesse oblige (Kemper, 2001), his power and authority should require him to support marginalized people (Wiley, et al., 2012; Flood, 2011). Gavin uses the term "engaged" to highlight himself as becoming involved and educated in violence against women and feminism more broadly. This term stems from the literature on how best to "engage" men and boys into feminism (Casey, et al., 2013; Freedman, 2012).

Throughout our conversation Gavin analysed the contestation of women-only spaces by comparing the request by women for women-only spaces with the request by 
other marginalized groups for their own space. His comparison of these three communities is interesting. In this excerpt, he speaks to the patriarchal driven barriers to women-only space;

So when members of the GLBTQ community do it, no one questions that. When people of colour have organizations on campus that are built solely for people of colour nobody really questions that. But still it is under contestation every single time when women want women-only spaces, and I think that's really problematic.

\section{Summary}

While not generalizable, the findings in this section illuminate the varied pathways these participants took to identify as feminists, these pathways are diverse, and the feminists are also diverse. There is no singular route or map taken to reach a feminist identity, there is no universal feminist identification. All of the participants have different goals, priorities and ideas about identity, space and movement. Much of the development of a feminist identity came through university, through reading feminist text, through immersing oneself in Women's Studies classes. Those participants who have either first hand experience with male violence, or who work with women who have experienced male violence were often more reticent about men's involvement in women-only spaces. Those participants, whose feminist work was based on violence against women, also seemed to have a greater understanding of the urgency and necessity of women-only spaces. Perhaps it is true that only those who experience violent oppression at the hands of men truly understand the arguments for women-only spaces. However, being cognizant of white privilege and cisgender privilege is important here. Celeste, Eadlyn and Gavin all acknowledged that for a large proportion of people, women-only spaces are not "safer" as they are not free from racism, classism, ageism or sexism. Having the ability to as Audre Lorde says, "work across differences" (1984/2007), is a challenge that 
feminists face daily. How to understand the oppression of another while not experiencing that same type of oppression is a struggle for everyone working towards social justice. 


\section{Chapter Six: Discussion and Conclusion}

The final chapter of this thesis is devoted to a brief overview of my research and discussions of how the findings relate to the literature, feminist theory and social work practice. I also discuss the future research that I see as emerging from this work and the limitations of the study. Finally, I spend some time reflecting on the implications of this project for structural social work, as well as provide suggestions for further research.

\subsection{Overview of Research Study}

My research provided insight into the gendered discourses of social movement participation that were operating among a small group of participants involved in the feminist movement in Ottawa. As the feminist movement attempts to progress in an inclusive manner, tensions are noticeable. The aim of my research was to gain a deeper comprehension of the lived experiences of those who participate in feminist movement in Ottawa. I hoped to discover the barriers that some feel to participation so as to develop a greater understanding of inner group dynamics and how it affects social change and leads to feelings of exclusion and/or solidarity. Specifically, I was interested in understanding the barriers that men perceive, and how women and gender non-conforming people experience this inclusion of men in the struggle to create gender equity. I had hoped that in understanding barriers, I would also gain greater insight into how to increase solidarity and improve social movement participation. In order for social justice to be recognized, a greater number of people who align with feminist movement and thought are required. If the feminist movement is to truly progress through understandings of the diversity of oppressions, and creating greater inclusion and solidarity, then these tensions must be examined. 
I interviewed eight participants, three of which where men, one was genderqueer and four were women. Using an interview guide I asked a range of questions relating to the participant's identity, self-defined feminism and their involvement in feminist social action in Ottawa. After transcribing the audiotaped interviews, I performed a qualitative critical feminist discourse analysis on the transcriptions. This involved a deep reading of each transcript, focusing on how discourses of power and control were created by each individual. I followed the analytic tools set out by James Paul Gee (2011), and produced a very fine reading of each transcript. I analysed the participant's response through a feminist lens, concentrating on how hegemonic discourses of femininities, masculinities, race and class were created. I concentrated on the use of language, tone and inflection to gain a more nuanced interpretation of each transcript. This allowed me to develop an analysis of each of the participant's own narratives and how each one was shaped by ideologies of power and control. From there I was able to uncover three pertinent themes relating to the gendered discourses of feminist movement. Those themes included; the emotional affect of participants in social movements, collective identity as it relates to gender and feminism, and the politics of space and pathways to feminist identity. Each of these themes provided a more nuanced understanding of the tensions within feminist movement in Ottawa.

\subsection{Discussion}

My research into the experiences of eight participants of feminist movement in Ottawa has enhanced my understanding of gendered discourse and the personal implications of self-defining as a feminist. Three meaningful areas of discussion arose from my analysis, they are; the impact of women's lack of authority in society, the 
necessity of alternative masculinities and the need for an expansion of the term feminist. I will develop each of these topics in the following section.

\section{Authority}

Women's lack of authority in society can have grave implications, from violence against women (DeKeseredy \& Schwartz, 1998), to exclusion from the political arena (Johnson, 2006), to de-legitimization in academic professions $(\mathrm{Ng}, 1993)$, and to not being believed when speaking about the oppression of women (Johnson \& Dawson, 2011). I imagine that this could be another reason why some people do not want to be labelled feminist. If being a woman holds such little power, then being an ally of women, and someone who challenges the dominant patriarchy might place that individual into a(n even more) subordinate position in society. As women lack authority and power to control even simple conversations with peers (Wodak, 1997), it is no wonder then that women who struggle against patriarchy are seen to lack legitimacy. This overall oppression of women, and suppression of feminist thought, perpetuates negative stereotypes of feminists and of women, therefore making it increasingly difficult for feminist movement to gain ground (Bashir, et al., 2013).

If women within the movement feel they lack authority, as was discussed by Helen and Alice, then the inclusion of men to the movement increases this tension. If men already hold authority in public, then they will remain authority figures in every domain they enter $(\mathrm{Ng}$, et al., 1995). The worry is that some women who specialize in feminist theory and oppression, will be passed over in order to speak to the men. This fear of men being the authority on feminism was echoed throughout the participants' 
narratives. In this excerpt, Alice discusses an example of her lack of authority in public, in contrast to her father's authority.

I wear a Real Men Don't Rape pin, and I have been challenged on it, more than, I mean I've worn pro-choice pins in the middle of like, pro-choice debates nationally, and I've had less flack than that Real Men Don't Rape pin. I've had a lot of people, yeah, it's been very interesting, and meanwhile... I think it's that, people view it as because I'm a woman, wearing a pin that Real Men Don't Rape, it's seen as in your face. I'm shoving stuff down your throat cause it's really provocative versus my FATHER, who saw that pin and was like "I love that pin" I was like "you should take it!" And then he wears it, wears it on his coat all the time and he said he's had SO many great conversations with people. He was like "I was at A\&W, buying a burger and I saw this guy was staring at me, and I couldn't figure out why, and then he was like "That's a really great pin" and then I had a chat with him about you know my daughter gave it to me, and I feel like if more men had that..." And then he did work on reserve, and some of the elders there really loved it, and so I sent him a whole bag and they were sort of giving it to men who were doing anti-violence against women work there. THAT to me is the power of including men that we were LITERALLY giving the same message, but HE his message was read differently. Now, I can sit here and piss and moan about how much that sucks. About how he was heard, and I wasn't. OR, I could just say you know what? That's the kicks. You [men] take it and you go, and that's your [men's] role is doing that.

Alice, however, would rather focus on the work of ending violence against women, and using all the tools at her disposal (her dad) rather than engage in a lengthy discussion about why men have more power than women. She acknowledges that this is the case, but for her, at least the work is getting done. I believe that for myself, and perhaps other women in feminist movement, this lack of authority and legitimacy on a daily basis is anger making. Add the fact that when men engage in feminist theory, due to historical advantage, they are better received, can make for marked cynicism within the movement.

In this excerpt, Celeste speaks to bitter feelings within the movement when men are asking for women's support to learn about and promote feminism. Celeste also speaks to the idea that men will receive greater recognition for their feminist actions, however 
she does not view this negatively, similarly to Alice, she views this as a known fact of life.

You know acknowledging that yes you know we [women in the movement] took so much time, and we [men] appreciate it, you know sometimes its like fuck why can't we just stand in solidarity why so much divide? You know? And who's not feminist enough? And if he's a man, he's just trying to take up space, and I'm sure he'll be on the news you know talking about his program, and I'm sure he gets funding for his program. And you know what I'm sure he fucking does get funding, but at the end of the day he's TRYING, we're in the same battle. Even though we may look different we are trying to end violence against women, so if that's what he's trying to do.... Challenge him on his problematic notions.... But support him on his trying to make change, because how many men actually.... You know... If we are talking about the more grandiose public education events. Not that many men do that, so when they do, why, it's like we are gnawing at our own hand you know its like we are a movement trying to end something. But if someone slightly strays from our philosophy or belief its like [noise to imitate biting off a head] ... bite their head off you know?

Celeste expresses the cynicism that some women feel regarding the participation of men in feminist movement, she also points to the inequality in funding and publicity.

I believe that the lack of authority that is expressed here by Alice and Celeste, and as was analysed earlier from Helen's description of her husband, speaks to the broader oppression of women in society. Which in turn leads to the oppression of women and marginalized individuals in academia. I believe, that this results in fewer people engaging with feminist thought, fewer people wanting to be labelled feminist, and fewer students gaining knowledge from women professors. Taking a look at the recent Canadian statistics of women in teaching professions, "While women are also the majority among high school and college teachers, the situation is completely different at the university level. In 2006, the proportion of female university professors reached 39\%, compared to 34\% 10 years earlier" (Turcotte, 2013). Meaning that the majority of professors in Canadian universities are men. bell hooks (1994) explores the issue of marginalization in 
academia in great detail in her book Teaching to Transgress, Education as the Practice of

Freedom, where she states,

Overall, black female scholars, already seriously marginalized by the institutionalized racism and sexism of the academy, have never been fully convinced that it is advantageous for them to declare publicly a commitment to feminist politics, either for reasons of career mobility or personal well-being. (p.124)

This idea that women lack authority to discuss feminist ideals with the public is something that lies at the heart of unequal power relations. Allan Johnson states that,

Since women are culturally disidentified with power, it's harder for them to exercise it in any situation. When women do find ways to be powerful in relation to men, it's usually in spite of the male dominated character of patriarchal systems as a whole (2006, p. 91 emphasis in original).

It is because of the persistence of this cultural patriarchal phenomenon of women lacking authority and power that feminist movement continues to be relevant. The feminists interviewed in my research are all attempting to disrupt the usual power and control paradigm of Western society. They are holding strong to convictions that are often looked at with contempt and negativity. However, the participants I interviewed have a great deal of power and are attempting to create their own authority.

\section{Alternative Masculinities}

Adhering to Butler's theory of gender as performance, which states that the socially constructed binary system creates gender performativity; coercing individuals to behave, think, and dress in masculine or feminine ways (1990), stringent gender categories that enforce subordination, the binary system and privilege, limit emotional affects of individuals. As was noted by Connell \& Messerschmidt (2005), hegemonic masculinity acts as a barrier to participation in feminist movement, by breaking these barriers there remain possibilities for alternative forms of masculinity (Stoltenberg, 1989). 
In order for men to be able to participate in feminist movement, they must unlearn some of the main facets of hegemonic masculinity (Flood, 2011). What was made clear through my interviews with the men in this study was that they were all practicing subversive masculinities. Due to the patriarchal constraints on the behaviour of men and the performance of masculinity, these men simply by talking about feminism, by laying claim to the label feminist, are transgressing their gender roles

I believe, and many authors and researchers agree (Anderson, 2009; Moffatt, 2012), that if society were to open up the rigid definitions of masculinity, many more men would be free to engage in feminist theory. I believe there are a lot of men, and women, who would be active in feminist thought if more opportunities existed for alternative masculinities and alternative femininities and trans* identities. This belief that for men, they must remain in an emotionless "box" (Tarrant, 2009), one that forces compulsory competitiveness, aggression and homohysteria (Anderson, 2009), acts as a barrier to men engaging in feminist thought and action. Scholars have been making great gains in analysing new possibilities for alternative masculinities, with Eric Anderson's 'inclusive masculinity theory' (2009), being for me, the most intriguing. He argues that Western society is on the verge of a cultural shift, where homohysteria is diminishing, and inclusive masculinities can exist (Anderson, 2009).

The belief that men benefit from patriarchy, is nothing new, however scholars are increasingly asserting that men also suffer under patriarchy,

Men still rule, and orthodox masculinity still exists. Men wedded to this framework are more apt to suffer, and more apt to cause social unrest than men who are not. Accordingly, I have previously described the construction of orthodox masculinity as a public health crisis (2005), pointing that masculinity both causes health problems and influences men to avoid seeking help for medical 
issues - all in order to gain and retain their esteemed orthodox masculinity. (Anderson, 2009, p. 46)

Anderson's hypothesis maintains that as North American society shifts culturally to a place where inclusive masculinity is possible, men who do transgress the hegemonic ideal experience less discomfort and negativity than they have in the past (2009). Therefore, Anderson is opening up possibilities for a paradigm shift that would invite men to practice inclusive masculinities and perhaps engage in feminist practice at the same time. Connell and Messerchmidt (2005) provide a promising conclusion, by stating that hegemony is something that is increasingly necessary to resist, and that the new global realities are creating even more spaces for men to resist the hegemonic masculinities together

\section{Reconceptualising the Term Feminist}

As is evidenced in my research, most of the participants would like to reconsider or expand on the term feminist. Due to a historical legacy of exclusion, racism and classism, feminism is often seen in a negative light even to those who hold feminist beliefs (Bashir, et al., 2013). Many theorists call for a fluidity and diversity to the term feminist (Hudson, 1985; Lister, 2005; Lutz, Vivar, \& Supik, 2011). Ahmed urges the movement to base solidarity across difference, rather than on "common oppressions" (2004). She maintains that a stronger movement can be created if identification, motivation and participation were based on "Speaking for something, rather than for someone," (Ahmed, 2004, p. 189). I believe that if, as a movement, there was an effort to state that feminism is based on intersectionality and anti-oppression frameworks, more people would feel comfortable calling themselves feminists. Many studies have been done which conclude that people agree with statements based on feminist politics, before 
attaching the term feminism to the statements, however once the word is attached, there is a marked decline in agreement (Wiley, et al., 2012).

Examining the restrictive barriers of the label feminist, intersectional and trans* feminist writers have noted that an expansion of the term is necessary and urgent (Feinberg, 1996; Miles, 1996; Scott-Dixon, 2006; hooks, 1984). The fact that a large percentage of the population, regardless of gender identity, believe in the main points of feminism; however reject the term, shows that a change is necessary (Bashir, et al., 2013; Erchull, Liss, Wilson, Bateman, Peterson, \& Sanchez, 2009; Feinberg, 1996; Wiley, Srinivasan, Finke, Firnhaber, \& Shilinksky, 2012). If people will only adopt social identities if they are positively perceived in the dominant culture (Aronson, 2003), then feminists and those who support the feminist movement must begin to reimagine a new feminist discourse. In order to struggle against a perceived negative stereotype, feminists and theorists must challenge the dominant discourse. Krista Hunt and Christine Saulnier (2001) suggest creating new discourses of feminist theory and practice, “...by challenging the boundaries created by dominant discourses, thus opening space for alternative conceptualizations of society's problems and solutions" (p.14). Their recipe for a more nuanced feminism requires,

Fighting against the multiplicity of complex factors (interests, ideas, and institutions) that work against social justice, means feminism must be flexible, plural and most importantly strategic if it is to avoid becoming an elite inwardlooking activity. (Hunt \& Saulnier, 2001, p. 10)

Feminist movement must focus on the "...multiplicity and interconnectedness of political power relations which work to oppress different groups of women" (Hunt \& Saulnier, 2001, p. 11). If feminist movement is to progress positively toward greater social justice, 
research into creating new discourses and new theories of gender inclusion, and theories that adequately reflect intersecting oppressions are needed now more than ever.

In the following excerpt, Eadlyn, describes their intersectional approach to feminism,

...acknowledging [...] capitalism and all those kinds of, that political economy piece that really plays a huge part in the way that kind of plays out ... for me its just kind of looking at an intersectional and anti-oppression approach, to like gender, race, using a gender based analysis and equity seeking issues, and it's really bringing like gender back into... all of the work that we do.

Many of the participants spoke about the restrictive nature of the term feminist, most of the women hesitated when agreeing that they were feminists. If feminist movement is to progress and grow in Ottawa, I believe that there needs to be a shift in thinking about what the term feminist means. From my research, the term feminist is not only something that white, middle-class women call themselves, but something that women of colour, trans*folk, and men call themselves as well. In thinking about the diversity of feminists and activism, I took a look back at a book from my first year undergraduate women's studies course. The book The Fire This Time, Young Activists and The New Feminism, contains a plethora of complex and diverse narratives from feminists all across the United States. With issues ranging from the media, culture, politics, globalization, body shaming and zines, this collection of essays is attempting to reframe the term feminist. In the introduction, editors Vivien Labaton and Dawn Lundy Martin claim

If we were to build a feminist movement made up primarily of "feminists" between the ages of eighteen and thirty-five, we would find no single ideological framework from which their activisms emerge. In fact, if we asked ten young feminists what feminism meant, we'd likely get ten different answers. (2004, p. xxxi) 
Throughout my research, participants have created their own discourse of feminisms; they have dismantled dominant paradigms and gender roles. Feminists cannot, as Audre Lorde (2003) says, 'use the masters tools to dismantle the masters house,' which means feminists must celebrate difference, practice inclusionary processes and not create hierarchies of oppression. Processes, which deny entry based on essentialized characteristics such as gender or race, perpetuate the oppressive notions of 'naturalness' and 'biological determinism' (Collins, 2010). If feminist movement is truly to expand its reach and be inclusive to all individuals, gender and racial policing must end. Looking forward, I take heed from a passage that Brandy articulated at the end of our interview,

The one thing that we can get ourselves really trapped in, is not recognizing that feminism is a movement. And a movement that could have started in one place, with one idea, but that it needs to change and adapt, so that one idea can change and adapt to be inclusive. So that what we think of today as you know the feminist movement, can't be what it used to be 30 years ago. But then it can't be so different and so changed, because we're not so different from 30 years ago, we just have a broader perspective on what oppression looks like.

\subsection{Implications for Structural Social Work}

The purpose of my research was to uncover the tensions that exist in feminist movement in Ottawa. If social change truly is one of the main tenets of structural social work, then diverse individuals must participate in the emancipation of all who are oppressed. For feminist movement to acknowledge and advance from the racist and classist implications of the past, greater inclusion is necessary. A movement that focuses on intersectionality and working with difference would include those who are both privileged and oppressed through gender regulation. In order to act in solidarity with one another in a movement to end sexist oppression, the first task would be to understand what barriers exist for the participation of all genders. If men are the single highest 
perpetrators of violence against women (Statistics Canada, 2013a), then their inclusion in feminist movement is both necessary and threatening.

My research made contributions to theories of gendered social movement participation and theories of gender identity and feminism. By asking the same questions to all eight participants, I explored the views and experiences of different genders in the movement. My findings indicate that there remains a gendered discourse of power and control within the movement, indicating that men wishing to join the movement are often met with resistance. This resistance stems from a discourse of pain and anger, and a feeling that men need to work on themselves prior to engaging in feminist movement. This contributes an understanding of the complexities of inner group dynamics, and the gendered motivations for social movement participation. In addition, my research provides insight into how collective identity and personal identity are connected, and created through participation in social movements.

The implications that my research has for structural social work practice and education stem from the notion that feminist counselling skills and consciousness raising are important social practices (Lundy, 2004). Social work scholarship and education empowers students and workers to gain a deeper understanding of the oppressive structures that influence their lives and the lives of those whom they work (Carniol, 1992). Through this acknowledgement of oppressive structures, social workers work to dismantle these structures, much like the aims of feminist movement. As violence against women is so pervasive, many social workers will work with survivors and perpetrators of violence. Through feminist counselling skills and feminist theory, a feminist approach to supporting survivors of violence is possible. A feminist understanding of violence 
suggests that the social structures of patriarchy enable heterosexual men to use violence, as a way of asserting their power and control over their heterosexual female partners, acquaintances, strangers, friends, spouses and so on (Johnson \& Dawson, 2011). This approach to support enables survivors to view their situation from a personal as well as

political standpoint, it also leaves room for empowerment, while denouncing victim blaming. These linkages between feminism and social work allow for the possibility of increasing diversity within both fields of study and work.

\subsection{Limitations}

As is noted in many studies my results are not generalizable, a significant limitation was that of sample size of eight participants. Thus the findings only speak to this small group of participants who were predominantly white, privileged, able-bodied, and heteronormative. The participants were more homogenous than I would have liked, with only two women of colour and one white genderqueer participant. All but two participants were currently working or studying at universities, which resulted in little diversity when it came to education level. Greater diversity of race, class, ability, education level and gender would have increased generalizability of my research findings. It would have also provided a more rich and nuanced understanding of the Ottawa feminist movement.

Another limitation is that two of the interviews were lost due to technical difficulties. These two interviews potentially could have provided greater knowledge for my research. That being said, all of the eight transcripts were far longer and provided much greater information than could have been covered in this paper. 
My own personal biases also influenced my research. As I am attempting to "analyse across difference," being a white able-bodied privileged cis-woman, I can only attempt to critically understand the lived experiences of women of colour, gender diverse people and men. My analyses of these eight transcripts are based on my readings of black feminist thought (Collins, 2000; Lorde, 1984/2007; hooks, 1984), transfeminist writers (Doan, 2010; Feinberg, 1996; Hines, 2007; Scott-Dixon, 2006), and masculinity theorists (Anderson, 2009; Flood, 2011; Moffatt, 2012). My analysis is based on my personal experiences as a white woman, having not experienced racism or exclusion from feminist movement. Therefore, my analysis is theoretically biased, and not grounded in personal experiences. This leads to analysis of situations that I have never personally experienced, I am relying on academic theorists and the participants to gain a deeper analysis of the transcripts. This has the potential to lead me to analyse the experiences in completely different ways than how the participants perceive their situations.

\subsection{Further Research}

This research lends itself to many other questions that could be asked of social work and of feminist movement. My first recommendation for further research would be a study based on race relations within the movement. My research does not focus enough on race, ignoring a significant dynamic within feminist movement. Therefore a study that focuses on the intersections of race and gender and how race is performed in feminist movement is essential. Interviewing women of colour about their experiences with white women in the movement, and vice versa, would contribute tremendously to the study of social movement participation. 
My second recommendation for further research includes studying social workers. Interviewing social workers that live in Ottawa, and asking them about their feminist identification, or lack thereof, would contribute to social work research and feminism in an interesting manner. Examining the diverse beliefs of social workers could provide insight into the profession in Ottawa. This could contribute to a dialogue about the multitude of reasons why individuals decide or end up in the field of social work. It could also add nuance to the field of feminist counselling.

\subsection{Conclusion}

As was stated in the introduction to this thesis, I am curious about the reasons, motivations and pathways to feminist identification. As Simone DeBeauvoir stated, "One is not born a woman, but rather becomes, a woman" $(1989$, p. 267). Through social constructions, limitations and pressures, people shift and meld into specific gender representations. Simone DeBeauvoir does not believe in the rigidity or stability of gender, but in the "performance" of gender. This argument has a number of links to Judith Butler's thesis that, “...gender is instituted through the stylization of the body and, hence, must be understood as the mundane way in which bodily gestures, movements, and enactments of various kinds constitute the illusion of an abiding gendered self," (1988, p. 519). If gender is malleable and recreated with each behaviour, then, as my research has shown, men can unlearn their hegemonic actions and join in solidarity with marginalized populations to fight oppression.

Based on my research, resistance to patriarchy must include a resistance to hegemonic masculinity. In order to increase participation of those privileged by sexism in feminist movement, alternative theories of identities, including masculinity must be 
adopted. These more inclusive identities can provide space for individual and group empowerment and consciousness raising (Anderson, 2009; Moffatt, 2012). The development of positive collective group identities, less gender policing, and an expansion of the term feminist, could prove to be beneficial to a large number of people. Solidarity across differences, and a recognition that feminist movement can benefit all genders could provide the deconstruction necessary to dismantle the oppressive structures of society. In the words of my late father Peter Leonard,

Such beliefs in interdependence, of course, lie as a foundation in the building of collectivity and collective resistance. It is the basis for the solidarity that is necessary to face the project of global market capitalism and its link to historic structures of patriarchy and colonialism. (2001) 


\section{Appendices}

\section{Appendix A: Interview Guide}

\section{Feminisms}

For all participants:
a. Can you tell me a story about what it means to be a feminist?
b. Can you tell me what "feminist practice" means to you?
c. Do you consider yourself to be a feminist? Please expand.
d. Can anybody be a feminist? Please explain this.
e. What does gender mean to you?
f. Does anyone have the right to lead feminist organizing?

For women:
a. What do you think of men engaging in feminist practice?
b. What do you think of men joining feminist marches and protests?
c. What do you think about transmen and transwomen being part of feminist movement?

\section{For Transmen and transwomen:}

a. How do you feel participating in feminist movement?

b. How do you feel about men and women "doing feminism(s)"

\section{Personal Experiences:}

a. Can you tell me a story about how your feminist stance is viewed by your friends?

b. Do you have and would you like to share any stories about your family's perspectives on your feminist involvement?

c. Do you have and would you like to share any stories about your colleague's or peers view of your feminist standpoint?

d. Does your job require you to "do feminism" or to be "involved in the movement"? Please explain. 


\section{Within the community:}

\section{For men:}

a. Can you tell me a story about your work in feminist movement, specifically working with women?

b. Do you have and can you share with me any stories about working with men in the movement?

c. Have you ever experienced any backlash or feelings of discrimination from within the feminist movement? What was that like? Can you tell me about these experiences?

d. Have you ever seen or heard backlash or feelings of discrimination from within the feminist movement directed to other people? What was that like? Can you tell me about these experiences?

e. Have you ever experienced negative feelings or misgivings from women within the movement? What was that like?

f. Can you tell me a story about working with transmen or transwomen in the movement?

g. Can you tell me a story about your experiences of solidarity within the feminist movement?

\section{For women:}

a. Can you tell me a story about working with men in the movement?

b. Have you ever experienced any backlash or feelings of discrimination from within the feminist movement? What was that like? Can you tell me about these experiences?

c. Have you ever seen or heard backlash or feelings of discrimination from within the feminist movement directed to other people? What was that like? Can you tell me about these experiences?

d. Have you ever experienced negative feelings or misgivings from cismen within the movement? What was that like? Can you tell me about these experiences?

e. Can you tell me a story about working with transmen or transwomen in the movement?

f. Can you tell me a story about experiences of solidarity within the feminist movement? 


\section{For Transmen and transwomen:}

a. Can you tell me a story about experiences working with men in the movement?

b. Can you tell me a story about experiences working with women in the movement?

g. Have you every experienced any backlash or feelings of discrimination from within the feminist movement? What was that like? Can you tell me a story about these experiences?

h. Have you ever experienced negative feelings or misgivings from men within the movement? What was that like? Can you tell me a story about these experiences?

c. Have you ever experienced negative feelings or misgivings from women within the movement?

i. Do you have any stories that you would like to share with me about working with transmen and or transwomen in the movement? What was that like? Can you tell me about these experiences?

d. Can you tell me a story about experiences of solidarity within the feminist movement?

\section{Future}

a. What are your future hopes for feminism?

b. Where do you see feminism going?

c. Is there anything that you would like to see differently within the movement? 


\section{Appendix B: Project Description Letter}

\section{Carleton}

\section{Participation and Feminist Discourse}

\section{What is this project about?}

The purpose of this research is to inquire about the experiences of people who work with and engage in 'feminism.' I am particularly interested in the experiences of women and men working together as activists, or working through feminist thought. The study aims at understanding the experiences and meaning that people attach to being part of the "women's movement" and/or being a 'feminist.' One does not need to label themselves feminists to actually be working to end sexist oppression. Therefore, I will be interviewing a diverse group of people who are engaged in ending gender discrimination through a variety of approaches, activities, and social actions. All people on the gender continuum are invited and encouraged to participate.

\section{Who is running this project?}

A Masters of Social Work student under supervision from the Carleton University School of Social Work.

\section{Who is the researcher?}

The research is being conducted by Polly Leonard BA (Hons), BSW (Hons) MSW Candidate. The researcher is supervised by Sarah Todd from the Faculty of Social Work.

\section{What do I have to do?}

I am asking participants to contact me, via email (participationresearch613@gmail.com), in order to set up a time and place that would be preferable to us both. I will be conducting open-ended qualitative interviews, more like guided discussions, that could last between 60 and 90 minutes. The interview will take place in a neutral location decided by the participant and the researcher. You will be asked about your community involvement and your feminist perspectives. The interview will be done face to face with an audio recorder and I will be writing a few notes. You will not be asked any information about your employment that would link back to your employer. Or about your role within a certain agency or organization, if an agencies name is mentioned I will delete it from the transcript. You may have up until March $31^{\text {st }} 2013$ to withdraw from the study completely, or to add any other information that you would like to the study. 


\section{What will happen to this information?}

This information will be used to understand the deeper experiences of people who are involved with feminist movement, or who are active in working to end sexist oppression. I will share the results through my MSW thesis. If you would like a copy of the study, you may contact me and we can arrange this.

\section{What are the risks?}

Talking honestly about your life and experiences may make you feel a range of emotions. However, you do not have to answer all the questions, and you may conclude the interview at any time. Your confidentiality will be guaranteed. Your personal information will not be tied to your interview. The name of your employer will never be asked, and therefore the interview will not be traced back to your employment.

The interview could cause emotional discomfort, however the participants will easily handle the impact.

\section{Will it be private?}

Yes. Your name will not be connected with the information that you provide. There will be no way of connecting you with the information you provide. This is private information and only the researcher and the research supervisor will be able to see your finished transcribed interview.

\section{How long will you keep my interview information?}

All information will be responsibly stored in an encrypted USB, stored under lock and key. The data will be kept indefinitely.

\section{Do I have to do the interview?}

No, you do not have to complete the interview. You can stop at any time. If there are questions you do not want to answer, we can simply move to the next section of the interview. Upon completion of the interview you may decide to withdraw from the research, at this time I will delete the audio recording of the interview, and shred the written notes.

\section{Who do I contact if I have questions about this research?}

If you have any questions about the interview, the research or your ethical rights you can contact the appropriate people listed below.

This project was reviewed and received ethics clearance by the Carleton University Research Ethics Board.

\section{The Researcher:}

Polly Leonard participationresearch613@gmail.com 
Carleton University Research Ethics Board

Prof Antonia Gualtieri, Chair

Carleton University

1125 Colonel By Drive

Ottawa, On, K1S 5B6

6135202517

ethics@carleton.ca

\section{Research Supervisor}

Sarah Todd

School of Social Work

1125 Colonel By Drive

Ottawa, On, K1S 5B6

6135205601 ex. 4498

Sarah_todd@carleton.ca 


\section{Appendix C: Informed Consent Form}

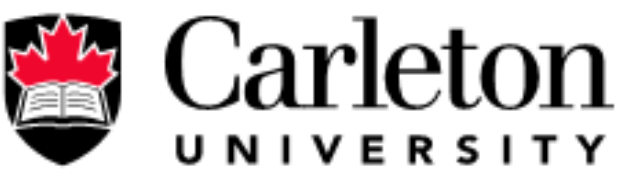

School of Social Work c/o Sarah Todd

1125 Colonel By Drive

Ottawa, ON Canada K1S 5B6

Sarah_todd@carleton.ca

Tel: (613) 520-2600 ex. 4498

Researcher:

Polly Leonard

participationresearch613@gmail.com

\section{Informed Consent Form}

\section{Participation and Feminist Discourse}

Thank you for agreeing to participate in this research study. I am Polly Leonard, and I am a Masters of Social Work student, this research is part of my MSW thesis. I will be conducting research to inquire about the experiences of people who work with and engage in 'feminism.' I am particularly interested in the experiences of women and men working together as activists, or working through feminist thought. The study aims at understanding the experiences and meaning that people attach to being part of the "women's movement" and/or being a 'feminist.' One does not need to label themselves feminists to actually be working to end sexist oppression. Therefore, I will be interviewing a diverse group of people who are engaged in ending gender discrimination through a variety of approaches, activities, and social actions. All people on the gender continuum are invited and encouraged to participate.

Participation in this interview is completely voluntary, and you may decline to answer any questions if you wish. You may also end the interview at any time. If you do decide to withdraw I will delete the audio recording and shred my written notes. By agreeing to this interview, you are also agreeing to have your voice recorded. This is done to ensure 
that I collect accurate data. You may also withdraw from the research study at any time, up until March $31^{\text {st }}$ 2013. If upon completion of the interview, you would like to withdraw please email me and I will delete the transcript and shred my written notes.

The interview should take approximately $60-90$ minutes, however if you would like to expand on any topic or bring up your own topics, that is completely allowable. All the information will be kept confidential. I will be keeping the data in a secure place, an encrypted USB in a locked file drawer. Only the research supervisor and I will have access to the information. Your anonymity will be secured, as no personal information will be attached to the interview. I will not be asking any information about your employment that would link back to your employer. Or about your role within a certain agency or organization, if an agencies name is mentioned I will delete it from the transcript.

\section{By agreeing to this interview, you are agreeing that:}

- You understand the main purpose of this interview.

- You understand that you might have a range of emotions from speaking about your community involvement and feminist perspectives.

- You understand that there may be possible benefits of completing this study, such as gaining a deeper understanding about yourself and your involvement in feminist movement. As well as having the opportunity to express your opinions about your involvement.

- You understand that you have the right not to participate in the study, and you can withdraw at any time. Up until March $31^{\text {st }} 2013$.

- You understand that you may refuse to participate without consequence. You are allowed to not answer questions for whatever reason.

- You have been told that your individual information will not be identified and will remain confidential.

- You are aware that you can choose to contact Polly Leonard now and in the future to ask any questions about the study. 
I have read the Project Description and the above informed consent form, and, with the understanding that I can withdraw at any time (until March $31^{\text {st }}$ 2013), and for whatever reason, I consent to participate in today's interview.

Participant's signature

Date

Interviewer's signature 


\section{Appendix D: Invitation to Promote}

\section{Carleton}

School of Social Work c/o Sarah Todd

1125 Colonel By Drive

Ottawa, ON Canada K1S 5B6

Sarah_todd@carleton.ca

Tel: (613) 520-2600 ex. 4498

Researcher:

Polly Leonard

participationresearch613@gmail.com

\section{(INSERT ADDRESS)}

\section{DATE TBA}

\section{To Whom It May Concern:}

My name is Polly Leonard, and I am a Masters of Social Work Student at the Carleton University School of Social Work. I will be conducting research to inquire about the experiences of people who work with and engage in 'feminism.' I am particularly interested in the experiences of women and men working together as activists, or working through feminist thought. The study aims at understanding the experiences and meaning that people attach to being part of the "feminist movement" and/or being a 'feminist.' One does not need to label themselves feminists to actually be working to end sexist oppression. Therefore, I will be interviewing a diverse group of people who are engaged in ending gender discrimination through a variety of approaches, activities, and social actions. All people on the gender continuum are invited and encouraged to participate.

I am the sole researcher on this project. Sarah Todd from the Faculty of Social Work is my research supervisor.

During this research process, I will develop, conduct and analyse qualitative interviews with approximately 8-10 participants. In order to gain a diverse population, and to gain deeper insight into the work and experiences of working to end sexist oppression, I am reaching out to people who self identify as feminists and people who work in social justice groups, non-profit agencies and universities. It is for this reason that I am writing to you today.

I am asking for permission from the (insert name of institution) to allow me to promote, through hard copy posters sent to you, my research study. I would also like permission to 
provide you with an electronic copy of the poster and letter of information that you can promote through your email list serve.

All research participants must be over 18, and all interviews be made anonymous by removing all identifying information. I will not be asking any information about your employment that would link back to your employer. Or about your role within a certain agency or organization, if an agencies name is mentioned I will delete it from the transcript. I will guarantee anonymity. I am looking for participants who can participate in interviews between January and March 2013.

In closing, I am looking for your permission to advertise for research participants through hardcopy posters and a digital poster. If permission is granted, I will send you the posters and Project Description of the research project to you.

The research study has been reviewed and cleared by the Carleton University Research Ethics Board (613-520-2517 or ethics@carleton.ca).

If you have further questions or wish to acquire additional information about this project, please feel free to contact the researcher Polly Leonard at

participationresearch613@gmail.com

If you have any concerns, feel free to contact Professor Sarah Todd at 613-520-2600 ex. 4498

Thank you in advance for your time and interest.

Yours respectively,

Polly Leonard (BA Hons, BSW Hons, MSW Candidate)

Research Supervisor: Sarah Todd (Ed.D) 
Appendix E: Poster

See next page 


\section{PARTICIPANTS NEEDED FOR RESEARCH IN}

\section{"Feminist Discourse and Cismale Participation"}

Are you active in your community, working to end sexist oppression? Are you a feminist? Or do you work from a feminist perspective?

I am looking for volunteers (over 18, who identify anywhere on the gender continuum) to take part in a study of experiences and meanings of participation within the "women's movement."

As a participant in this study, you would be asked to participate in a 60-90 minute openended interview.

For more information about this study,

or to volunteer for this study, please contact: Polly Leonard Polly Leonard
This project was reviewed and received ethics clearance until May $31^{\text {st }} 2013$, by the Carleton University Research Ethics Board

1301 Dunton Tower 1125 Colonel By Drive Ottawa, ON, Canada, K1S 5B6 Tel: (613) 520-2600 ext. 3591

Email: curo@carleton.ca

\section{feministresearch613@gmail.com}




\section{Appendix F: Analytical Tool Kit}

Theme 1: Language and Context

1) The Deixis Tool.

For any communication, ask how deictics are being used to tie what is said to context and to make assumptions about what listeners already know or can figure out. Consider uses of the definite article in the same way. Also ask what deictic like properties any regular words are taking on in context, that is, what aspects of their specific meanings need to be filled in from context. (Gee, 2011, p. 195)

\section{2) The Fill in Tool.}

For any communication, ask: Based on what was said and the context in which it was said, what needs to be filled in here to achieve clarity? What is not being said overtly, but is still assumed to be known or inferable? What knowledge, assumptions and inferences do listeners have to bring to bear in order for this communication to be clear and understandable and received in the way the speaker intended? (Gee, 2011, p. 195)

\section{3) The Making Strange Tool.}

For any communication, try to act as if you are an "outsider." Ask yourself: What would someone (perhaps even a Martian) find strange here (unclear, confusing, worth questioning) if that person did not share the knowledge and assumptions, and make the inferences, that render the communication so natural and taken-forgranted by insiders? (Gee, 2011, p. 195)

Theme 2: Saying, Doing, and Designing

\section{4) The Vocabulary Tool.}

For any English communication, ask what sorts of words are being used in terms of whether the communication uses preponderance of Germanic words or of Latinate words. How is this distribution of words types functioning to mark this communication in terms of style (register, social language)? How does it contribute to the purposes of communicating? (Gee, 2011, p. 196) 
Theme 3: Building Things in The World

5) The Identities Building Tool.

For any communication, ask what socially recognizable identity or identities the speaker is trying to enact or to get others to recognize. Ask also how the speaker's language treats other people's identities, what sorts of identities the speaker recognizes for others in relationship to his or her own. Ask, too, how the speaking is positioning others, what identities the speaker is "inviting" them to take up. (Gee, 2011, p. 199)

Theme 4: Theoretical Tools

6) The Intertextuality Tool.

For any communication, ask how words and grammatical structures (e.g., direct or indirect quotation) are used to quote, refer to, or allude to other "texts" (that is, what others have said or written) or other styles of language (social languages). Does intertextuality go so far as to be an example of mixing or switching between voices or styles of language (social languages)? (Gee, 2011, p. 201) 


\section{Works Cited}

Adichie, C. N. (2009, July). The Danger of the Single Story. (C. N. Adichie, Performer) TEDGlobal.

Agyeman, G. S. (2008). White Researcher- Black Subjects: Exploring the Challenges of Researching the Marginalised and 'Invisible'. The Electronic Journal of Business Research Methods , 6 (1), 77-84.

Ahmed, S. (2004). The Cultural Politics of Emotion. Edinburgh: Edinburgh University Press.

Alcoff, L. (1988). Cultural Feminism versus Post-Structuralism: The Identity Crisis in Feminist Theory. Signs, 13 (3), 405-436.

Alinsky, S. D. (1971). Rules for Radicals, A Pragmatic Primer for Realistic Radicals. New York: Vintage Books, A Division of Random House.

Amnesty International . (2004). Canada Stolen Sisters, A Human Rights Response to Discrimination and Violence against Indigenous Women in Canada. Report, Amnesty International.

Andersen, M. (2010). The Nexus of Race and Gender; Parallels, Linkages and Divergences in Race and Gender Studies. In P. H. Collins, \& J. Solomos (Eds.), The SAGE Handbook of Race and Ethnic Studies (pp. 166-187).

Anderson, E. (2009). Inclusive Masculinity, The Changing Nature of Masculinities. New York: Routledge.

Anthias, F., \& Yuval-Davis, N. (1992). The concept of 'race' and the racialization of social divisions. In Racialized Boundaries: Race, Nation, Gender, Colour and Class in the Antiracist Struggle (pp. 1-20). London: Routledge.

Aronson, P. (2003). Feminists or "Postfeminists"? Young Women's Attitudes toward Feminism and Gender Relations. Gender \& Society , 17 (6), 903-922.

Aylward, C. (1999). Chapter 1, Canadian Critical Race Theory. In Canadian critical race theory: Racism and the law (pp. 1-19). Halifax, NS: Fernwood Publishing Co. Inc. .

Baines, D. (Ed.). (2011). Doing Anti-Oppressive Practice: Social Justice Social Work (2nd Edition ed.). Black Point, Nova Scotia: Fernwood Publishing.

Banks, O. (1986). Becoming a Feminist: The Social Origins of 'First Wave' Feminism. Brighton: Wheatsheaf Books.

Bashir, N. Y., Lockwood, P., Chasteen, A. L., Nadolny, D., \& Noyes, I. (2013, August). The ironic impact of activists: Negative stereotypes reduce social change influence. European Journal of Social Psychology , 1-13. 
Blair, M. E. (2009). "A Dynamic Force in Our Community": Women's Clubs and SecondWave Feminism at the Grassroots. Frontiers: A Journal of Women Studies , 30 (3), 3051.

Bordt, R. L. (1997). How Alternative Ideas Become Institutions: The Case of Feminist Collectives. Nonprofit and Voluntary Sector Quarterly , 26 (2), 132-155.

Brown, L., \& Strega, S. (Eds.). (2005). Research As Resistance: Critical, Indigenous, \& AntiOppressive Approaches. Toronto: Canadian Scholars' Press/Women's Press.

Buchwald, E., Fletcher, P. R., \& Roth, M. (2005). Transforming a rape culture (2nd Edition ed.). Washington: Milkweed Editions.

Bunch, C. (1987). Passionate Politics, Essays 1968-1986 Feminist Theory in Action. New York: St. Martin's Press.

Butler, J. (1988). Performative Acts and Gender Constitution: An Essay in Phenomenology and Feminist Theory. Theatre Journal , 40 (4), 519-531.

Butler, J. (1990). Gender Trouble : Feminism and the Subversion of Identity. New York : Routledge.

Butler, J. (2010). Performativ Acts and Gender Constitution: An Essay in Phenomenology and Feminist Theory. In C. McCann, \& S.-K. Kim (Eds.), Feminist Theory Reader (pp. 419-430). London: Routledge.

Cameron, D. (1990). Introduction: why is language a feminist issue? In D. Cameron (Ed.), The Feminist Critique of Language: A reader (pp. 1-28). London: Routledge.

Carmen. (2014, January 27). \#ProTransProChoice: Launching A New Reproductive Rights Movement. Retrieved June 25, 2014 from Autostraddle: http://www.autostraddle.com/protransprochoice-launching-a-new-reproductiverights-movement-219937/.

Carniol, B. (1992). Structural Social Work: Maurice Moreau's Challenge to Social Work Practice. Journal of Progressive Human Services , 3 (1), 1-20.

Casey, E., \& Smith, T. (2010). "How Can I Not?": Men's Pathways to Involvement in AntiViolence Against Women Work. Violence Against Women , 18 (8), 953-973.

Casey, E., Carlson, J., Fraguela-Rios, C., Kimball, E., Neugut, T., Tolman, R., et al. (2013). Context, Challenges, and Tensions in Global Efforts to Engage Men in the Prevention of Violence against Women: An Ecological Analysis. Men and Masculinities , 16 (2), 228-251.

Collins, P. H. (2000). Black Feminist Thought: Knowledge, Consciousness and the Politics of Empowerment (2nd Edition ed.). New York: Routledge.

Collins, P. H. (2010). Defining Black Feminist Thought. In C. McCann, \& S.-k. Kim (Eds.), Feminist Theory Reader: Local and Global Persepctives (pp. 341-356). 
Combahee River Collective. (1978). A Black Feminist Statement. In Z. Eisentein (Ed.), Capitalist Patriarchy and the Case for Socialist Feminism (pp. 210-218). New York: Monthly Review Press.

Connell, R. (2010). Bio. Retrieved October 4, 2012 from Raewyn Connell: http://www.raewynconnell.net/p/about-raewyn_20html.

Connell, R. W., \& Messerschmidt, J. W. (2005). Hegemonic Masculinity: Rethinking the Concept. Gender \& Society , 19, 829-859.

Cornwall, A., \& Lindisfarne, N. (Eds.). (1994). Dislocating Masculinity: Comparative Ethnographies. London : Routledge.

Cudd, E. A. (2006). Analyzing Oppression. New York : Oxford University Press.

DeBeauvoir, S. (1989). The Second Sex. (H. Parshley, Ed., \& H. Parshley, Trans.) New York: Vintage Books, Random House Inc.

DeKeseredy, W. S., \& Schwartz, M. D. (1998). Woman Abuse on Campus: Results From the Canadian National Survey. Thousand Oaks: SAGE Publications.

Delph-Janiurek, T. (2000). 'Walking the walk and talking the talk': bodies, conversation, gender and power in higher education in England. Social \& Cultural Geography , 1 (1), 83-100.

Dietz, M. G. (2003). Current Controversies in Feminist Thought. Annual Review of Political Science, 6, 399-431.

Digby, T. (Ed.). (1998). Men Doing Feminism. New York : Routledge.

DiQuinzio, P. (1993). Exclusion and Essentialism in Feminist Theory: The Problem of Mothering. Hypatia , 8 (3), 1-21.

Doan, P. L. (2010). The tyranny of gendered spaces - reflections from beyond the gender dichotomy. Gender, Place and Culture , 17 (5), 635-654.

Dominelli, L., \& McLeod, E. (1989). Feminist Social Work. London: Macmillan Education Ltd.

Downing, N. E., \& Roush, K. L. (1985). From Passive Acceptance to Active Commitment: A Model of Feminist Identity Development for Women. The Counseling Pscyhologist, $13(4), 695-709$.

Eichler, M. A. (2010). Joining the Family: Experiences of Being and Becoming Ally Activists of LGBTQ People. Journal of Transformative Education , 8 (2), 89-102.

Enke, A. (2007). Finding the Movement, Sexuality, Contested Space, and Feminist Activism. Durham: Duke University Press.

Enns, C. Z., \& Fischer, A. R. (2012). On the Complexity of Multiple Feminist Identities. The Counseling Psychologist, 40 (8), 1149-1163. 
Erchull, M. J., Liss, M., Wilson, K. A., Bateman, L., Peterson, A., \& Sanchez, C. E. (2009). The Feminist Identity Development Model: Relevant for Young Women Today? Sex Roles, $60,832-842$.

Fairclough, N. (1995). Critical Discourse Analysis: The Critical Study of Language. London: Longman.

Fairclough, N. (2003). Analysing Discourse; Textual analysis for social research . London: Routledge.

Feinberg, L. (1996). Transgender Warriors: Making History from Joan of Arc to Dennis Rodman. Boston: Beacon Press.

Fletcher, P. R. (2010). Dismantling Rape Culture around the World: A Social Justice Imperative. Forum on Public Policy, 1-14.

Flood, M. (2011). Men as Students and Teachers of Feminist Scholarship. Men and Masculinities , 14 (2), 135-154.

Fonow, M. M., \& Cook, J. A. (1991). Back to the Future: A Look at the Second Wave of Feminist Epistemology and Methodology. In M. M. Fonow, \& J. A. Cook (Eds.), Beyond Methodology: Feminist Scholarship as Lived Research (pp. 1-16). Bloomington: Indiana University Press.

Foucault, M. (1990). The History of Sexuality: Volume I: An Introduction (1978 ed.). New York: VIntage Books.

Freedman, J. (2012). Engaging men in the fight against gender violence: case studies from Africa. New York: Palgrave Macmillan.

Freire, P. (2010). Pedagogy of the Oppressed (30th Anniversary Edition ed.). (M. B. Ramos, Trans.) New York: Continuum.

Friedan, B. (1963). The Feminine Mystique. New York: Dell Publishing Co., Inc. .

Gee, J. P. (2011). How to do Discourse Analysis; A Toolkit. Oxon: Routledge.

Goodwin, J., Jasper, J. M., \& Polletta, F. (2001). Introduction: Why Emotions Matter. In Passionate Politics, Emotions and Social Movements (pp. 1-24). Chicago: The University of Chicago Press.

Gorelick, S. (1991). Contradictions of Feminist Methodology. Gender \& Society, 5 (4), 459477.

Gramsci, A. (1971). Selections from the Prison Notebooks (1st Edition ed.). (Q. Hoare, G. N. Smith, Eds., Q. Hoare, \& G. N. Smith, Trans.) New York: International Publishers.

Hanisch, C. (2006, January). The Personal is Political (1969), The Women's Libreration Movement classic with a new explanatory introduction. New York. 
Henderson, S. L., \& Jeydel, A. S. (2007). Participation and Protest, Women and Politics in a Global World. New York: Oxford University Press.

Hepshiba. (2011). White Privilege Diary Series 1 White Feminist Privilege in Organizations. Retrieved June 14, 2013 from Daily Kos: http://www.dailykos.com/story/2011/05/22/957012/-White-Privilege-DiarySeries-1-White-Privilege-in-Organizations\#.

Hesse-Biber, S. N., \& Leavy, P. L. (2007). Feminist Research Practice : A Primer. London: SAGE Publications.

Hick, S. F., \& Murray, K. (2009). Structural social work. In M. Gray, \& S. A. Webb (Eds.), Social Work Theories and Methods (pp. 86-98). Thousand Oaks: SAGE Publications.

Hines, S. (2007). TransForming gender, Transgender practices of identity, intimacy and care. Bristol, Great Britain: The Policy Press.

hooks, b. (1984). Feminist Theory From Margin to Center. Boston: South End Press.

hooks, b. (1994). Teaching to Transgress, Education as the Practice of Freedom. New York: Routledge.

hooks, b. (2000). Feminism is for Everybody: Passionate Politics. Brooklyn: South End Press.

hooks, b. (2004). The Will to Change: Men, Masculinity and Love. New York: Washington Square Press.

Hopkins, P. D., May, L., \& Strikwerda, R. A. (1996). Rethinking Masculinity: Philosophical explorations in light of feminism (2nd Edition ed.). Lanham: Rowman \& Littlefield.

Hudson, A. (1985). Feminism and Social Work: Resistance or Dialogue? British Journal of Social Work , 15, 635-655.

Hunt, K., \& Saulnier, C. (Eds.). (2001). Feminism(s) on the Edge of the Millennium. Toronto: Inanna Publications and Education Inc. .

Jardine, A., \& Smith, P. (1987). Men in feminism. New York : Methuen.

Jeffries, V., Johnston, B. V., Nichols, L. T., Oliner, S. P., Tiryakian, E., \& Weinstein, J. (2006, Fall). Altruism and Social Solidarity: Envisioning a Field of Specialization. The American Sociologist.

Jetsilver. (2009, November 4). (no subject). Retrieved August 3, 2013 from Jetsilver Dreamwidth: http://jetsilver.dreamwidth.org/?skip=20.

Jiwani, Y. (2006). Discourse of Denial : Mediations of race, gender, and violence. Vancouver: UBC Press.

Johnson, A. G. (2006). Privilege, Power and Difference (2nd Edition ed.). Boston: McGraw Hill. 
Johnson, D. (2014, May 28). How Often Does Your College Report Sexual Assaults? . Retrieved July 6, 2014 from Time: time.com/119070/college-sexual-assualt-reporting/.

Johnson, H., \& Dawson, M. (2011). Violence Against Women in Canada : Researh and Policy Perspectives. Oxford: Oxford University Press.

Kaufman, M. (Ed.). (1987). Beyond Patriarchy; Essays by men on pleasure, power and change . Toronto : Oxford University Press.

Kemper, T. D. (2001). A Structural Approach to Social Movement Emotions. In J. Goodwin, J. M. Jasper, \& F. Polletta (Eds.), Passionate Politics, Emotions and Social Movements (pp. 58-73). Chicago: The University of Chicago Press.

Kirsch, G. E. (1999). Ethical Dilemmas in Feminist Research : The Politics of Location, Interpretation, and Publication . Albany: State University of New York Press.

Knowles, C. (2010). Theorizing Race and Ethnicity: Contemporary Paradigms and Perspectives. In P. H. Collins, \& J. Solomos (Eds.), The SAGE Handbook of Race and Ethnic Studies (pp. 23-42).

Koskela, H. (1999). 'Gendered Exclusions': Women's Fear of Violence and Changing Relations to Space. Geografiska Annaler: Series B, Human Geography , 81 (2), 111124.

Kramarae, C., \& Treichler, P. A. (1985). A Feminist Dictionary. (A. Russo, Ed.) Boston: Pandora Press.

Labaton, V., \& Martin, D. L. (Eds.). (2004). The Fire This Time, Young Activists and The New Feminism. New York: Anchor Books.

Landau, J. (2012). Reproducing and Transgressing Masculinity: A Rhetorical Analysis of Women Interacting with Digital Photographs of Thomas Beatie. Women's Studies in Communication, 35, 178-203.

Lazar, M. M. (Ed.). (2005). Feminist Critical Discourse Analysis; Gender, Power and Ideology in Discourse. New York, New York : Palgrave Macmillan.

Lazar, M. M. (2007). Feminist Critical Discourse Analysis: Articulating a Feminist Discourse Praxis. Critical Discourse Studies , 4 (2), 141-164.

Leathwood, C. (2004). Doing Difference in Different Times: Theory, Politics, and WomenOnly Spaces in Education. Women's Studies International Forum , 27, 447-458.

Leonard, P. (2001). The Future of Critical Social Work in Uncertain Conditions. Critical Social Work , 2 (1).

Lister, P. G. (2003). Feminist Dilemmas in Data Analysis: Researching The Use of Creative Writing by Women Survivors of Sexual Abuse. Qualitative Social Work, 2 (1), 45-59. 
Lister, R. (2005). Being Feminist. Politics of Identity -VIII , 442-463. (R. Bellamy, Ed.) Oxford: Blackwell Publishing.

Lorde, A. (1984/2007). Sister Outsider: Essays and Speeches by Audre Lorde. Berkeley: Crossing Press.

Lorde, A. (2003). The Master's Tools will Never Dismantle the Master's House. In R. Lewis, \& S. Mills (Eds.), Feminist Postcolonial Theory. Edinburgh University .

Lundy, C. (2004). Social Work and Social Justice: A Structural Approach to Practice. Peterborough: Broadview Press.

Lutz, H., Teresa Herrera Vivar, M., \& Supik, L. (Eds.). (2011). Framing Intersectionality, Debates on a Multi-Faceted Concept in Gender Studies. Frankfurt: Ashgate.

Martin, P. Y. (1990). Rethinking Feminist Organizations. Gender \& Society , 4 (2), 182-206.

Mauthner, N. S., \& Doucet, A. (2003). Reflexive Accounts and Accounts of Reflexivity in Qualitative Data Analysis. Sociology, 37 (3), 413-431.

McClintock, A. (1994). The angel of progress: pitfalls of the term "postcolonialism". In F. Barker, P. Hulme, \& M. Iversen, Colonisl discourse/postcolonial theory (pp. 253-266).

McInturff, K. (2013a, February 14). Sweet heart, bitter pill: Rising, dancing, and costing violence against women in Canada. (C. C. Alternatives, Producer) Retrieved June 21, 2013 from Behind the numbers, A blog from the Canadian Centre for Policy Alternatives: http://behindthenumbers.ca/2013/02/14/sweet-heart-bitter-pillrising-dancing-andcosting-violence-against-women-in-canada/.

McInturff, K. (2013b, March 21). New Shoes and a Haircut: Budget 2013 not so pretty for women in Canada . (C. C. Alternatives, Producer) Retrieved June 21, 2013 from Behind the numbers, a blog of the Canadian Centre for Policy Alternatives.

Meyers, M. (1997). News Coverage of Violence Against Women: Engendering Blame . California: Sage Publications Inc. .

Miles, A. (1996). Integrative Feminisms, Building Global Visions 1960s-1990s. New York: Routledge.

Modleski, T. (1991). Feminism Without Women: Culture and Criticism in a "Postfeminist" Age. New York: Routledge.

Moffatt, K. (Ed.). (2012). Troubled Masculinities, Reimagining Urban Men. Toronto: University of Toronto Press.

Mohanty, C. (2003). Feminism Without Borders: Decolonizing Theory, Practicing Solidarity. New York: Duke UP.

Moraga, C., \& Anzaldua, G. (Eds.). (1981). This Bridge Called My Back, Writings by Radical Women of Color (2nd Edition ed.). New York: Kitchen Table: Women of Color Press. 
Moreau, M. (1990). Empowerment through advocacy and consciousness-raising: Implications of a structural approach to social work. Journal of Sociology and Social Welfare, 17 (2), 53-67.

Moreau, M., \& Leonard, L. (1989). Empowerment Through a Structural Approach to Social Work: A Report from Practice. Montreal, Quebec and Ottawa, Ontario : Ecole de Service Social, Universite de Montreal; Carleton University School of Social Work.

Morris, B. J. (2005). Commentary, Valuing Woman-Only Spaces. Feminist Studies , 31 (3), 619-630.

Mullaly, R. (1993). Structural Social Work: Ideology, Theory, and Practice . Toronto: McClelland \& Stewart Inc. .

Murphy, M. (2013, August 7). Unpopular Opinion. It pisses me off when men call themselves feminists. Retrieved August 22, 2013 from XO Jane: http://www.xojane.come/issues/upopular-opinion-it-pisses-me-off-when-mencall-themselves-feminists.

Murphy, P. F. (Ed.). (2004). Oxford Readings in Feminism : Feminism \& Masculinities. New York: Oxford University Press.

Naples, N. A. (2003). Feminism and Method: Ethnography, discourse analysis and activist research. New York: Routledge.

Ng, R. (1993). "A Woman Out of Control": Deconstructing Sexism and Racism in the University. Canadian Journal of Education , 18 (3), 189-205.

Ng, R., Staton, P., \& Scane, J. (Eds.). (1995). Anti-Racism, Feminism, and Critical Approaches to Education. Westport: Bergin \& Garvey.

Ostrander, S. A. (1999). Gender and Race in a Pro-Feminist, Progressive, Mixed-Gender, Mixed-Race Organization. Gender \& Society , 13 (5), 628-642.

Pain, R. (1991). Space, sexual violence and social control: integrating geographical and feminist anlyses of women's fear of crime. Progress in Human Geography , 15 (4), 415-431.

Palys, T. (2003). Research Decisions: Quantitative and Qualitative Perspectives (3rd Edition ed.). Scaborough, Canada: Thomson Nelson.

Penelope, J. (1990, May). Women- and Lesbian- Only Spaces: Thought Into. Off Our Backs , 20 (5), pp. $14-16$.

Pierce, G. (2010). Poststructural Feminist Pedagogy in a Post-Katrina World. Feminist Teacher , 21 (1), 36-53.

Pink Triangle Services Ottawa. (2012). Glossary of Terms. Retrieved October 6, 2012 from PTS Ottawa: http://ptsottawa.org/glossary-of-terms/. 
Polletta, F., \& Jasper, J. M. (2001). Collective Identity and Social Movements. Annual Review of Sociology , 27, 283-305.

Price, M. (2011). Cripping Revolution: A Crazed Essay. SDS.

Ragins, B. R., \& Winkel, D. E. (2011). Gender, emotion and power in work relationships. Human Resource Management Review , 21, 377-393.

Ramsey, L. R., Haines, M. E., Hurt, M. M., Nelson, J. A., Turner, D. L., Liss, M., et al. (2007). Thinking of Others: Feminist Identification and the Perception of Others' Beliefs. Sex Roles , 56, 611-616.

Reinharz, S. (1992). Feminist Methods in Social Research . New York : Oxford University Press.

Rennie, S. (2014, March 3). University of Ottawa Suspends Men's Hockey Program. Retrieved July 6, 2014 from Maclean's: http://www.macleans.ca/education/uniandcollege/university-of-ottawa-suspendsmens-hockey-program/.

Reynolds, V. (2010). Doing Justice as a Path to Sustainability in Community Work. PhD Dissertation, Tao Institute.

Reynolds, V. (2011, August). Supervision of solidarity practices: Solidarity teams and people-ing-the-room. Context (116), p. 4.

Riley, D. (1988). "Am I That Name?" Feminism and the Category of 'Women' in History. Minneapolis: University of Minnesota.

Rubin, G. S. (2011). Deviations: A Gayle Rubin Reader. Durham: Duke University Press.

Rubin, H. J., \& Rubin, I. S. (1995). Qualitative Interviewing: The Art of Hearing Data. Thousand Oaks: Sage Publications.

Ruby, J. (2003). Women-Only And Feminist Spaces: Important Alternatives to Patriarchy. Off Our Backs, A Women's Newsjournal , 33 (5/6), 13-15.

Saulnier, C. F. (2000). Incorporating Feminist Theory into Social Work Practice: Group Work Examples. Social Work With Groups , 23 (1), 5-29.

Schacht, S. P. (1998). Feminism and men: Reconstructing gender relations. New York : New York University Press.

Schacht, S. P., \& Ewing, D. W. (2004). Feminism with Men : Bridging the Gender Gap . Toronto : Rowman \& Littlefield Publishers, Inc. .

Scott, E. K. (1998). Creating Partnerships for Change: Aliiances and Betrayals in the Racial Politics of Two Feminist Organizations. Gender \& Society, 12 (4), 400-423. 
Scott-Dixon, K. (Ed.). (2006). Trans/forming Feminisms: Trans/Feminists Speak Out. Toronto: Sumach Press.

Seymour, K. (2012). Feminist Practice: Who I am or What I do? . Australian Social Work, 65 (1), 21-38.

Siebritz, E. (2008, August). Why we need women-only spaces. Sister Namibia.

Sirianni, C., \& Negrey, C. (2000). Working Time as Gendered Time. Feminist Economics, 6 (1), 59-76.

Smith, A. (2005). Sexual Violence as a Tool of Genocide . In Conquest: Sexual VIolence and American Indian Genocide (pp. 7-33). Cambridge, MA: South End Press.

Smith, L. T. (2012). Decolonizing Methodologies: Research and Indigenous Peoples (2nd Edition ed.). New York: Zed Books.

Smith, L., \& Redington, R. M. (2010). Lessons From the Experiences of White Antiracist Activists. Professional Psychology: Research and Practice , 41 (6), 541-549.

Snodgrass, J. (Ed.). (1977). For men against sexism: A book of readings. Albion: Times Change Press.

Speer, S. A. (2001). Reconsidering the Concept of Hegemonic Masculinity: Discursive Psychology, Conversation Analysis and Participants' Orientations. Feminism \& Psychology , 11 (1), 107-135.

Stark, E., \& Flitcraft, A. (1996). Women at Risk: Domestic Violence and Women's Health . Thousand Oaks: SAGE Publications.

Stark, E. (2007). Coercive Control: How Men Entrap Women in Personal Life. Oxford: Oxford University Press.

Statistics Canada. (2013a, February 25). Measuring Violence Against Women: Statistical Trends. Juristat Article . (M. Sinha, Ed.) Canada.

Statistics Canada. (2013b, February 25). Violence Against Women, 2011. The Daily. Canada.

Statistics Canada. (2013c, June 25). Family Violence in Canada: A Statistical Profile, 2011. The Daily. Canada.

Status of Women Canada. (2008, 12 31). Governor General's Awards in Commemoration of the Persons Case. Retrieved September 6, 2013, from Satus of Women Canada: www.swc-cfc.gc.ca

Stokoe, E. H. (1998). Talking about gender: the conversational construction of gender categories in academic discourse. Discourse \& Society , 9 (2), 217-240.

Stoltenberg, J. (1989). Refusing to be a Man . Portland, Oregon: Breitenbush Books Inc. . 
Strauss, A. L., \& Corbin, J. M. (1998). Basics of Qualitative Research: Techniques and Procedures for Developing Grounded Theory (2nd Edition ed.). Thousand Oaks: Sage Publications.

Take Back the Night Foundation. (2013). About Take Back the Night. Retrieved September 7, 2013 from Take Back The Night: takebackthenight.org.

Tarrant, S. (2009). Men and Feminism. Berkeley, California: Seal Press.

The Government of Ontario . (2012, September). The Gender Wage Gap . (Queen's Printer for Ontario, 2010-2012) Retrieved June 15, 2013 from Pay Equity Commission : www.payequity.gov.on.ca/en/about/pubs/genderwage/wagegap.php.

Turcotte, M. (2013, May 13). Women in Education. Retrieved July 6, 2014 from Statistics Canada: www.statcan.gc.ca/pub/89-503-x/201001/article/11542-eng.htm\#a13.

Tyler, I. (2005). 'Who put the "Me" in feminism?" The Sexual Politics of Narcissism. Feminist Theory, 6 (1), 25-44.

Valentine, G. (1992). Images of Danger: Women's Sources of Information about the Spatial Distribution of Male Violence. Area , 24 (1), 22-29.

Valverde, M. (1990). Poststructuralist Gender Historians: Are We Those Names? Labour/Le Travail , 25, 227-236.

Van Dijk, T. A. (2001). Critical Discourse Analysis. In D. Tannen, D. Schiffrin, \& H. Hamilton (Eds.), Handbook of Discourse Analysis (pp. 352-371). Oxford: Blackwell.

Wakefield, J. (2014, February 20). Critics Oppose 'Don't Walk Alone' Message. Retrieved July 6, 2014 from Maclean's: http://www.macleans.ca/education/university/criticsoppose-don't-walk-alone/.

Weatherall, A. (2002). Towards understanding gender and talk-in-interaction. Discourse and Society, 13 (6), 767-781.

Weedon, C. (1987). Feminist Practice \& Postructuralist Theory. Cambridge, MA: Blackwell.

Weldon, S. L. (2011). When Protest Makes Policy, How Social Movements Represent Disadvantaged Groups. Ann Arbor: The University of Michigan Press.

White, S. (2009). Discourse Analysis and Reflexivity. In M. Gray, \& S. A. Webb (Eds.), Social Work Theories and Methods (pp. 161-171). Thousand Oaks: SAGE Publications.

Wiley, S., Srinivasan, R., Finke, E., Firnhaber, J., \& Shilinksky, A. (2012). Positive Portrayals of Feminist Men Increase Men's Solidarity With Feminists and Collective Action Intentions. Psychology of Women Quarterly, 37 (1), 61-71.

Wodak, R. (Ed.). (1997). Gender and Discourse. London: Sage Publications. 
Wodak, R., \& Meyer, M. (2009). Critical Discourse Analysis: History, Agenda, Theory and Methodology. In R. Wodak, \& M. Meyer, Methods for Critical Discourse Analysis (2nd Edition ed., pp. 1-33). Sage Publications Ltd.

Wood, G. G., \& Tully, C. T. (2006). Structural Approach to Direct Practice in Social Work : A Social Constructionist Perspective. New York : Columbia University Press.

Yulia, Z. (2010). Social Movements Through the Gender Lens. Sociology Compass , 4 (11), 628-641.

Yuval-Davis, N. (2006). Intersectionality and Feminist Politics. European Journal of Women's Studies , 13 (3), 193-209. 